\title{
Microfluidic Impedance-Metric Biosensor for Monitoring Carbon Nanotube-Induced Epithelial Permeability
}

\author{
Zhouchun Huang \\ West Virginia University
}

Follow this and additional works at: https://researchrepository.wvu.edu/etd

\section{Recommended Citation}

Huang, Zhouchun, "Microfluidic Impedance-Metric Biosensor for Monitoring Carbon Nanotube-Induced Epithelial Permeability" (2013). Graduate Theses, Dissertations, and Problem Reports. 4972.

https://researchrepository.wvu.edu/etd/4972

This Thesis is protected by copyright and/or related rights. It has been brought to you by the The Research Repository @ WVU with permission from the rights-holder(s). You are free to use this Thesis in any way that is permitted by the copyright and related rights legislation that applies to your use. For other uses you must obtain permission from the rights-holder(s) directly, unless additional rights are indicated by a Creative Commons license in the record and/ or on the work itself. This Thesis has been accepted for inclusion in WVU Graduate Theses, Dissertations, and Problem Reports collection by an authorized administrator of The Research Repository @ WVU. For more information, please contact researchrepository@mail.wvu.edu. 


\title{
Microfluidic Impedance-Metric Biosensor for Monitoring Carbon Nanotube-Induced Epithelial Permeability
}

\author{
Zhouchun Huang
}

Thesis submitted to the

Benjamin M. Statler

College of Engineering and Mineral Resources

at West Virginia University

In partial fulfillment of the requirements for the degree of

Master of Science

in

Electrical Engineering

Yuxin Liu, Ph.D, Chair

Nianqiang Wu, Ph.D.

Thirimachos Bourlai, Ph.D.

Lane Department of Computer Science and Electrical Engineering

Morgantown, West Virginia

2013

Keywords: Microfluidics; Impedance; Epithelial Permeability; Carbon Nanotubes Copyright 2013 Zhouchun Huang 


\title{
ABSTRACT \\ Microfluidic Impedance-metric Biosensor for Monitoring Carbon Nanotubes Induced Epithelial Permeability
}

\begin{abstract}
Zhouchun Huang
Carbon nanomaterials, including carbon nanotubes (CNTs) gain increasing interest in commercial and biomedical applications. Adverse health effects of engineered CNTs may result from either direct exposure during production, inadvertent exposure during use of by-products, and/or release of these materials into the environment. Recent studies have shown that CNTs can induce cytotoxicity, apoptosis, DNA damage, and tumor formation in animals, suggesting their potential toxicity in humans. To address the current needs in developing in vitro cell assays for assessment of the adverse health effects of CNTs in lung respiratory, we have developed a microfluidic impedance-metric biosensor for investigation of multi-walled CNTs (MWCNTs) effects on the cultured monolayer of human lung epithelial cells. Microfluidic based cell assays provide the ability and flexibility to control spatiotemporal biochemical parameters, and further for manipulating cell behaviors in well-established microenvironments. The biosensor consists of a transparent porous polyester cell-culture membrane embedded with a double-layer poly(dimethylsiloxane) (PDMS) microfluidic channels. Two electrodes can be easily inserted to the biosensors for impedance measurements. Experimental results show that human lung epithelial cells can form a tight monolayer within 10 days culture inside the device. Raw, purified and functionalized MWCNTs are introduced to the monolayer and their effects on epithelial permeability are measured and reflected by impedance spectroscopy. The miniaturized impedance-metric biosensor can provide label-free evaluation of the impacts of CNTs on the epithelial monolayer integrity with accurate reading and reduced noises.
\end{abstract}




\section{Acknowledgement}

First and foremost, I would like to show my deepest gratitude to my supervisor, Dr. Yuxin Liu, for her professional guidance, continuous encouragement and impressive kindness. It has been an absolute pleasure time to work with such a nice and resourceful advisor. Her enthusiasm, religious attitude and keen observation toward scientific research deserve my great respect. Her teaching and instruction enlightens me not only through my MS program but also in the future study. I am also grateful to all my lovely partners in MICRoChip lab who are always kind and helpful to me. I am proud of being part of the group with these hardworking graduate students and we spent a lot of pleasant time cooperating and sharing experience with each other.

I wish to extend my thanks to Dr. Nianqiang Wu who kindly provided me with the facilities in his labs. It played a significant part in accomplishing my thesis. I would also like to thank Dr. Thirimachos Bourlai for his help and effort for being the committee member. I also wish to acknowledge Dr. Yon Rojanasakul, Dr. Yongju Lu and Dr. Varisa Pongrakhananon for their patient teaching and training of biological knowledge and cell experiments. Dr. Mingjia Zhi and Dr. Honglei Gou provided me with many valuable advices in the area of electrical impedance and I am very grateful. I also owe thanks to Bashar Hamza for his great help with the cleanroombased micro fabrication.

Last but not least, I would like to thank my family for their understanding, support and love in my life. To them I dedicate the thesis.

Zhouchun Huang 


\section{Table of Contents}

Microfluidic Impedance-Metric Biosensor for Monitoring Carbon Nanotube-Induced Epithelial

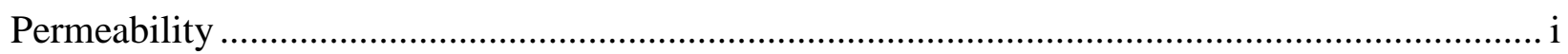

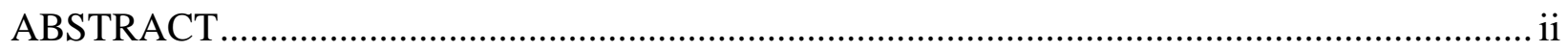

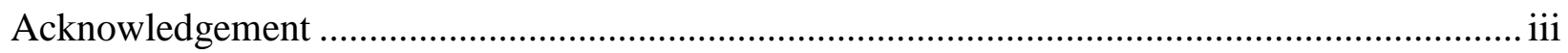

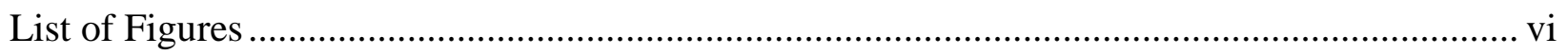

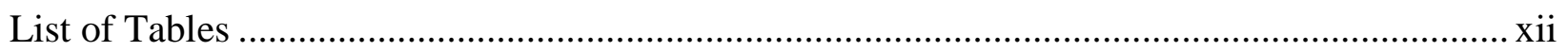

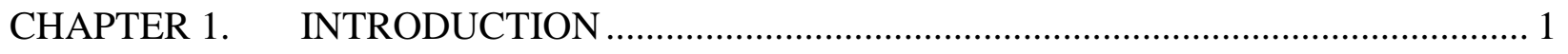

1.1 The Importance to Study Lung Epithelium .................................................... 1

1.2 Importance to Study Adverse Health Effects of Carbon Nanotubes............................ 4

1.3 Conventional Methods to Study Epithelium Permeability ....................................... 8

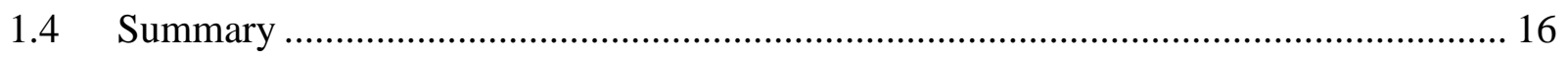

CHAPTER 2. LITERATURE REVIEW OF MICROFLUIDICS AND THE ADVANTAGES 18

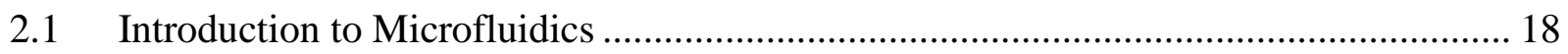

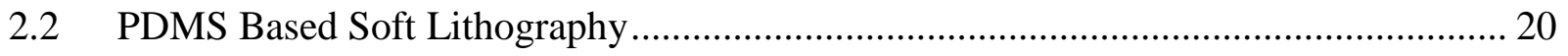

2.3 Microfluidic Applications in Molecular, Cell and Tissue Biology ............................ 23

2.4 Microfluidics and Electrical Impedance Spectroscopy …...................................... 28

CHAPTER 3. DESIGN AND FABRICATION OF THE MICROFLUIDIC IMPEDANCE BIOSENSOR 33 
3.1 Design of the Microfluidic Impedance Biosensor................................................. 33

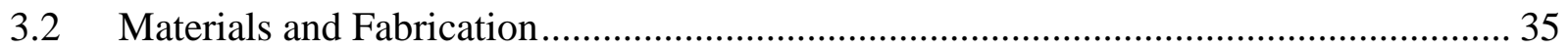

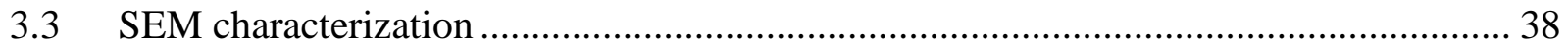

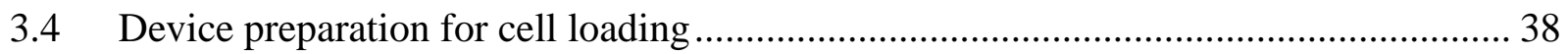

CHAPTER 4. CELL CULTURE ............................................................................... 40

4.1 Calu-3 cell line as a lung epithelium model ...................................................... 40

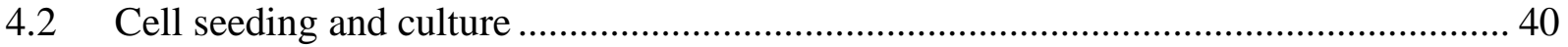

4.3 Immunofluorescence characterization............................................................... 43

CHAPTER 5. ELECTRICAL IMPEDANCE SPECTROSCOPY ..................................... 45

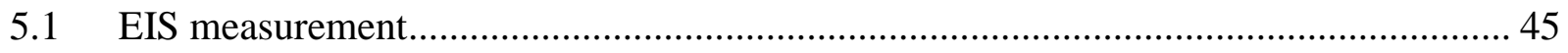

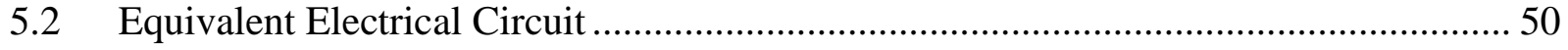

5.2.1 The electrode/culture medium system without cells .................................................. 50

5.2.2 The system with cultured Calu-3 cell monolayer........................................................... 52

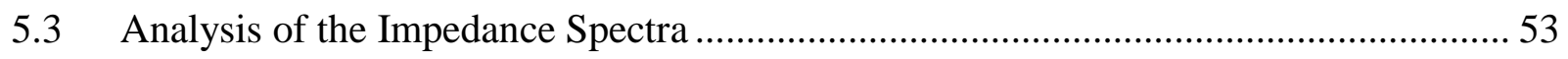

CHAPTER 6. MWCNTS EFFECTS ON EPITHELIAL PERMEABILITY ...................... 60

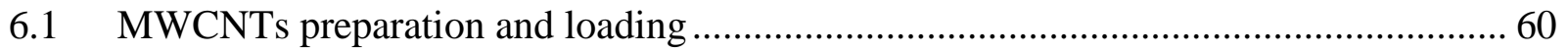

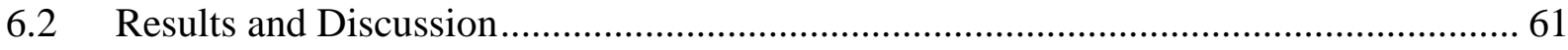

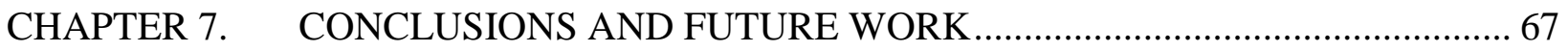

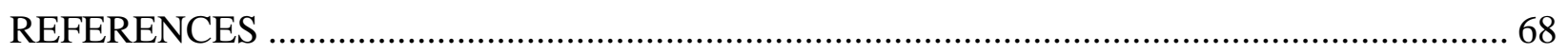




\section{List of Figures}

Figure 1-1. Human lung structure 1

Figure 1-2. A) The diagram structure of respiratory epithelium, which acts as the mechanical barrier against potentially toxic agents. B) The aerial view of a smokestack shows that how quickly and extensively airborne material spreads. ${ }^{4}$. 3

Figure 1-3. Scanning electron microscopy (SEM) images of raw single- (A) and multi-walled (B) carbon nanotubes. ${ }^{13}$ 5

Figure 1-4. CNT carries drugs and moieties ${ }^{15}$ 5

Figure 1-5. Effect of raw SWCNT (a) and SWCNT bundles (b) on cell proliferation (DNA) and cell activity (MTT conversion) of mesothelioma cells after 6 days exposure. White bar control culture, $0 \mu \mathrm{g} / \mathrm{mL}$; grey bar $3.75 \mu \mathrm{g} / \mathrm{mL}$; dark grey bar $7.5 \mu \mathrm{g} / \mathrm{mL}$; black bar $15 \mu \mathrm{g} / \mathrm{mL} .{ }^{18} \ldots \ldots . .6$ Figure 1-6.The effect of L-MWCNTs (A) and L-SWCNTs (B) on the TEER value of Calu-3 cell monolayers (x-axis unit: day). ${ }^{22}$ 8

Figure 1-7. Representative diagram of tight junctions 9

Figure 1-8. Morphological appearance of rabbit tracheal epithelial cells and the monolayers under SEM. A) isolated RTE cells in suspension, B) An air-interfaced RTE cell monolayer, C) The tight junctions (indicated by an arrowhead), D) The ciliary appearance of the air-interfaced RTE cell monolayer (top) and denuded cilia on ciliated cells observed in liquid-covered RTE cell layer (bottom). ${ }^{27}$ 11

Figure 1-9. A) Confluent Calu-3 monolayer imaged using an optical microscope. B) Log permeability coefficients for the passage of small molecules across the Calu-3 monolayer culture in a Transwell versus log of the molecule's respective octanol: $\mathrm{H}_{2} \mathrm{O}$ partition coefficient. ${ }^{7}$...... 12 
Figure 1-10. Antioccludin immunofluorescent staining of Caco-2 cell monolayers cultured in media supplemented with $0.05 \mathrm{mM}$ linoleic acid (LA) (A) and trans-10 conjugated linoleic acid (CLA) (B) for 21 days; Anti-ZO-1 immunofluorescent staining of Caco-2 cell monolayers cultured in media supplemented with $0.05 \mathrm{mM}$ cis-9 CLA (C) and trans-10 conjugated linoleic acid (CLA) (D) for 14 and 21 days, respectively. The scale bar is $100 \mu \mathrm{m} .{ }^{28}$ 13

Figure 1-11. A) EVOM and B) PC-controlled Automated TEER Measuring System used for TEER measurement 14

Figure 1-12. A) Decreased TEER values were measured on a cultured brain endothelial cell layer after the treatment of LPA. B) The flux of sucrose across the cell layer was increased, indicating increasing tight junction permeability. ${ }^{32}$ 15

Figure 2-1. Schematic representations of the gradient generator and gradient characterization. (A) Top view of the whole device (B) Three-dimensional schematic representation of gradient generating. ${ }^{36}$ 19

Figure 2-2. Optical micrograph of a microfluidic integration chip. The various inputs have been loaded with food dyes to visualize the channels. ${ }^{39}$ 20

Figure 2-3. Schematic representation of the fabrication processes for PDMS microfluidic devices. ${ }^{43}$ 22

Figure 2-4. A robust and scalable microfluidic device that is able to screen protein crystallization conditions. A) Section of a device showing three pairs of compound reaction chambers. The upper chamber and lower chambers were isolated by a closed barrier valve. B) Loading of reagents using pressurized outgas priming method. C) A gradient of dye concentration was formed by open the barrier valve to allow diffusion. D) Prototype protein crystallization chip. The scale bars are $1 \mathrm{~mm} .{ }^{44}$ 23 
Figure 2-5. A) Schematic representation of the experimental setup and the detection arrangement. B) Separation of $\varphi$ X-174/HaeIII DNA restriction fragments in a PDMS device. ${ }^{45}$

Figure 2-6. A) Layout of the optical switch in the microfluidic-based cell sorter. B) Bright field (left) and fluorescence (right) images of the resulting cell populations in the collection well (top) and waste well (bottom). ${ }^{50}$ 26

Figure 2-7. A) Schematic formation of the bioinsipred breathing lung-on-a-chip microdevice. B) Computer-controlled vacuum was applied to the side chambers to achieve cyclic stretching of the PDMS membrane. C) Intercellular junctions were formed evident by the fluorescence staining. D) More acute lung inflammation was caused by exposure to silica nanoparticles when the cyclic stretching was performed. ${ }^{51}$ 27

Figure 2-8. Average normalized real impedance waveforms of single human glioblastoma cells in response to CTX at varying concentrations. ${ }^{53}$ 29 Figure 2-9. A two-layered impedance microfluidic system was developed to study the barrier properties of epithelial or endothelial cell monolayers and the equivalent circuit model was built for the system. ${ }^{57}$ 31

Figure 3-1. a) Schematic design and assembling process of the microfluidic impedance biosensor; b) Two holes were punched to locate $\mathrm{Ag} / \mathrm{AgCl}$ electrodes for impedance measurement.

Figure 3-2. Applied alternating current flows from one electrode, culture media which serves as the electrolyte and lung epithelial cell monolayer, to the other electrode. 34 
Figure 3-3. The photomask was designed using AutoCAD and printed with desired patterns. The photoresists underlying the clear region was expected to be exposed and polymerized, which would cause the resists to remain on substrates................................................................ 36

Figure 3-4. The fabricated microfluidic impedance-metric biosensor..................................... 37

Figure 3-5. A) SEM picture shows the membrane bonding between two PDMS channels; B) Enlarged SEM picture shows the bonding between membrane and the PDMS........................ 38

Figure 4-1. The processes of pipet-based injection cell seeding ...................................... 41

Figure 4-2. Calu-3 cell monolayer was formed after $\sim 10$ days culturing in the microfluidic biosensor 43

Figure 4-3. Immunohistochemical staining showed Calu-3 cells growing into a tight monolayer in the microfluidic impedance biosensor. a) ZO-1 (green) for tight junction protein staining, b) actin staining (red), and c) nucleus staining (blue); d) combined image indicated monolayer formation. 44

Figure 5-1. Gamry Reference 3000 was used to measure impedance of cell monolayers and

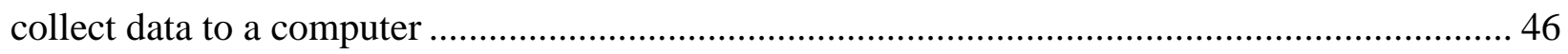

Figure 5-2. Setup window in the Gamry Framework for Potentiostatic EIS.......................... 47

Figure 5-3. Bode (top) and Nyquist (bottom) diagrams were acquired by the Potentiostatic EIS

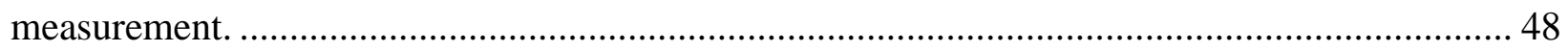

Figure 5-4. Nyquist diagram of a parallel RC circuit is plotted to be a semicircle with the diameter of R.

Figure 5-5. The Bode (top) and Nyquist (bottom) plots before cells were seeded and after a complete tight monolayer was formed. 50

Figure 5-6. Equivalent circuit for the $\mathrm{Ag} / \mathrm{AgCl}$ working electrode 51 
Figure 5-7. Equivalent circuit of the cell culture medium

Figure 5-8. An equivalent electrical circuit was generated to model the microfluidic system without cells, in which the $R_{1}$ and $C_{1}$ represent the culture medium, and $R_{2}, C_{2}$ and $R_{3}$ represent the interface between the working $\mathrm{Ag} / \mathrm{AgCl}$ electrode and the medium. 52

Figure 5-9. Equivalent electrical circuit of Calu-3 epithelial cell monolayer.......................... 52

Figure 5-10. The equivalent circuit model of the microfluidic system for EIS measurements. .. 53

Figure 5-11. Impedance spectra for the microfluidic system without cells. A) Bode diagram. B)

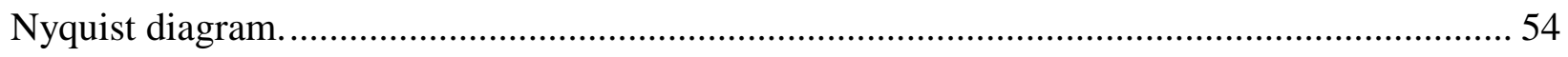

Figure 5-12. Nyquist plots showed the appearance and growing of a third semicircle (arrow). . 55

Figure 5-13. Bode diagram showed the frequency response of imaginary impedance during the formation of epithelial cell monolayer. Arrows indicate the critical frequencies of the microfluidic biosensor. 56

Figure 5-14. Impedance Fitting was performed to obtain the values of parameters in the equivalent circuit model which described the behavior of the microfluidic system with a tight epithelial cell monolayer being formed. A) Fitting result in Bode plot. B) Fitting result in Nyquist plot. 57

Figure 5-15. TEER values of Calu-3 cell monolayer growing in the biosensors were obtained by analyzing the impedance measurement results. Low TEER values $(\sim 160 \Omega \cdot \mathrm{cm} 2)$ were measured when the cell monolayer was formed. High TEER values $(\sim 1500 \Omega \cdot \mathrm{cm} 2)$ were achieved after more days of culture (usually one week) in the microfluidic biosensor (Mean \pm S.E.M, N=4).. 59 Figure 6-1. Three types of MWCNTs were initially dispensed and stored in PBS 61

Figure 6-2. Dose-dependent effects of $r$-MWCNTs on the TEER of tight Calu-3 cell monolayers. 
Figure 6-3. Dose-dependent effects of $p$-MWCNTs on the TEER of tight Calu-3 cell monolayers.

Figure 6-4. The effects of carboxyl $f$-MWCNTs on the TEER of tight Calu-3 cell monolayers in the microfluidic impedance-metric biosensors. 64

Figure 6-5. The change in the TEER of tight Calu-3 monolayers exposed to different types of MWCNTs at the concentration of $2.25 \mu \mathrm{g} / \mathrm{cm}^{2}$. 64

Figure 6-6. The effect of MWCNTs on the capacitance of lung epithelial cell monolayer was studied and significant decrease during the treatment of non-functionalized MWCNTs was observed. 65 


\section{List of Tables}

Table 2-1. Advantages and disadvantages of existing methods for epithelium study ............... 32

Table 5-1. The fitting results of one impedance spectrum measured before cell loading.......... 55

Table 5-2. The fitting results of one impedance spectrum which was measured after tight cell

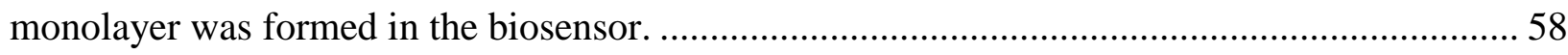




\section{CHAPTER 1. INTRODUCTION}

\subsection{The Importance to Study Lung Epithelium}

The lung is the organ of respiration in human body and it plays a vital role in maintaining the metabolism in humans. There are two lungs inside the chest, a right and a left, which are not identical to each other. The two lungs are connected to two branches of the trachea, which is the main air way, respectively. The branches are called bronchi divided within the lung to bronchioles and the bronchioles continue branching into the alveolar sacs, which are the smallest gas exchange unit in the respiratory parenchyma (Figure 1-1). ${ }^{1}$

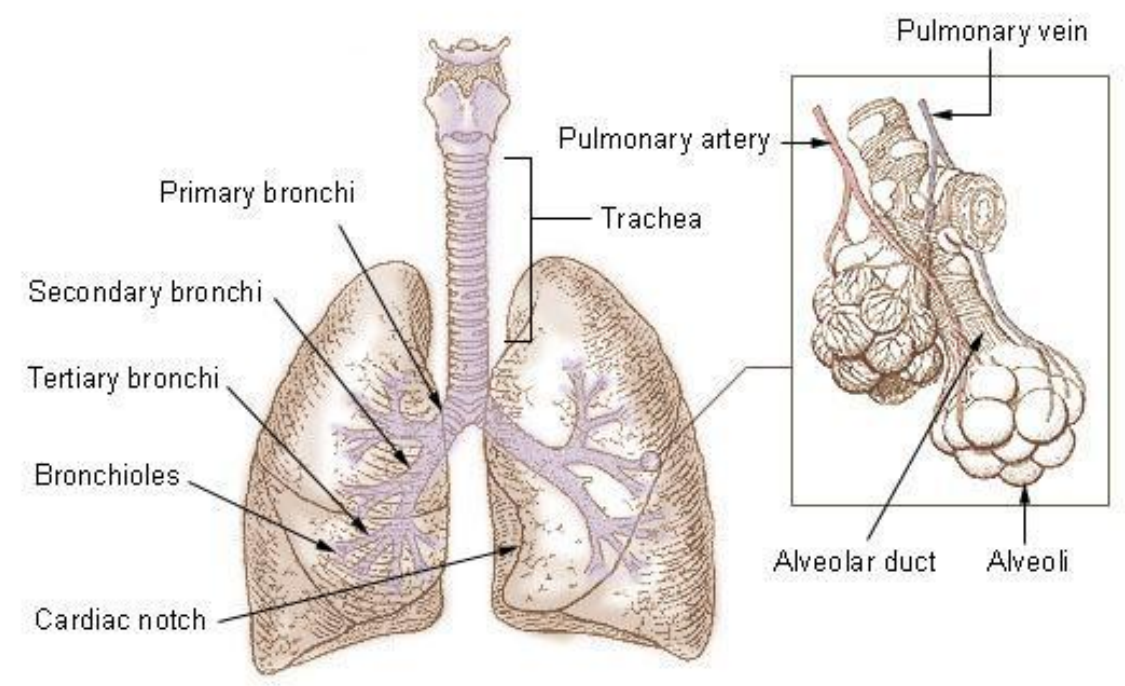

Figure 1-1. Human lung structure ${ }^{2}$

The principal function of the human lung is to absorb oxygen into blood circulatory system, and to release carbon dioxide from the system into the atmosphere. In addition to this respiratory function, the lungs alter the $\mathrm{pH}$ value of blood, filter out small blood clots, and protect against alien toxins. As common health problems worldwide, lung diseases would heavily disrupt the regular pulmonary functions. Many factors contribute to lung diseases, such as regional 
environmental pollution, smoking, infection, and genetics. A large number of people are suffering from lung diseases, including asthma, bronchitis, chronic obstructive pulmonary disease (COPD), and lung cancers, which affect the airways, air sacs and the interstitium of human lungs and thus can further affect life processes.

Epithelial tissue covers all external body surfaces as well as nearly all internal body surfaces and is a key component of host defense to provide a mechanical barrier against potentially harmful substances including parasites, invading bacteria and harmful chemicals. ${ }^{3}$ The airways in human lungs, starting from two main bronchi to a large number of alveoli, provide a vast surface area to the ambient air to allow the efficient gas exchange. However, the lung epithelium is also exposed to inhaled particles and pollutants, toxins, and a wide range of airborne pathogens (Figure 1-2). For example, large varieties of materials and chemicals have been widely used in industry and commercial activities, the particles of which may become aerosolized or airborne in the form of fibers, fume, mists, or dust. ${ }^{4}$ These ultrafine particles (e.g. welding fume, metal fume and diesel exhaust) would be inhaled by people in the workplace and thus can affect the pulmonary epithelium. The environmental exposures can quickly spread into the general population thus causing urban pollution. Additionally, industrial accidents may happen due to fault operations and release irritant gases including chlorine, phosgene and sulfur dioxide. These irritant gases could be inhaled, dissolved in the fluid of respiratory tract mucosa, and then threaten the health of the lung airways. The integrity and permeability of the lung epithelium is crucial for normal pulmonary functions to protect human body against these xenobiotic substances. Therefore, disruption of the epithelial barrier may lead to acute lung injury, pneumonia, and acute respiratory distress syndrome, etc. 

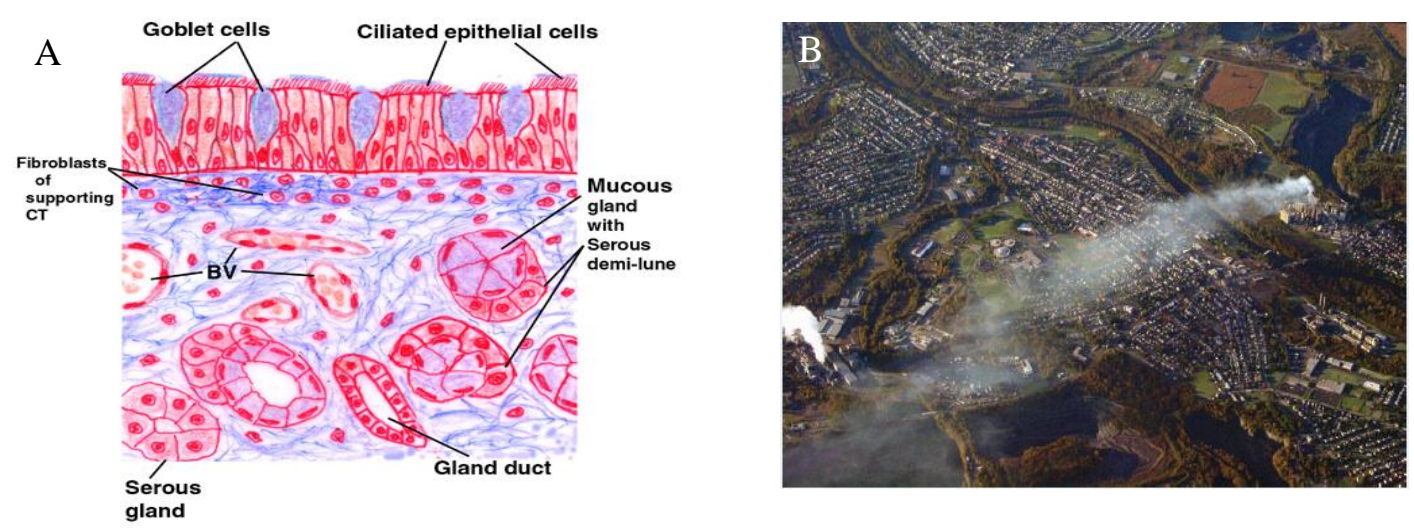

Figure 1-2. A) The diagram structure of respiratory epithelium, which acts as the mechanical barrier against potentially toxic agents. ${ }^{5}$ B) The aerial view of a smokestack shows that how quickly and extensively airborne material spreads. ${ }^{4}$

Furthermore, drug delivery is the method of administering a pharmaceutical compound to achieve a therapeutic effect in human body. The processes of drug delivery include drug release, absorption, distribution and elimination. The way of drug administrations may be varied due to different drugs and their target regions. The common ways for drugs include non-invasive peroral (through the mouth), topical (skin) and transmucosal (nasal, sublingual, vaginal, ocular and rectal), etc. ${ }^{6}$ Growing attentions have been focusing on the pulmonary route as a noninvasive administration of therapeutic agents because the lungs could provide a large absorptive surface area (up to $\left.100 \mathrm{~m}^{2}\right)$ with extremely thin $(0.1 \mu \mathrm{m}-0.2 \mu \mathrm{m})$ absorptive mucosal membrane. In addition, respiratory circulation system provides good blood supply and can avoid the hepatic first pass effect. Furthermore, drugs can be locally delivered to the lung in case of pulmonary diseases. ${ }^{7}$ Although these advantages benefit for drug administration, risks associated with exposure the pulmonary to other xenobiotic agents (such as carbon nanotubes (CNTs)) are also very high. With the development of more and more materials, especially in applications with nanomaterials and nanotechnologies, efficient tools for transporting and translocating therapeutic 
molecules are versatile. The potential toxicities of these agents may result in the disruption of lung epithelium integrity and affect the permeability of the barriers.

Therefore, understanding the role of the lung epithelium and its responses to external substances, either from commercial activities or environmental pollutions, play a key role in determining the toxicities of those substances.

\subsection{Importance to Study Adverse Health Effects of Carbon Nanotubes}

Nanomaterials, which are materials with one or more external dimensions or internal structures at the nanoscale ${ }^{8}$, possess various new properties and their industrial and research uses create new opportunities in healthcare, electronics and other areas, however, they also present new risks and uncertainties due to the unknown properties in the nanoscale range. The number of products in commerce and under development that contain nanomaterials has grown rapidly to include products such as plastics, metal, ceramics, surface coatings, creams, sprays, cosmetics, electronics, clothing, drugs, medical devices, and medical imaging aids. Exposure potential for nanomaterials can be expected to be strongly dependent on industrial manufacturing and processing methods, the nanomaterial state and physic-chemical properties, and the nanomaterial applications. ${ }^{9}$ Growing production and uses of nanomaterials result in an increasing number of workers and consumers exposed to nanomaterials. This leads to a greater need of information for nanomaterials' effects on human health and environment.

Within the family of nanomaterials, CNT is allotrope of carbon with a cylindrical nanostructure. CNT can be imaginatively produced by rolling up either a single layer of graphene sheet (single-walled CNT; SWCNT) ${ }^{10,11}$ or many layers of graphene sheets to form concentric cylinders (multi-walled CNT; MWCNT), with diameters of a few nanometers (Figure 
$1-3)^{12,13}$. Due to their outstanding properties, such as morphology, nano-spaces, and large specific surface areas ${ }^{14}$, CNTs have been widely utilized in drug delivery and diagnostic applications ${ }^{15}$, such as for vaccine and gene delivery ${ }^{16}$, and selective molecular absorption ${ }^{17}$.

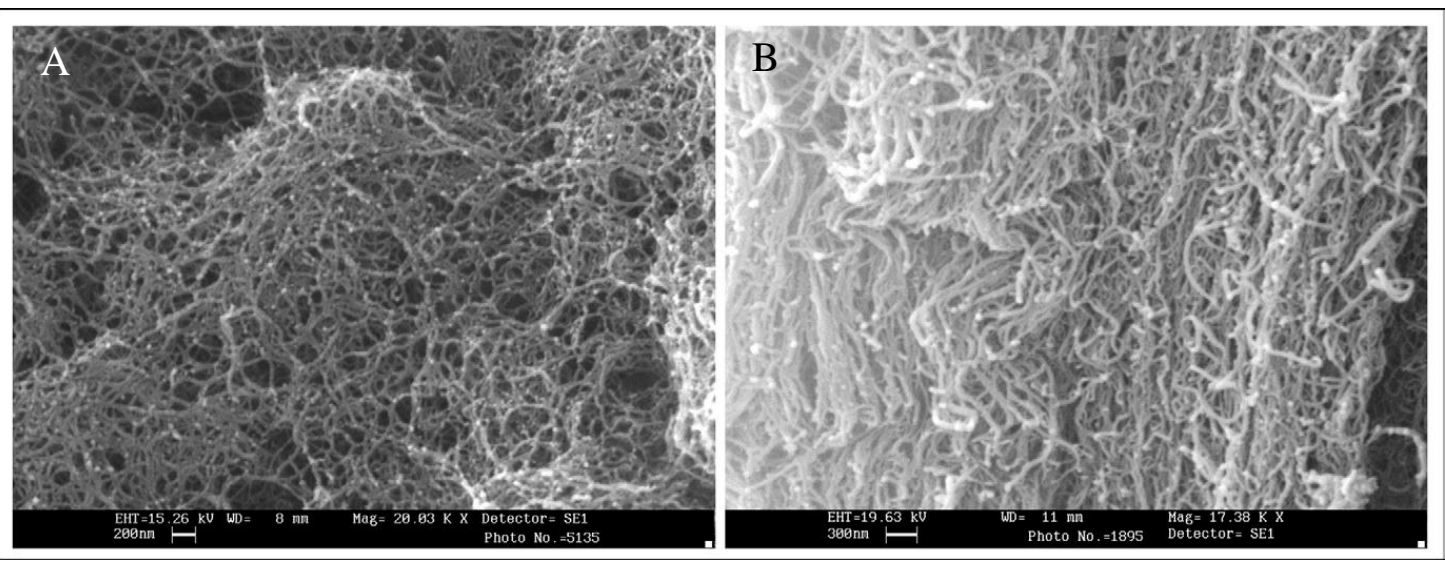

Figure 1-3. Scanning electron microscopy (SEM) images of raw single- (A) and multi-walled (B) carbon nanotubes. ${ }^{13}$

Specifically in drug delivery system, the CNTs have the ability of crossing biological barriers effectively, which allows their use in the delivery of therapeutically active molecules. As shown in Figure 1-4, the CNT is bonded with drugs either covalently or non-covalently and carries several moieties for targeting, imaging and therapy, which makes it to be a versatile carrier for drug delivery. ${ }^{15}$

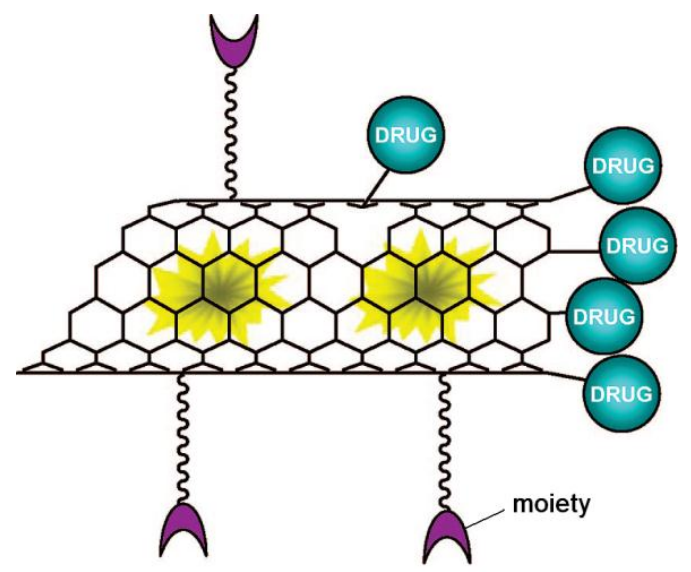

Figure 1-4. CNT carries drugs and moieties ${ }^{15}$ 
With intense investigations of CNT applications, the health concern is also generated. Either direct exposure during production, inadvertent exposure to CNTs during the use of byproducts, and/or release of these materials into the environment may result in potential adverse health effects. The biocompatibility and cytotoxicity of the CNTs were investigated by many groups to determine how they can be safely used for nanomedicine, nanotools, and other biomedical applications. For example, the toxicity of SWCNTs was studied by Kaiser's group and they found that the SWCNTs were able to affect cell functionality in a time and dose dependent manner ${ }^{18}$. After treated with raw SWCNT and SWCNT bundles respectively, the proliferation and activity of the cultured mesothelioma cells were dramatically reduced, as shown in Figure 15. The fast uptake of CNTs by mesothelioma cells was considered to be one of the reasons that resulted in these effects. In addition, other effects of SWCNTs on cell functions, including cell spreading, apoptosis and adhesion, were observed by the authors, and their results showed that the purity of SWCNTs is a factor which can lead to cellular toxicities.
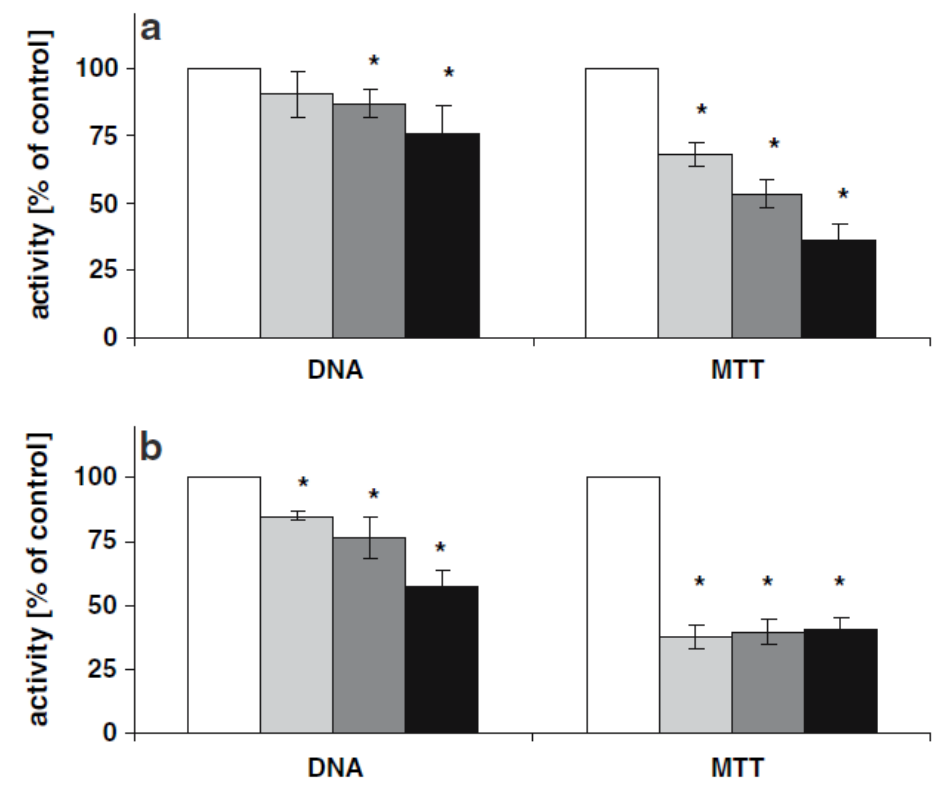

Figure 1-5. Effect of raw SWCNT (a) and SWCNT bundles (b) on cell proliferation (DNA) and cell activity (MTT conversion) of mesothelioma cells after 6 days exposure. White bar control culture, $0 \mu \mathrm{g} / \mathrm{mL}$; grey bar $3.75 \mu \mathrm{g} / \mathrm{mL}$; dark grey bar $7.5 \mu \mathrm{g} / \mathrm{mL}$; black bar $15 \mu \mathrm{g} / \mathrm{mL} .{ }^{18}$ 
Another group studied the toxicological properties of MWCNTs and they investigated the effect of CNT's length on cytotoxicity ${ }^{14}$. Different responses were observed in subcutaneous tissue in vivo for CNTs with different lengths of $220 \mathrm{~nm}$ and $825 \mathrm{~nm}$, respectively. It was found that the inflammatory response induced by $220 \mathrm{~nm}$ CNTs was mild than that caused by $825 \mathrm{~nm}$ CNTS in the subcutaneous tissue of rats.

Studying toxic effects of CNTs on pulmonary is a new growing research area that has received considerable attentions. ${ }^{19,20}$ Because CNTs tend to form aggregates or bundles due to the van der Walls interactions among them, those aggregated CNTs cannot penetrate through the lung alveoli when they are inhaled. However, non-aggregated CNTs had been found inside alveoli because of their nano-scaled sizes. Once the CNTs penetrate into the alveoli, they can interact with surfactant proteins and lipids. ${ }^{21}$ In addition, the clearance rate of the CNTs in lung is extremely low, which can lead to higher bio-persistence and tissue burden. To investigate these issues, many toxicological studies have been conducted in recent years to identify the health risks posed by various types of CNTs, with a focus on respiratory system exposure, such as the studies of CNTs effects on epithelial permeability and cellular toxicities. For example, in Rotoli's group, the lung epithelium dysfunction induced by exposure to non-functionalized MWCNTs was studied in vitro. ${ }^{22}$ No significant changes in cell viability were observed after the Calu-3 cell monolayer was exposed to various MWCNTs. However, the decreases of transepithelial electrical resistance (TEER) of the monolayers were measured upon treatment with 5-9 $\mu \mathrm{m}$ long MWCNTs and 0.5-100 $\mu \mathrm{m}$ long SWCNTs, respectively (Figure 1-6). The results indicated that certain lengths of CNTs can affect the integrity and permeability of the cell monolayers. 

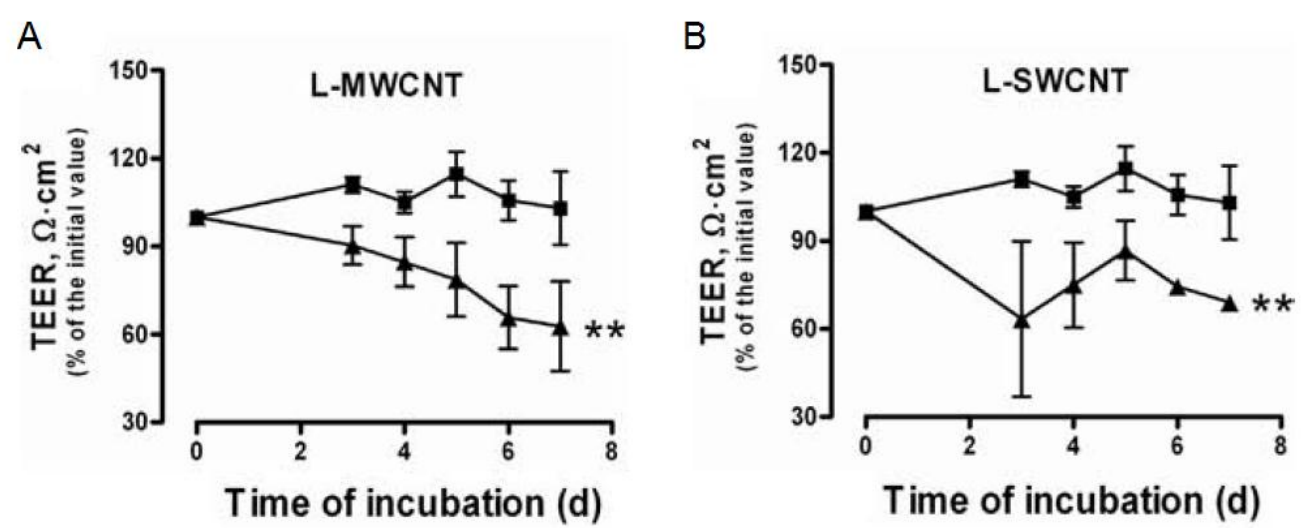

Figure 1-6.The effect of L-MWCNTs (A) and L-SWCNTs (B) on the TEER value of Calu-3 cell monolayers (x-axis unit: day). ${ }^{22}$

\subsection{Conventional Methods to Study Epithelium Permeability}

The main barrier functions of the epithelium are achieved by tight junctions, which are characterized by fusion of the adjacent cell membranes resulting in obliteration of the intercellular space over variable distances forming a continuous and beltlike structure. ${ }^{23,24} \mathrm{As}$ shown in Figure 1-7, the tight junction protein complex delineate the apical (upper) and basal (lower) regions of epithelial cells, which are connected to external circumstance and underlying tissues respectively. The formed tight junction strands seal space between adjacent cells and act as selective permeability barrier to the diffusion of molecules and ions through the paracellular pathway. ${ }^{[25]}$ Many studies have been performed to analyze epithelial integrity and permeability via characterizing the tight junction complexes. 

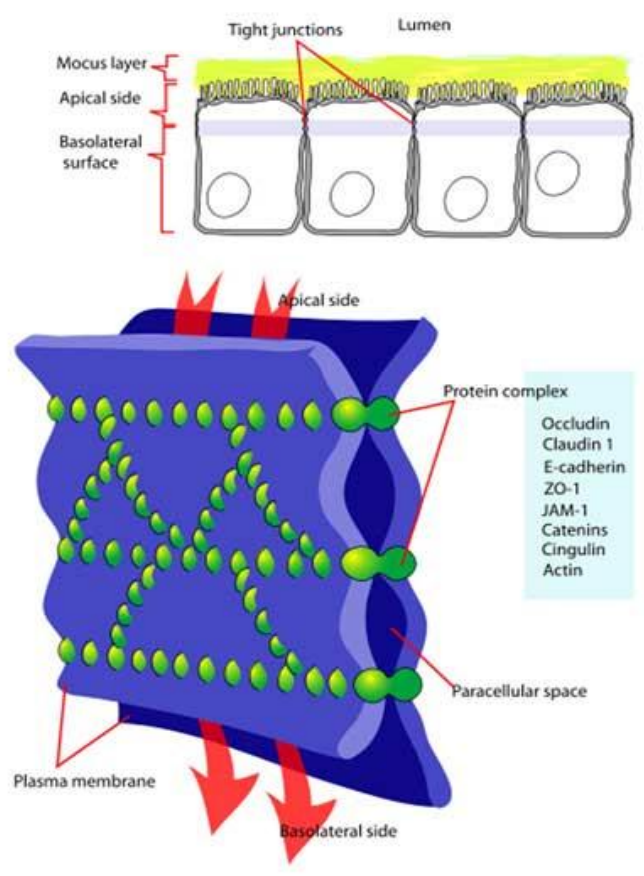

Figure 1-7. Representative diagram of tight junctions ${ }^{26}$

Different models, such as animals, cell assays and biomolecule assays, have been used to assess adverse health effects of xenobiotic agents. Effective approaches, such as assessing morphological features of tight junction complexes by imaging techniques (electron microscopy or indirect immunofluorescence), have been applied. For example, pathogen-free mice were used for animal studies to test the effects of dispersed SWCNTs on the lungs in Wang's group. ${ }^{19}$ The animals were anesthetized by an intraperitoneal (ip) injection of ketamine and xylazine (45 and 8 $\mathrm{mg} / \mathrm{kg}$ ) and placed on a board in the supine position. The animal's tongue was extended with padded forceps. A suspension of dispersed single-walled nanotubes (DSWCNTs), dispersed ultrafine carbon black (DUFCB) (both at $10 \mu \mathrm{g} / 100 \mu \mathrm{l}$ per mouse), or sterile phosphate-buffered saline (PBS) was placed on the back of the tongue. A slight pull of the tongue resulted in a reflex gasp and aspiration of the droplet. The tongue was held and the animal monitored for a few 
breaths after aspiration. All mice recovered by this procedure within minutes. Mice were sacrificed at indicated time points after the treatment, and bronchoalveolar lavage (BAL) was conducted to collect fluids to evaluate markers for the lung damage. After the examination of the BAL fluids from DSWCNT-treated mice, the results showed that a transient rise in inflammation at 1 day post-exposure and returned to the baseline level by 7 days post-exposure, which indicated that the absence of significant cytotoxicity or persistent inflammation at this relatively low administered dose of DSWCNTs exposure. In vivo animal models have vastly improved our understanding of physiology and pathophysiology, however, they are very expensive and labor intensive, highly variable, difficulty to manipulate, time and space consuming, experimental results may be confounded, and raising important animal welfare concerns.

Current in vitro cellular models, such as the use of multi-well microplates or a Petri dish, have been built to investigate the permeability characteristics of lung epithelium in different culture conditions. In Mathias's group, the rabbit tracheal epithelial (RTE) cells were cultured for drug transport studies. ${ }^{27}$ The RTE cells were isolated and plated onto collagen-treated permeable supports, and cultured either air-interfaced condition (AIC) or under conventional liquid covered condition (LCC). Scanning electron microscopy (SEM) revealed mature cilia in AIC cell layers and less prominent cilia or denuded ciliated in LCC cells (Figure 1-8). The permeability of LCC and AIC monolayer were both studied and the results showed that the culture conditions affected the transport of the hydrophilic drugs more than that of the lipophilic drugs. The difference in tight junction arrangement under these two conditions was considered as one of the possible reasons. The results indicated that the AIC might be a favorite approach as an in vitro model for respiratory studies. 


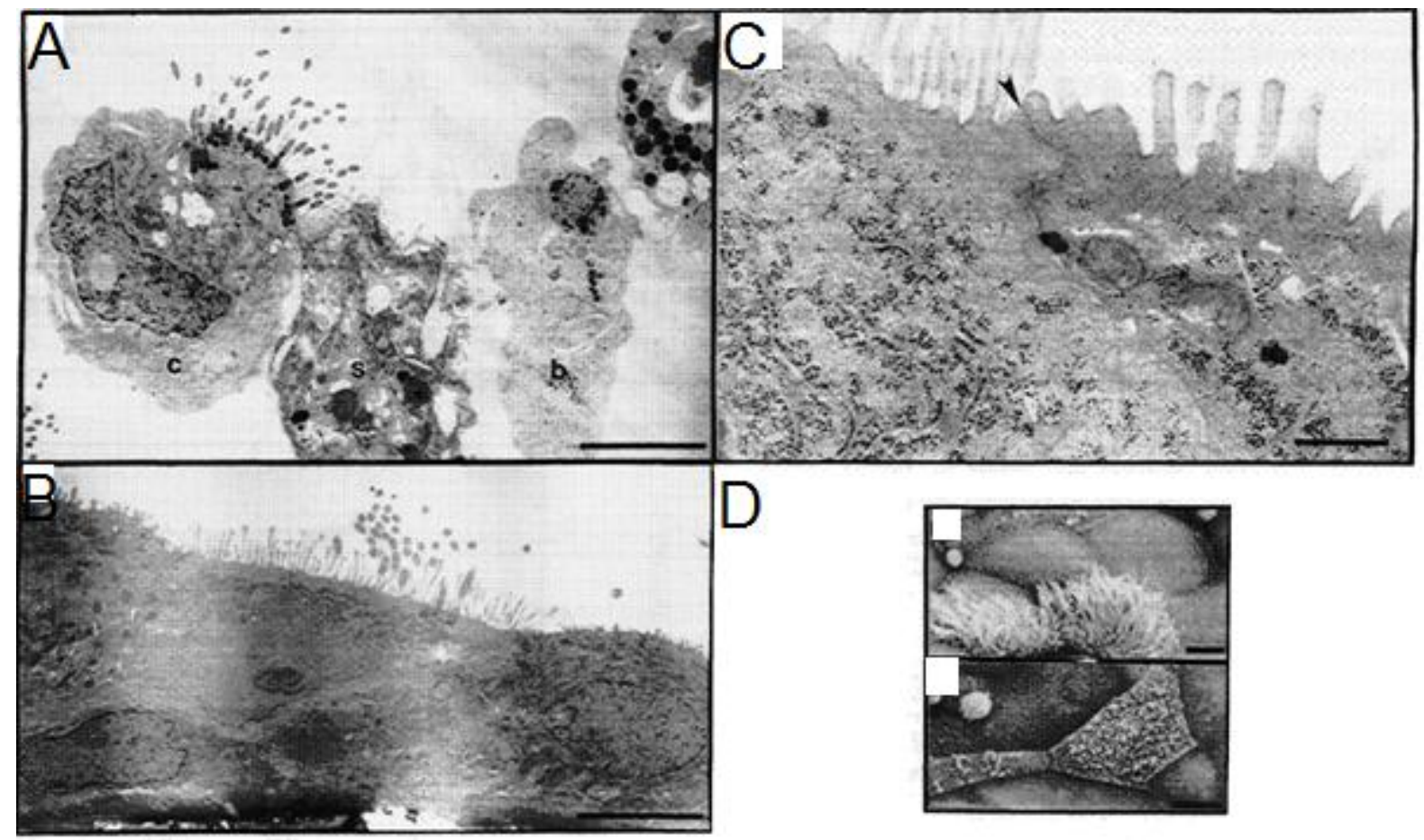

Figure 1-8. Morphological appearance of rabbit tracheal epithelial cells and the monolayers under SEM. A) isolated RTE cells in suspension, B) An air-interfaced RTE cell monolayer, C) The tight junctions (indicated by an arrowhead), D) The ciliary appearance of the air-interfaced RTE cell monolayer (top) and denuded cilia on ciliated cells observed in liquid-covered RTE cell layer (bottom). ${ }^{27}$

Furthermore, research studies have been focused on examining the human sub-bronchial gland cell line (Calu-3) and assessing its potential as a metabolic and transport model to study drug delivery to the respiratory epithelium. ${ }^{7}$ For example, the studies were conducted using Calu-3 cells grown in Transwells or in multiwall cluster plates. Confluent Calu-3 monolayer was imaged using optical microscopy as shown in Figure 1-9. Permeability data for small lipophilic molecules across Calu-3 monolayers indicated that there was a linear relationship between the $\log$ of the permeability of the examined drug substances and the log of their octanol/water partition coefficient excluding sucrose. Based on their results, the authors concluded that the 
Calu-3 cells can work as a suitable model to examine the transport of low molecular weight substances and xenobiotics.
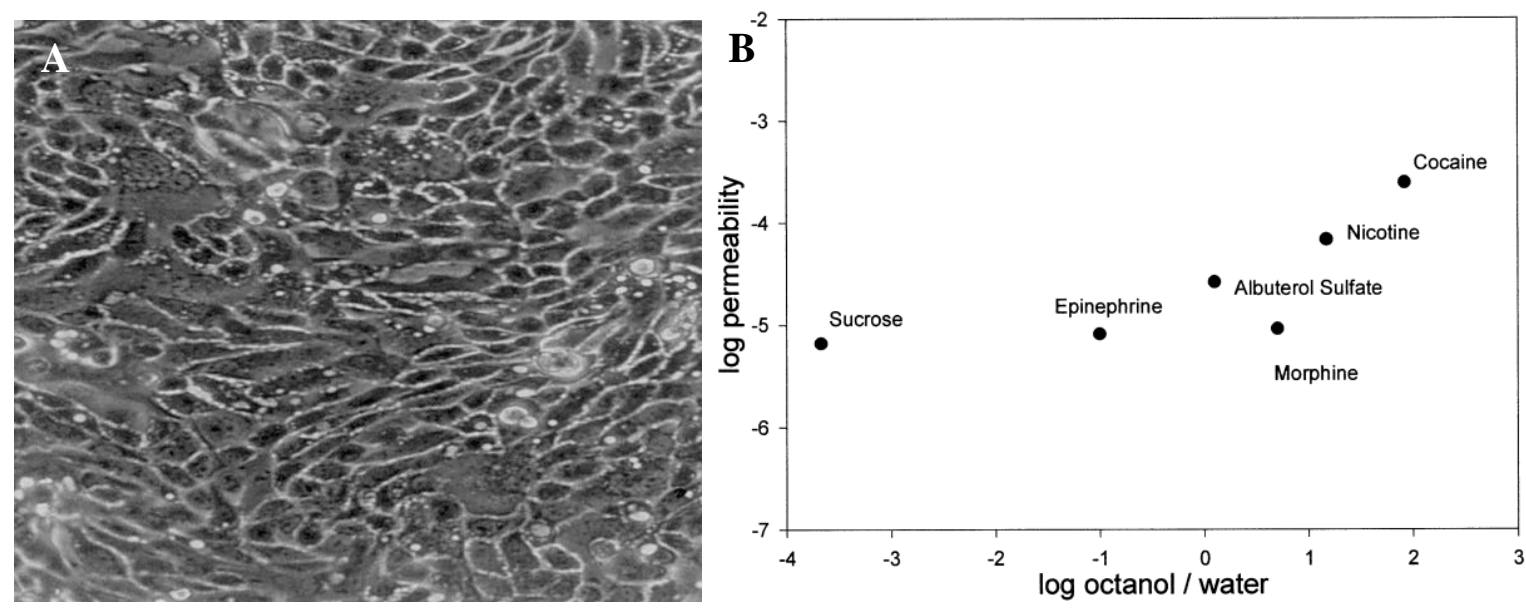

Figure 1-9. A) Confluent Calu-3 monolayer imaged using an optical microscope. B) Log permeability coefficients for the passage of small molecules across the Calu-3 monolayer culture in a Transwell versus log of the molecule's respective octanol: $\mathrm{H}_{2} \mathrm{O}$ partition coefficient. ${ }^{7}$

Immunofluorescence is a technique to target specific biomolecules within cells using fluorescent probes and to detect the targeted molecules under fluorescent microscopes. This technique is commonly used to analyze the distribution of tight junction proteins expressed by epithelial cells to study the epithelial integrity and permeability. The effect of the different fatty acids on occluding and ZO-1 expression in Caco-2 cell epithelial monolayers was analyzed by immunofluorescent staining. ${ }^{28}$ The Caco- 2 cells were cultured for 14 and 21 days in control and supplemented media, respectively. Fluorescent staining was performed after the media was removed and the monolayers were washed twice with phosphate buffered saline (PBS). Briefly, cells were fixed in ice cold methanol for five minutes at $-20^{\circ} \mathrm{C}$, allowed to dry for three hours, and stored at $-20^{\circ} \mathrm{C}$. The monolayers were rehydrated in blocking solution (3\% skimmed milk powder in Tween-Tris buffer (50 mM Tris, $150 \mathrm{mM} \mathrm{NaCl}, 0.05 \%$ Tween 20)) followed by incubation with anti-occludin or anti-ZO-1 rabbit polyclonal antibodies. Cells were washed and 
incubated with fluorescein isothiocynate anti-rabbit secondary antibody, and then, the cell monolayer was mounted on glass slides in fluorescent mounting medium for microscopic examination. Immunofluorescent analysis respectively showed the abnormally distributed and granular occludin as well as the ruffled ZO-1 in cells cultured in media supplemented with trans10 CLA, compared with the well-defined localization of the two kinds of tight junction proteins in membranes of cells supplemented with LA or cis-9 CLA, as shown in Figure 1-10.

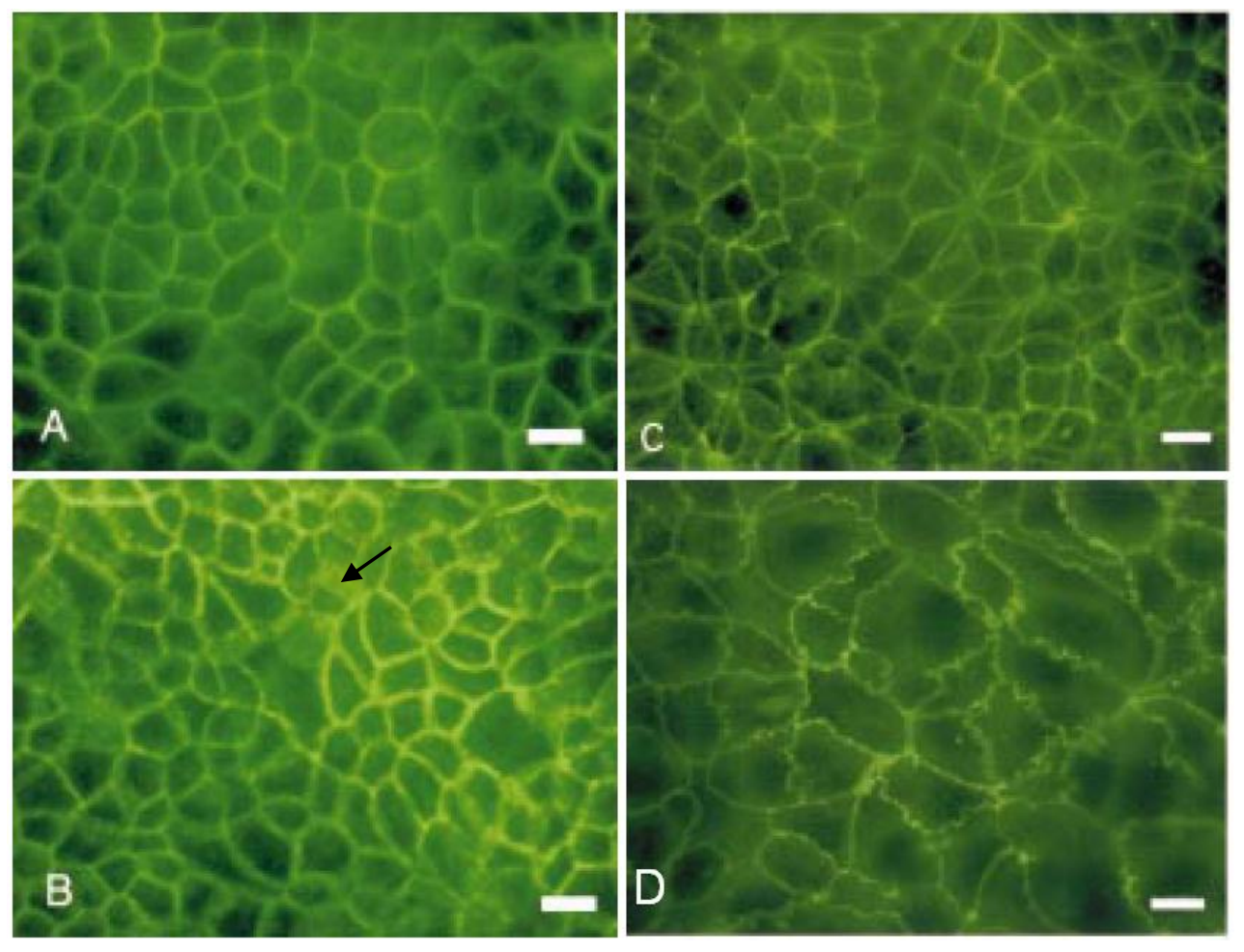

Figure 1-10. Antioccludin immunofluorescent staining of Caco-2 cell monolayers cultured in media supplemented with $0.05 \mathrm{mM}$ linoleic acid (LA) (A) and trans-10 conjugated linoleic acid (CLA) (B) for 21 days; Anti-ZO-1 immunofluorescent staining of Caco-2 cell monolayers cultured in media supplemented with $0.05 \mathrm{mM}$ cis-9 CLA (C) and trans-10 conjugated linoleic acid (CLA) (D) for 14 and 21 days, respectively. The scale bar is $100 \mu \mathrm{m} .{ }^{28}$

Since the TEER measurement technology was first introduced by World Precision Instrument Inc. (WPI) in the middle of 1980s, it has been widely used as an established standard method for monitoring tight junction integrity, monolayer formation, and paracellular 
permeability in polarized, transporting epithelial cells. ${ }^{29,30}$ The Epithelial Voltohmmeter (EVOM) with chopstick-type electrodes was the first instrument designed specifically to perform this measurement, as shown in Figure 1-11. Other instruments were later developed based on the EVOM, such as ENDOHM and Automated TEER Measuring System, to provide either reproducible resistance measurements or PC-controlled measurement system.

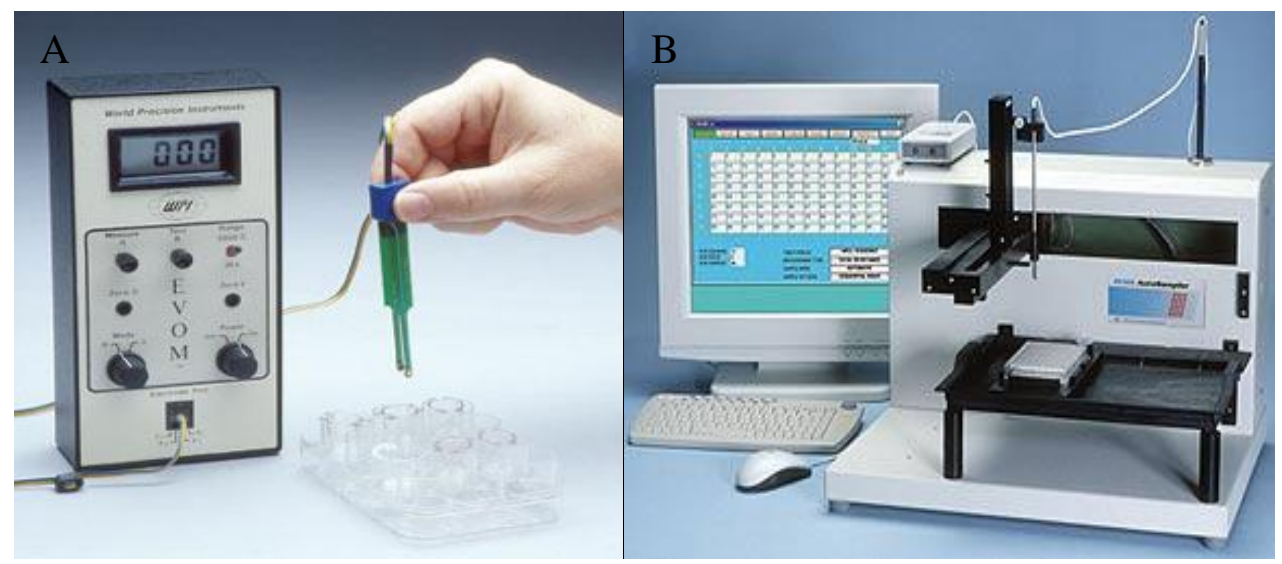

Figure 1-11. A) EVOM and B) PC-controlled Automated TEER Measuring System used for TEER measurement ${ }^{31}$

The regulation of tight junction permeability in cultured brain endothelial cells by phospholipid lysophosphatidic acid (LPA) was studied using the TEER technology. ${ }^{32}$ Pig brain endothelial cells were isolated and cultured to a cell layer, and then were treated with the LPA at the concentrations of 1,10 , and $100 \mu \mathrm{M}$, respectively. The TEER was measured at different time points and a drop of the value was observed after the treatment of LPA (Figure 1-12). The flux of membrane-impermeant sucrose across the cultured cell layer was significantly increased with the addition of LPA, indicating that the decrease of TEER reflected the increasing tight junction permeability instead of increasing membrane conductance. 

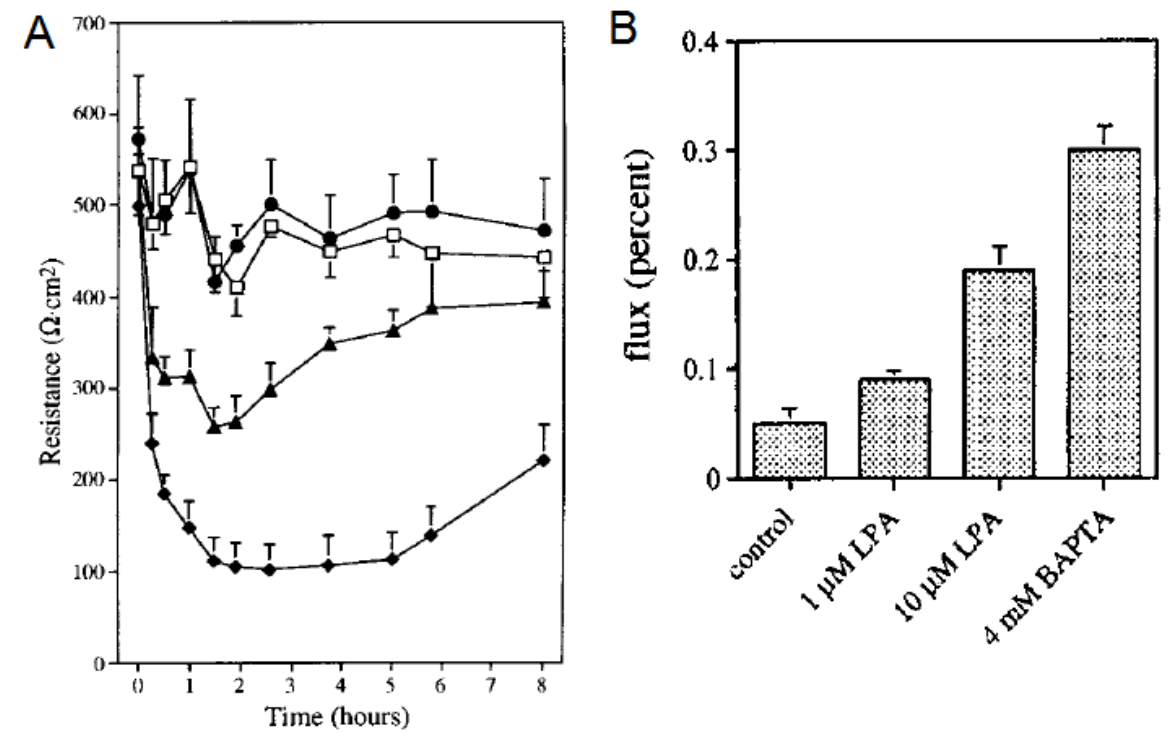

Figure 1-12. A) Decreased TEER values were measured on a cultured brain endothelial cell layer after the treatment of LPA. B) The flux of sucrose across the cell layer was increased, indicating increasing tight junction permeability. ${ }^{32}$

All in vitro cell models and molecule-based assays discussed above have been used to analyze the effects of various xenobiotic substances on the lung epithelial permeability and integrity. However, in exchange for experimental convenience, many of current in vitro models sacrifice physiological accuracy, such as lack of an appropriate balance and supply of growth factors, elimination of metabolic toxins, and the complexity of cells to cells interactions in tissue. Data obtained from molecule-based assays may not represent actual interactions between the nanomaterials and the targeted molecules in a complicated biological system. The optical and biochemical characterizations require chemical targeting prior to the analysis, which results in complex and lengthy preparation protocols. ${ }^{33}$ In this thesis, a microscale impedance-metric biosensor was developed based on microfluidic technology. This technology has the potential to easily integrate well-defined patterns within microfluidic devices and thus to provide a low-cost and real-time method for monitoring the effect of CNTs on pulmonary epithelial permeability. 


\subsection{Summary}

In this introduction, the importance of studying the adverse health effect of CNTs on lung epithelium permeability was discussed. Several conventional methods and their limitations were introduced and discussed for the analysis of the integrity and permeability of epithelium. As a suitable model, calu-3 cells can be cultured into a monolayer for the study of lung epithelium permeability. The TEER measurement provides a quick and easy method for the analysis. However, the in vitro cellular models and molecule-based assays limit its application due to the lack of system effects.

In the Chapter 2, the microfluidic technology was introduced and its advantage over the conventional methods was discussed. By using PDMS soft lithography techniques, microfluidic devices can be easily and inexpensively fabricated. The application of microfluidics was discussed and some literatures were reviewed.

The Chapter 3 discussed the design and fabrication of a microfluidic impedance-metric biosensor developed in this thesis work for monitoring the CNTs effects on lung epithelium permeability. Standard photolithography and soft lithography were used for the microfabrication.

The Chapter 4 explained why the Calu-3 cells were selected as in vitro models of lung epithelium. The cell seeding and culture were also discussed. The feasibility of the microfluidic biosensor was approved by immunofluorescence staining of the Calu-3 cell monolayer formed in the biosensor.

The Chapter 5 introduced the setup of EIS measurements and demonstrated equivalent circuit model for the microfluidic biosensor with measured impedance spectra. TEER values of lung epithelial cell monolayers were resolved by fitting the circuit. 
The Chapter 6 presented the effects of different MWCNTs (raw, purified and carboxyl functionalized MWCNTs) on epithelial permeability. The nanotoxicities of these three types of MWCNTs were studied by analysis of measured electrical impedance spectra in the microfluidic biosensor. 


\section{CHAPTER 2. LITERATURE REVIEW OF MICROFLUIDICS AND THE ADVANTAGES}

\subsection{Introduction to Microfluidics}

Microfluidics is the science and technology referring to analyze fluids phenomena and manipulate their behaviors in channels with dimensions of tens to hundreds of micrometers

(Figure 2-1). ${ }^{34}$ Compared to macroscale technologies, the microfluidics possesses a number of advantages, such as microfluidic technologies require small volumes of samples and reagents due to the small sizes of channels, and are less expensive due to low volumes of solutions and low cost of materials. ${ }^{35}$

Laminar flow is also an important benefit provided by the microfluidics. The behavior of fluids is described by the Reynolds number: $R_{e}=\frac{\rho v L}{\mu}$, where $\rho$ is the density of fluid, $\mathrm{v}$ is the velocity of the fluid, $\mathrm{L}$ is the cross-sectional dimension, and $\mu$ is the viscosity of the fluid. Because of the micro-scaled channels and low flow rates, $R e$ is usually much less than 100 or even less than 1 , which indicates that the flow is completely laminar. Compared to the turbulent flow, the laminar fluid flow is steady and constant, and allows to precisely control the flow rate either by applying a pressure difference between input and output or using pumps such as syringe pumps, piezoelectric pump and electro-osmotic pumps. Additionally in microfluidic systems, different streams flow in the channel and require long time and long travel distance to mix under the effects of diffusion. This feature of laminar flow has been applied to generate stable gradients of soluble molecules, as shown in Figure 2-1. ${ }^{36}$ This microfluidic gradient generator was formed by bonding a PDMS layer with a network of microchannels to a glass coverslip. The fluid streams were split and mixed in the branched array of the microchannels 
and were recombined in the main channel to produce and maintain the gradient, which was perpendicular to the direction of the flow.

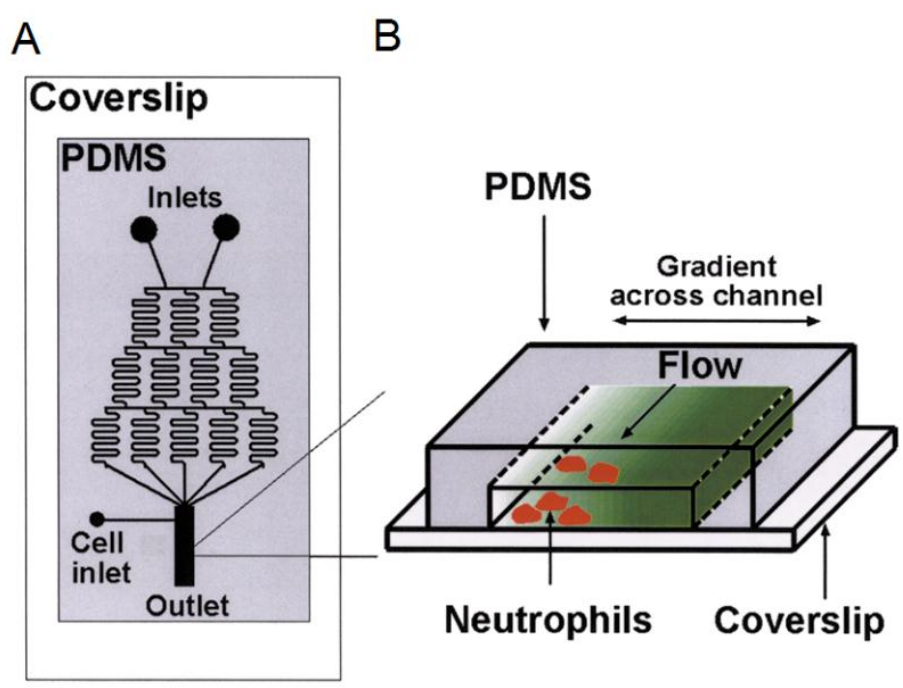

Figure 2-1. Schematic representations of the gradient generator and gradient characterization. (A) Top view of the whole device (B) Three-dimensional schematic representation of gradient generating. ${ }^{36}$

Another characteristic of microfluidic devices is the large surface area to volume ratio (SAV), which can enhance the rate of heat and mass transfer and thus achieve shorter reaction and analysis time. The high value of SAV can also lead to unconventional overriding forces like the surface tension, which is dominant in microfluidic systems instead of inertial and body forces. ${ }^{37}$ By taking this advantage, a microfluidic device was developed to sort cells and encapsulate single cell and reagents into pico-liter droplets for single cell analysis. ${ }^{38}$ The droplets containing labeled cells were formed by the surface tension.

The scaling of dimensions is another important character for microfluidics. It allows largescale integration and automatic control by miniaturized single functional unit. Many microfluidic components, including valves, pumps, reaction chambers and mixers, can be integrated in a small area in microfluidic devices. Complex tasks can be performed with high degree of 
parallelization while small volumes of fluids need to be manipulated. For example, a highdensity microfluidic chip was developed containing 256 sub-nanoliter compartments, which were individually addressed and isolated by 2056 valves, as shown in Figure 2-2. ${ }^{39}$ The microchannel layout contained four columns consisting of 64 chambers per column. Fluid was loaded into the device through two separate inputs and then mixed pairwise in the chambers, which were controlled by the multiplexors.

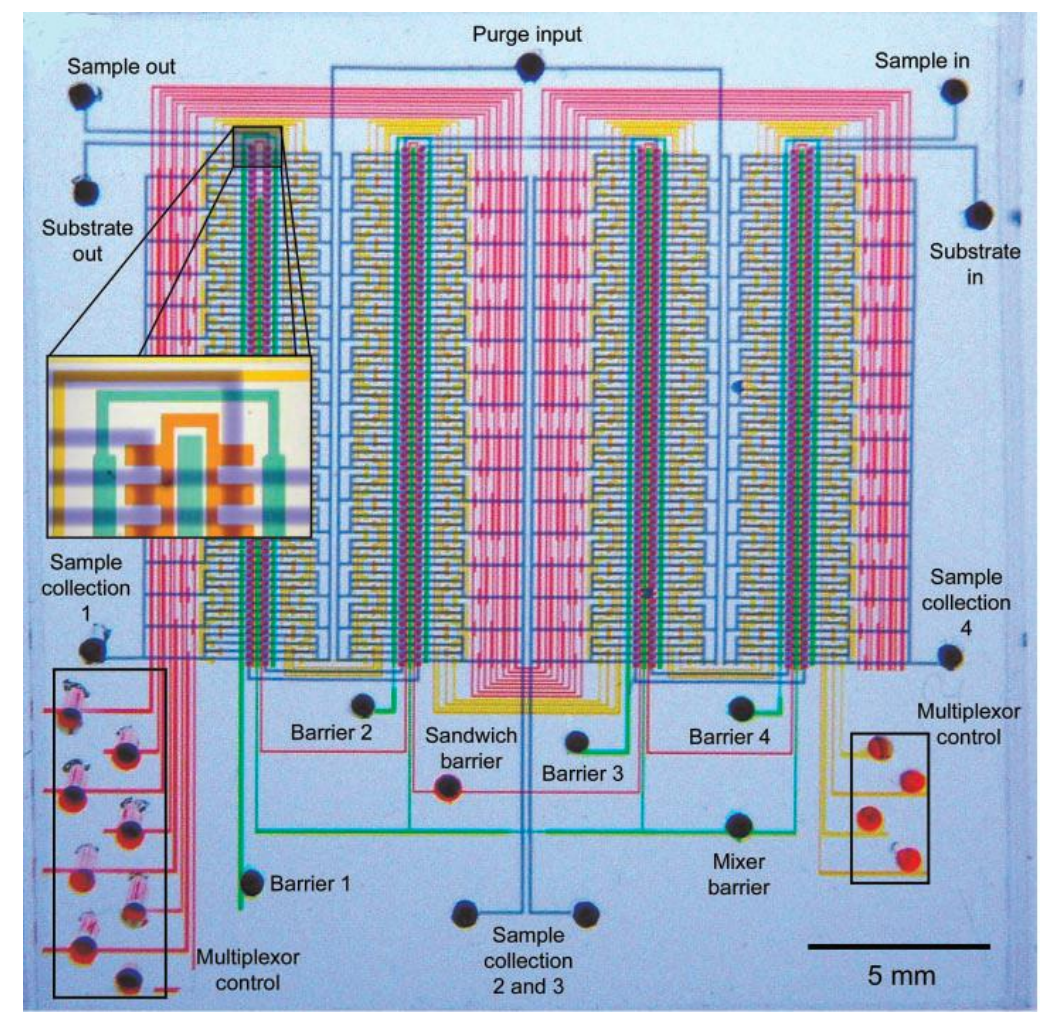

Figure 2-2. Optical micrograph of a microfluidic integration chip. The various inputs have been loaded with food dyes to visualize the channels. ${ }^{39}$

\subsection{PDMS Based Soft Lithography}

Initially, microfluidic devices were made of silicon and glass and fabricated by photolithography and etching techniques. Although, these techniques have been well developed, they are normally very expensive and time-consuming. Thus, polymer materials have been used to replace those 
rigid materials for microfluidic device fabrication, such as epoxy, poly(methyl methacrylate) (PMMA), polyurethane (PU), polystyrene (PS), polyethylene (PE), and poly(dimethylsiloxane) (PDMS). Polymer-based microfluidic devices can be fabricated by a series of microfabrication methods called soft lithography, including replica molding and cast molding, microcontact printing, microtransfer molding and micromolding in capillaries, etc. ${ }^{40}$ For example, a low cost plastic casting technique has been applied for fabricating epoxy-based microfluidic features with high resolution and quality, and can be used for various biochemical applications, such as polymerase chain reaction (PCR) and capillary electrophoresis. ${ }^{41}$

The polymer microfluidic devices fabricated using the soft lithography techniques are low cost and disposable, easy to create, and can be fabricated on both planar and non-planar surfaces. These features make polymer materials more and more attractive in the field of microfluidic fabrication and applications. PDMS, with favorable physical-chemical properties, has been one of the most actively developed polymers for microfluidic devices. ${ }^{42}$ Microfluidic channel features can be easily obtained and inexpensively fabricated by PDMS replica molding. Fabrication of systems and channels in PDMS is particularly straightforward because it can be cast against a mold with sub-0.1- $\mu$ m fidelity. PDMS is more than a structural material, and its chemical and physical properties make it possible to fabricate devices with useful functionalities. The optical property of this material allows the optical detection from $240 \mathrm{~nm}$ to $1100 \mathrm{~nm} .{ }^{43} \mathrm{In}$ addition, electrical circuits can be embedded in PDMS because of its high electrical resistivity and chemical resistance, which can insulate heated solutions and be non-reactive toward most agents. Specifically for biological studies, PDMS is biocompatible, impermeable to solutions and permeable to gases. It can be constructed to mimic two-dimensional or three-dimensional features of biological systems and is suitable for the development of in vitro models. Currently, 
the most commonly used approach for microfluidic fabrication is the combination of photolithography (master molds) and soft lithography techniques (replica molding) using PDMS as a material for microfluidic fabrication. The fabrication processes for a microfluidic device is shown in Figure 2-3, which starts with uniform deposition of photoresist on a silicon wafer. Ultra-violet (UV) light is then applied to the wafer through a photomask with designed microscale features. The master mold is obtained after the photoresist is exposed and developed. Then, soft lithography process involves PDMS replication of the master mold. PDMS consists of two parts, prepolymer and curing agent, both of which are commercially available. Once mixed and poured on the master mold, the liquid polymer are cross-linked at $60^{\circ} \mathrm{C}$ for 3 hours and form the replica of the micro-sized features of the mold. Cured PDMS can be easily peeled away from the master mold without any damage due to its elasticity. After oxygen plasma treatment, PDMS can be sealed to itself or surfaces of other materials, e.g. glass, to form sealed microfluidic channels.

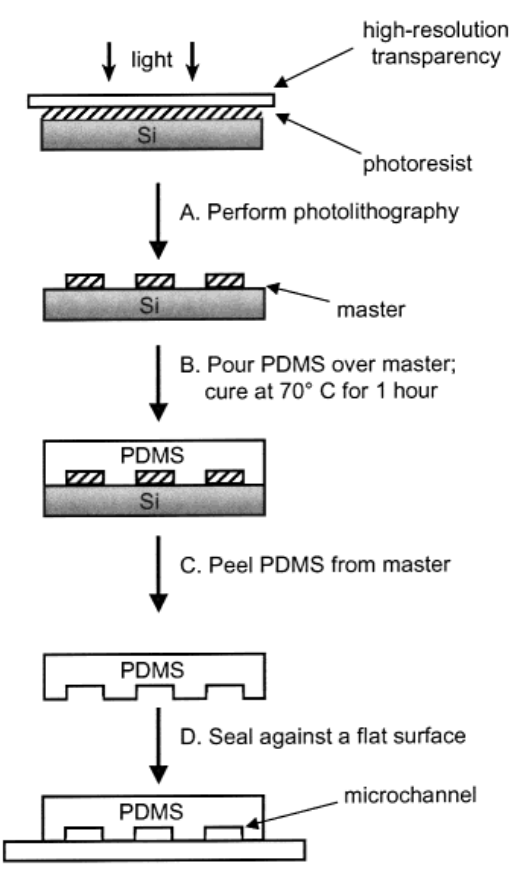

Figure 2-3. Schematic representation of the fabrication processes for PDMS microfluidic devices. $^{43}$ 


\subsection{Microfluidic Applications in Molecular, Cell and Tissue Biology}

Although the microfluidic technology is still in its earlier stage, it is attracting more and more researchers and scientists from difference disciplinary, such as biology, chemistry, engineering and medicine, to apply this technology in their research projects, and the microfluidic applications in these areas have been widely recognized and developed. A microfluidic chip called barrier interface metering (BIM) was built to rapidly screen conditions for protein crystallization, as shown in Figure $2-4 .{ }^{44}$ In comparison with conventional crystallization techniques such as microbatch or hanging-drop vapor diffusion which use large volume of protein samples, the BIM chip requires ultra-small volume samples. The chip has 480 active valves and performs 144 parallel reactions, each of which uses only $10 \mathrm{~nL}$ of the protein sample. A fast protein crystal growth was achieved and the crystallization conditions including viscosity, ionic strength, surface tension and $\mathrm{pH}$ value were monitored and screened in each chip.

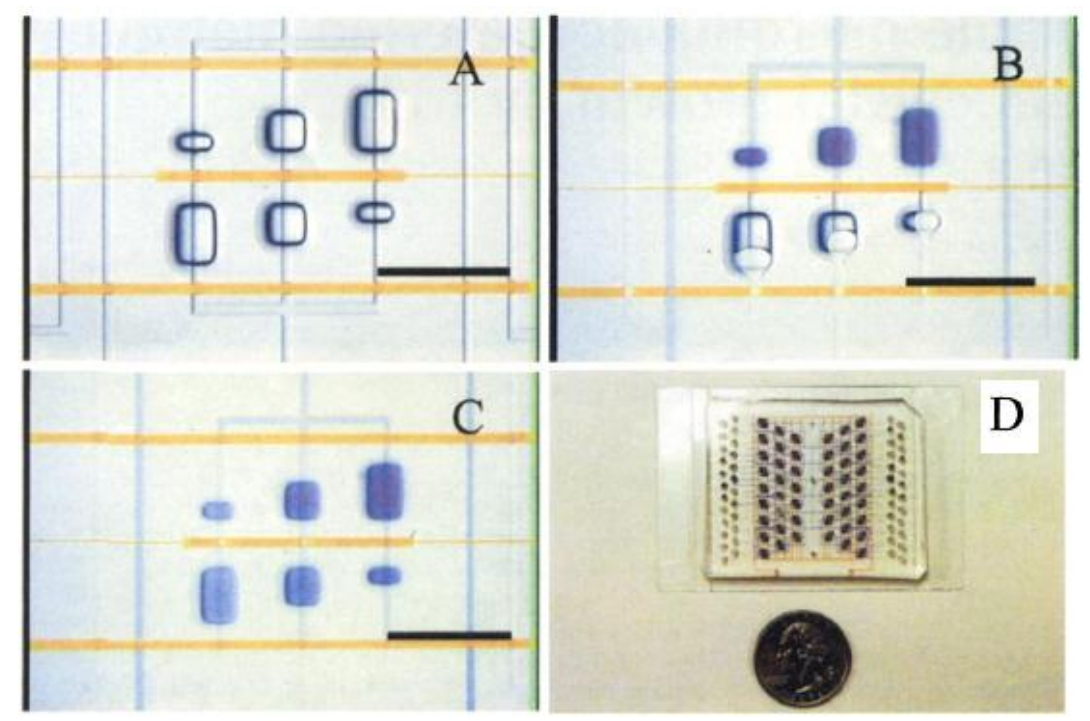

Figure 2-4. A robust and scalable microfluidic device that is able to screen protein crystallization conditions. A) Section of a device showing three pairs of compound reaction chambers. The upper chamber and lower chambers were isolated by a closed barrier valve. B) Loading of reagents using pressurized outgas priming method. C) A gradient of dye concentration was formed by open the barrier valve to allow diffusion. D) Prototype protein crystallization chip. The scale bars are $1 \mathrm{~mm} .{ }^{44}$ 
A novel platform for DNA separation was developed by performing electrophoresis experiments in a microfluidic system. The efficient separation of DNA fragments in microfluidic channels using electrokinetic flow in a sieving matrix was achieved by Effenhauser's group. ${ }^{45}$ Completely sealed microchannels were formed by bonding a PDMS chip to a glass support. The microfluidic channels were then filled with the buffer solution and separation media. The sample solution with $\varphi \mathrm{X}-174 / \mathrm{HaeIII}$ DNA restriction fragments or $\lambda$-DNA was pipetted into one reservoir located in the end of a channel. Platinum electrodes were dipped into all reservoirs for applying the electrophoresis force. The whole PDMS chip was mounted on the stage of an inverted microscope for the fluorescent detection as shown in Figure 2-5A. Electrophoresis was performed by applying a separated potential between reservoirs. The PDMS, which exhibits a considerably high electrical resistivity, has the ability to prevent the electrical current leakage. A fast separation of $\varphi \mathrm{X}-174 / \mathrm{Ha}$ III DNA restriction fragments was obtained and detected in the PDMS chip with the effective separation length as long as $35 \mathrm{~mm}$, as shown in Figure 2-5B.

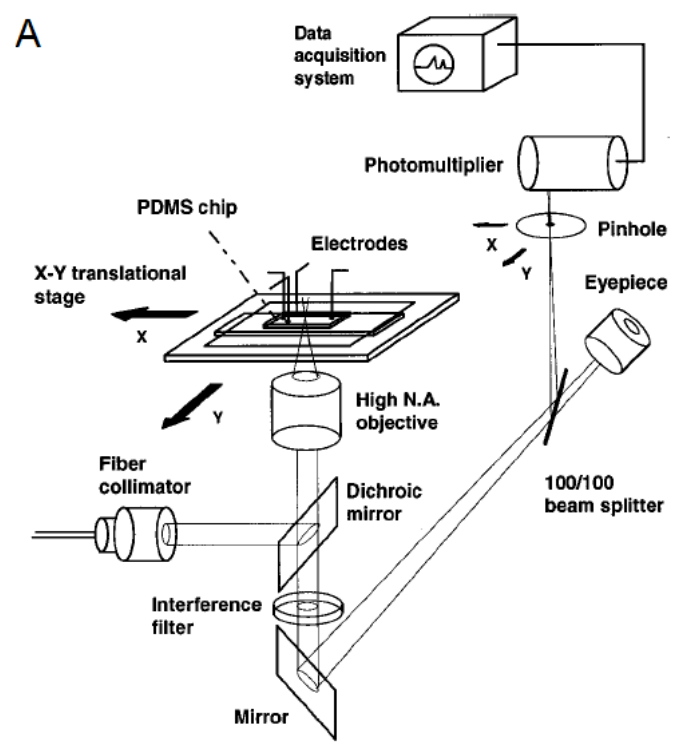

B

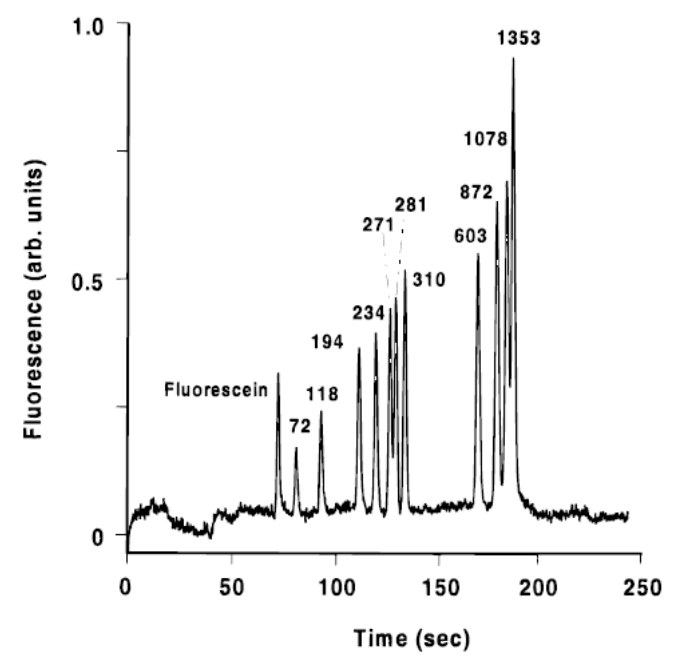

Figure 2-5. A) Schematic representation of the experimental setup and the detection arrangement. B) Separation of $\varphi$ X-174/HaeIII DNA restriction fragments in a PDMS device. ${ }^{45}$ 
The microfluidics offers structures with the scales that are comparable to the intrinsic dimensions of cells, tissues and organelles, and thus provides a powerful tool in the study of cell biology. ${ }^{46}$ Microfluidic based cell culture technologies provide novel cell culture platforms that expand our ability to control the local cellular microenvironment, for example, it can continuously transfer media, buffers and even oxygen supplies while waste products can be drained in a manner resembling the human circulatory system. ${ }^{47,}{ }^{48}$ Microfluidic technologies and biomedical devices have been widely applied for manipulating cells and studying cell biology.

Separation and isolation of rare cell populations from a heterogeneous suspension is essential and necessary for many medical applications, ranging from disease diagnostics and drug treatment analysis to conducting fundamental studies. ${ }^{49}$ A microfluidic-based device for sorting mammalian cells was developed by using optical force switching method. ${ }^{50}$ The microfluidic channels were fabricated in glass by isotropic etching techniques. The solution, containing histone-green fluorescent protein (GFP) expressing cells and non-expressing parental cells, was pneumatically driven through the microfluidic chip. When no optical beam was present, all cells flew to the waste channel. However when a GFP-expressing cell was detected in the analysis region, the optical switch was activated and a near-infrared laser deflected the detected cell to the collection channel, as shown in Figure 2-6. This optical force can reach magnitudes on the order of $1 \mathrm{pN} / \mathrm{mW}$ for cells with diameter about $10 \mu \mathrm{m}$, and is large enough to drive the cell flowing without damaging the cells. 

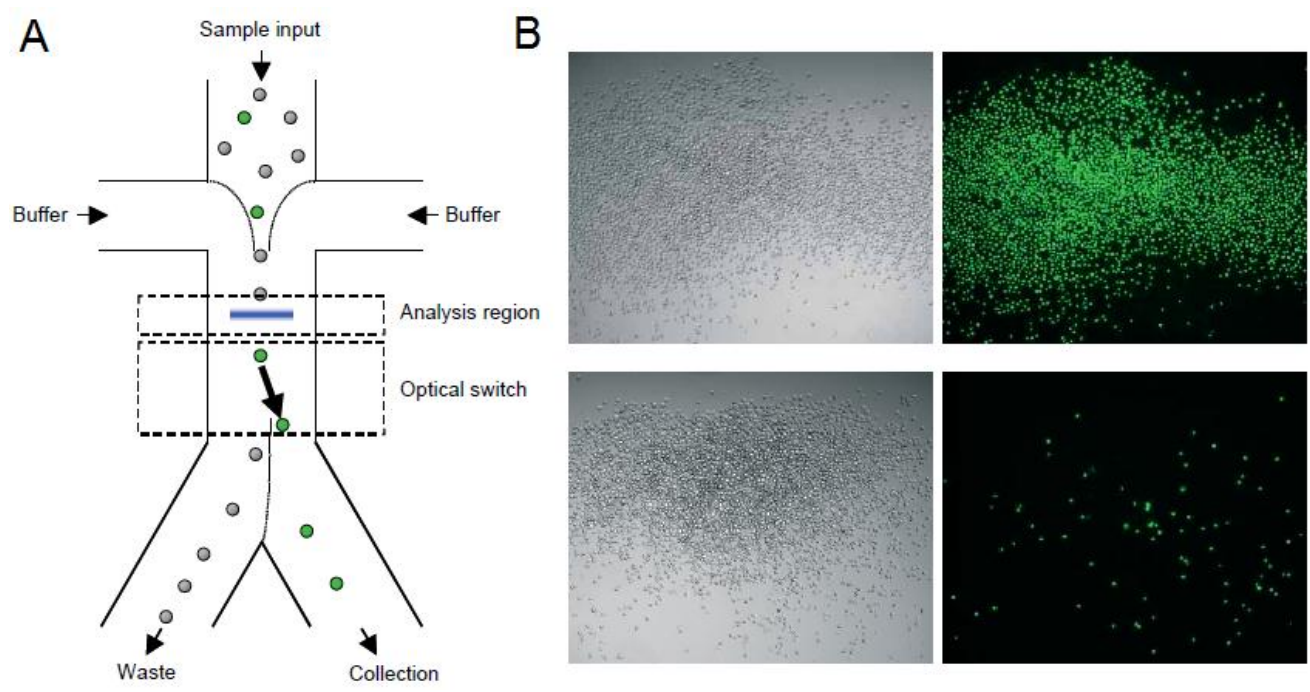

Figure 2-6. A) Layout of the optical switch in the microfluidic-based cell sorter. B) Bright field (left) and fluorescence (right) images of the resulting cell populations in the collection well (top) and waste well (bottom). ${ }^{50}$

Currently, a new trend for microfluidic technologies is to create 3-D chips with living cells and tissues that accurately model the structure and function of human organs, such as the lung, liver and heart. These bio-engineered devices will be functionally relevant and accurately reflect the complexity of the tissue of origin, including genomic diversity, disease complexity and pharmacological response. For example, a novel living and breathing human lung-on-a-chip was created by researchers at Harvard's Wyss Institute. ${ }^{51}$ The fabrication of this biomimetic microfluidic chip started with alignment and bonding of two PDMS layers sandwiched by a 10 $\mu \mathrm{m}$ thick PDMS membrane, as shown in Figure 2-7A. A PDMS etching solution was then applied to dissolve the membrane in the side channels and to form two hollow side chambers. Human alveolar epithelial cells and microvascular endothelial cells were cultured in the central channels respectively and formed monolayers on the opposite surfaces of the PDMS membrane, which contained an array of holes with the diameter of $10 \mu \mathrm{m}$ and was coated with extracellular matrix gels. When computer-controlled vacuum was applied to the chambers, the flexibility of 
the PDMS membrane allowed the cyclic stretching of the alveolar-capillary interface for mimicking breathing movements (Figure2-7B). Nanotoxicology studies were performed in the devices, which indicated that the breathing motions enhanced the uptake of nanoparticulates and accentuated the toxic and inflammatory responses of the lung. For instance, when the silica nanoparticles were added to the alveolar microchannel, more ICAM-1 expression was observed when the mechanical strain was applied (Figure 2-7D), revealing that the artificial lung motions would induce more acute lung inflammation.
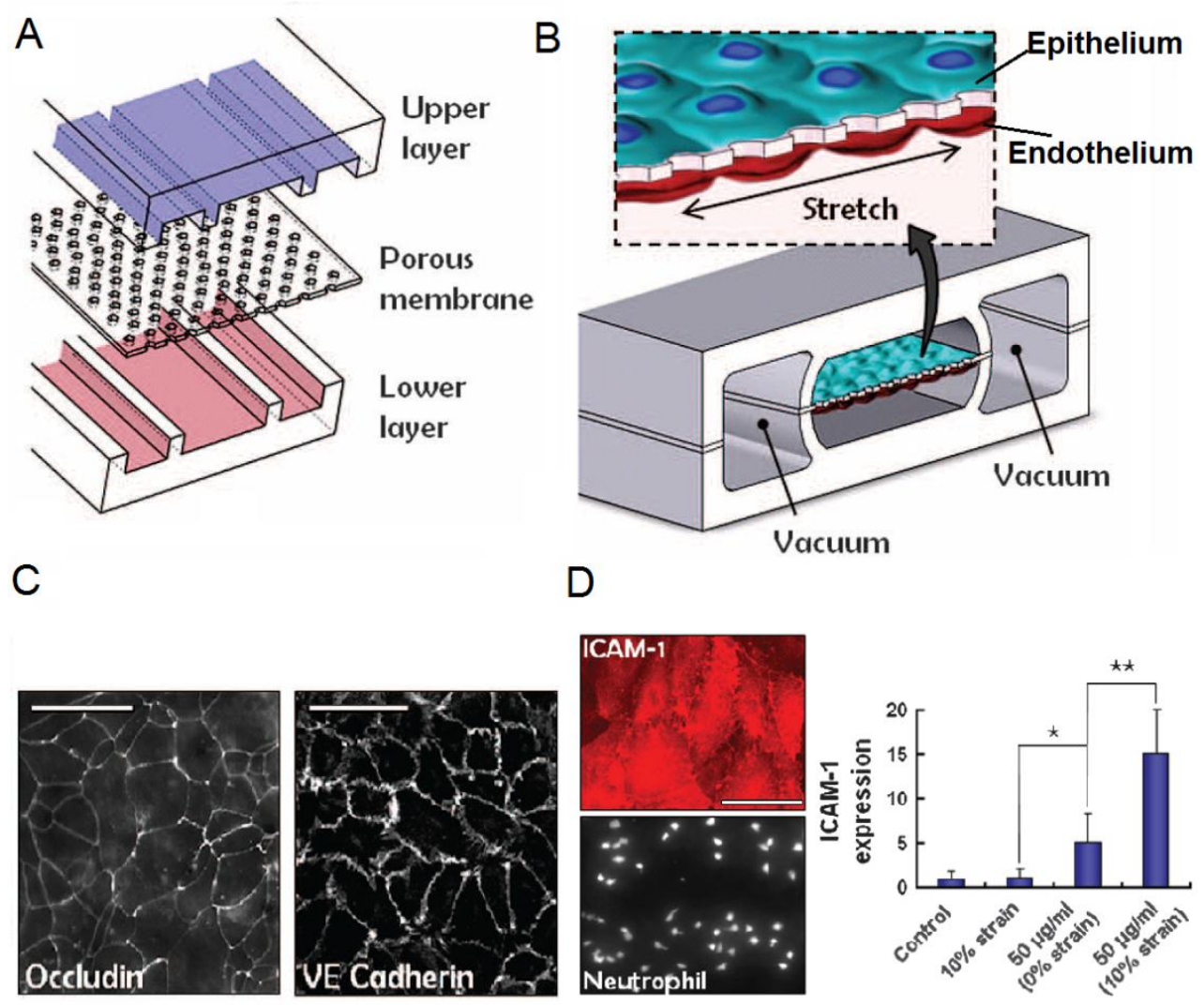

Figure 2-7. A) Schematic formation of the bioinsipred breathing lung-on-a-chip microdevice. B) Computer-controlled vacuum was applied to the side chambers to achieve cyclic stretching of the PDMS membrane. C) Intercellular junctions were formed evident by the fluorescence staining. D) More acute lung inflammation was caused by exposure to silica nanoparticles when the cyclic stretching was performed. 51 


\subsection{Microfluidics and Electrical Impedance Spectroscopy}

Compared to conventional in vitro assays for studying cell behaviors, electrical impedance spectroscopy (EIS) is a low-cost, high throughput technology that can be used for continuously monitoring biological variation of cells in real-time. By utilizing microfabricated techniques, well defined patterns (i.e. metal electrodes and polymer structures) can be easily integrated within microfluidic devices to enable electrical characterizations, such as impedance measurement. This approach offers low-power means of applying traditional electrical impedance measurement to the investigation of complex-valued dielectric properties of small structures $^{52}$, and the development of micro analysis systems for electrical characterization of cells.

An on-chip cell impedance biosensor that host individual cells was developed to detect the response of cells to a chemical or biological agent. ${ }^{53}$ Au was deposited onto a wafer by electronbeam evaporation to form the detecting microelectrodes with the diameter of $20 \mu \mathrm{m}$ to host single cells. The response of human glioblastoma cells to chlorotoxin was detected by impedance measurements, which were taken by applying an input signal of $10 \mathrm{mV}$ sine wave with a frequency range of $500 \mathrm{~Hz}$ to $20 \mathrm{kHz}$. The normalized real impedance waveforms of the single cells treated with varying concentrations of chlorotoxin were shown in Figure 2-8. The results showed that when the concentrations of the chlorotoxin were increased to $5 \mu \mathrm{M}$, significant impedance change was achieved, indicating a change of cell morphology. 


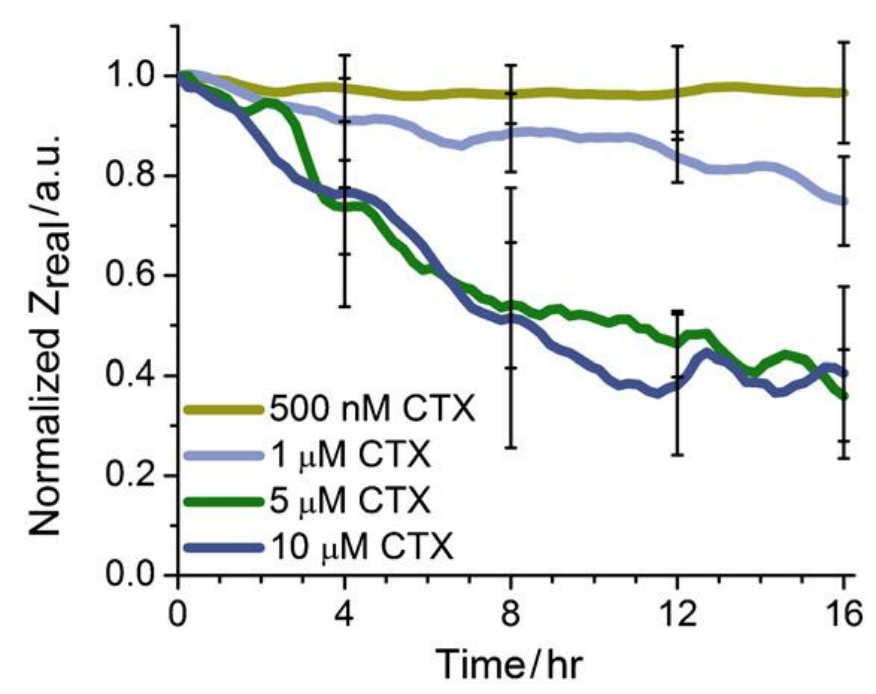

Figure 2-8. Average normalized real impedance waveforms of single human glioblastoma cells in response to CTX at varying concentrations. ${ }^{53}$

In addition to provide an efficient method for the detection in single cell experiment, EIS, such as bioimpedance probes and electric cell substrate impedance sensing (ECIS) for in vivo or in vitro measurement ${ }^{54}$, offers a label-free approach and a quantitative technique to measure the integrity of cell junctions, cellular membrane functions, and tissue composition parameters. The amplitude and phase spectra obtained from the impedance measurements can provide sufficient information for studying growing processes of cell monolayers, the formation of cell-cell junctions, and reagents' effects on monolayer integrity and permeability.

A measuring system was developed for measuring impedance of epithelial or endothelial cell monolayers directly cultured on gold surfaces. ${ }^{55}$ Impedance analysis was carried out in the frequency range from $1 \mathrm{~Hz}$ to $100 \mathrm{kHz}$ to accurately determine the TEER value of the formed cell monolayer. This approach provided a reliable method to study the properties of the monolayer. However, the application system was limited by the absence of the microenvironment and the opaque gold electrodes prevented optical observation during the formation of the cell monolayer. In addition, the absence of sandwiched support, which can 
divide cell culture chamber into two compartments, limited the permeability study of the cell monolayer.

Commercially available systems like cellZscope were also developed as powerful tools for studying epithelial or endothelial cells in vitro. The impedance of the cell monolayer is measured by applying a wide spectrum of frequencies to obtain the TEER values. A high level of automation of data acquisition and analysis is implemented in the system, which makes the cellZscope measurement as a label-free and reliable tool to study the barrier properties of the cell monolayer.

A similar concept is with the TransWell system, in which epithelial or endothelial cells are cultured on a porous membrane to form into a monolayer, and two recording electrodes are placed above and beneath the membrane in a two-layered channel system. ${ }^{56}$ The system was built by incorporating electrodes into PDMS microfluidic devices, which enabled the impedance measurement in the microfluidic system. Impedance spectra were obtained by applying alternating current across two embedded $\mathrm{Ag} / \mathrm{AgCl}$ electrodes in the frequency range from $10 \mathrm{~Hz}$ to $1 \mathrm{MHz}$. An equivalent circuit model was built to represent the biological system, as shown in Figure 2-9. The TEER value of the cultured cell monolayers can be determined by fitting measured impedance data to the circuit. We initially attempted to use a similar system to test the response of lung epithelium to MWCNTs but found that the Calu-3 cells failed to grow on the porous membrane, which we believe was induced by the toxicity of the $\mathrm{Ag} / \mathrm{AgCl}$ electrodes. The impact of the $\mathrm{Ag} / \mathrm{AgCl}$ electrodes on biological systems have been reported previously and it was recognized that the silver ions would be resolved into surrounding solutions and introduce damage to biological tissues. ${ }^{57}$ In addition, the impedance spectra of cell monolayers were obtained by subtracting the control impedance results, which were acquired before cell loading, 
from the experimental results, which were acquired after cell monolayers were formed. The TEER values of the cell monolayers were then resolved by fitting the impedance spectra to the equivalent circuit as shown in Figure 2-9. However, this method of data analysis may not be accurate and reliable because the conditions of culture medium and electrodes would change over time.

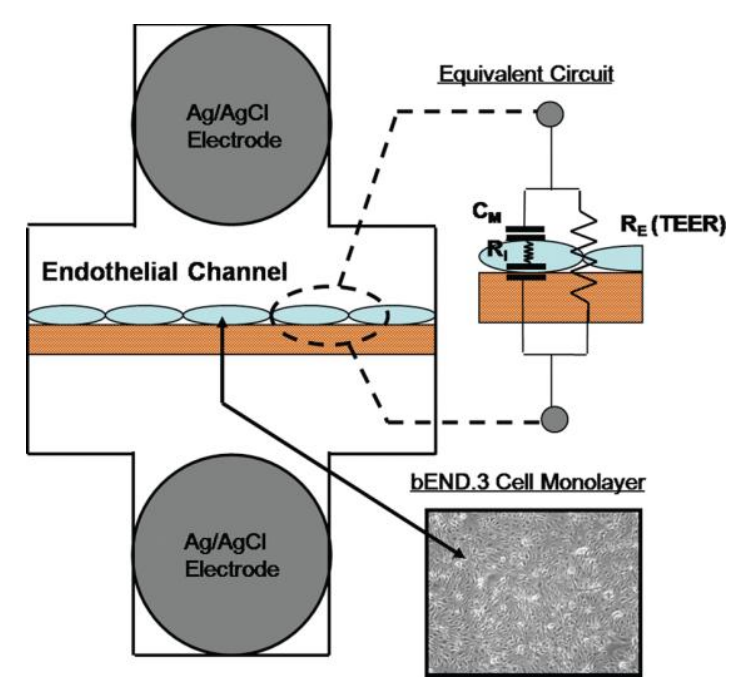

Figure 2-9. A two-layered impedance microfluidic system was developed to study the barrier properties of epithelial or endothelial cell monolayers and the equivalent circuit model was built for the system. ${ }^{57}$

The advantages and limitations of existing conventional methods for studying epithelial permeability are summarily shown in Table $2-1$. Here, we presented a microfluidic impedance biosensor and its capability for studying CNTs effects on human lung airway epithelial integrity and permeability, which allowed more reliable and accurate impedance measurement under microfluidic environment. 
Table 2-1. Advantages and disadvantages of existing methods for epithelium study

\begin{tabular}{|l|l|l|}
\hline \multicolumn{1}{|c|}{ Existing methods } & \multicolumn{1}{c|}{ Advantages } & \multicolumn{1}{c|}{ Disadvantages } \\
\hline Animal study & $\begin{array}{l}\text { Improve understanding of } \\
\text { physiology and } \\
\text { pathophysiology. }\end{array}$ & $\begin{array}{l}\text { Labor intensive, expensive, } \\
\text { difficult to manipulate, } \\
\text { time and space consuming. }\end{array}$ \\
\hline $\begin{array}{l}\text { SEM/Immunofluorescence } \\
\text { characterization in } \text { in vitro } \\
\text { models }\end{array}$ & $\begin{array}{l}\text { Reflect the formation and } \\
\text { show the morphology of } \\
\text { tight junctions. }\end{array}$ & $\begin{array}{l}\text { Chemical targeting is } \\
\text { needed. }\end{array}$ \\
\hline $\begin{array}{l}\text { TEER measurement in } \\
\text { Transwell system }\end{array}$ & $\begin{array}{l}\text { No cell damage; Reflect } \\
\text { the formation process of } \\
\text { tight junctions. }\end{array}$ & $\begin{array}{l}\text { Inaccurate measuring } \\
\text { results; Lack of } \\
\text { microenvironment. }\end{array}$ \\
\hline $\begin{array}{l}\text { Two-layered microfluidic } \\
\text { system }\end{array}$ & $\begin{array}{l}\text { No cell damage; } \\
\text { Microfluidic environment. }\end{array}$ & $\begin{array}{l}\text { Inappropriate data analysis } \\
\text { method; toxicity from } \\
\mathrm{Ag} / \text { AgCl electrodes. }\end{array}$ \\
\hline
\end{tabular}




\section{CHAPTER 3. DESIGN AND FABRICATION OF THE MICROFLUIDIC IMPEDANCE BIOSENSOR}

\subsection{Design of the Microfluidic Impedance Biosensor}

A double-layered microfluidic system was designed for reliable, low-cost and real-time impedance measurement of a lung epithelial cell monolayer. A porous membrane was sandwiched between two layers as the support for the cell monolayer. This design will allow the cell monolayer formed between two medium channels and is convenient for medium change (dynamic or static change), chemical loading, and the permeability test. In addition, two electrodes can be easily integrated within the device. Figure 3-1a provides a schematic design of the biosensor and assembling process. The device is composed of two PDMS layers, each of which contains a main microfluidic channel for the access of cells and cell growth media and a branch channel intersecting the main one at $45^{\circ} .{ }^{56}$ The thickness of the main channels is designed to be $150 \mu \mathrm{m}$ and the width to be $2 \mathrm{~mm}$. A chamber with the area of $4 \mathrm{~mm}^{2}(2 \mathrm{~mm} \times 2$ $\mathrm{mm}$ ) for cell culture is formed by overlapping the top and bottom main channels. Holes are punched at the end of the branch channels for the electrode access, as shown in Figure 1b. The transparent polyester porous membrane is cut from the TransWell (Corning, NY) and trimmed to a size slightly larger than the area of the cell culture $(2 \mathrm{~mm} \times 2 \mathrm{~mm})$. Then, the cut membrane is sandwiched between the top and bottom PDMS layers. 

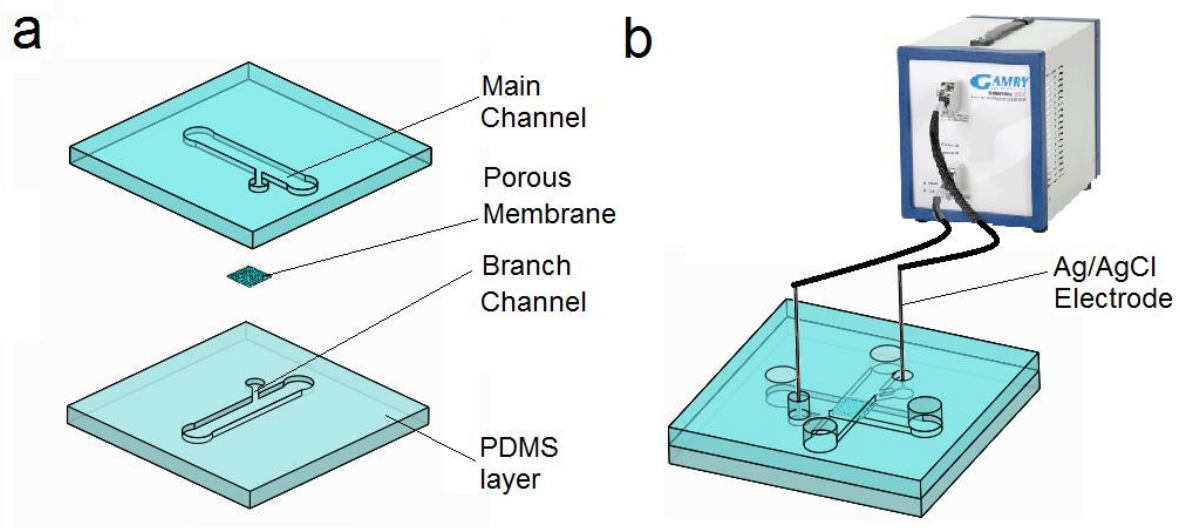

Figure 3-1. a) Schematic design and assembling process of the microfluidic impedance biosensor; b) Two holes were punched to locate $\mathrm{Ag} / \mathrm{AgCl}$ electrodes for impedance measurement.

Lung epithelial cells are expected to grow and form cell monolayer on the porous membrane located in the center of the chamber. The culture media inside the branch channel serves as the electrolyte connecting the chamber to the electrodes, as shown in Figure 3-2. Alternating current can be applied through the electrodes which are dipped into the culture media to obtain the impedance measurements.

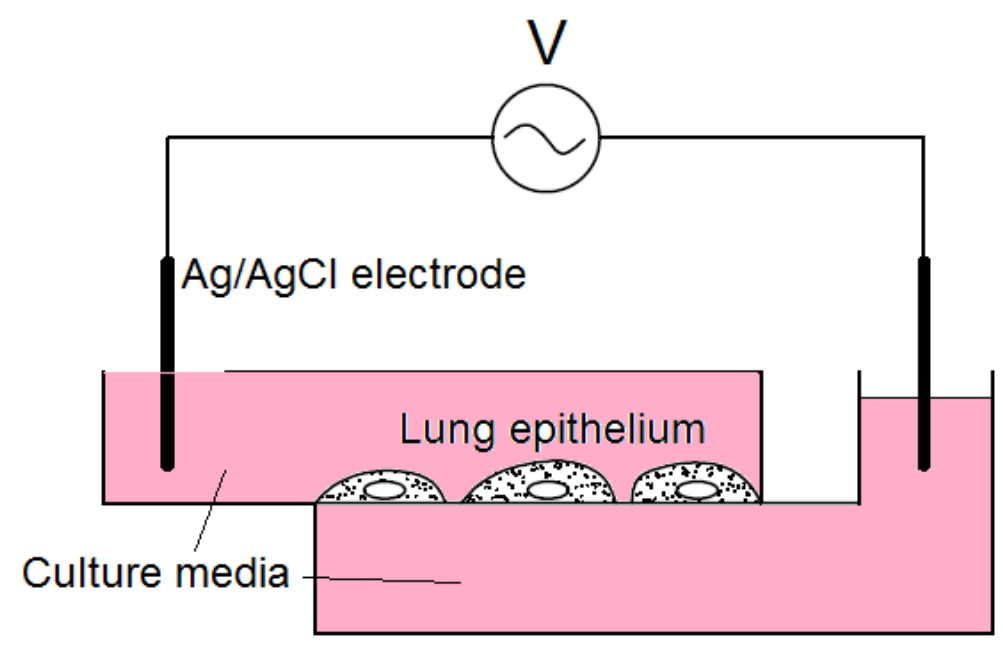

Figure 3-2. Applied alternating current flows from one electrode, culture media which serves as the electrolyte and lung epithelial cell monolayer, to the other electrode. 


\subsection{Materials and Fabrication}

PDMS (Dow corning, MI), which can be used to inexpensively and easily fabricate microfluidic channel systems to provide a biocompatible microenvironment for cell biology study, was commonly selected as the material for microfluidic devices. The high electrical resistivity of PDMS can prevent the leakage of electrical signals in the microfluidic system. This makes PDMS as an ideal material in the application of the electrical impedance measurements. In addition, the transparency of the PDMS allows optical observation of cell growth in the microfluidic biosensors. Negative tone photoresist SU-8 2050 (MicroChem, MA), which is chemically and thermally stable, was used to create master molds on $\mathrm{Si}$ wafers. Thick and high contrast features with vertical sidewalls can be obtained from the photoresist. $\mathrm{Ag} / \mathrm{AgCl}$ electrodes (A-M systems, WA) were used for the impedance measurements as they are inexpensive, commercially available and can provide stable potential. As discussed in Chapter 2, however, cell damage was observed in the microfluidic devices with the electrodes incorporated immediately close to porous membranes. This result, compared to the normal cell growth and proliferation in the microfluidic devices without electrode insertion, indicated the toxic effect of $\mathrm{Ag} / \mathrm{AgCl}$ electrodes on the Calu-3 cells. The microfluidic biosensor was then modified by relocating the electrodes farther from the cell culture chamber. Althouth the electrodes' damage was thus alleviated, the accuracy of the impedance measurements was heavily affected because of the long distance between electrodes and cultured cell. The biosensor was further developed by creating two holes at the ends of the branch channels so that the electrodes can be dipped into culture medium during the measurement and removed after it to avoid the introduction of toxicity. 
The microfluidic channel patterns were firstly designed and drawn using AutoCAD and then printed into a photomask. Exposure to UV light causes negative resists like SU-8 2050 polymerized. The exposed resists will remain on the Si surface while the unexposed portions will be removed by the developer solution. Therefore, the clear and dark regions were printed on the photomask as shown in Figure 3-3 for creating raised features on Si substrates.

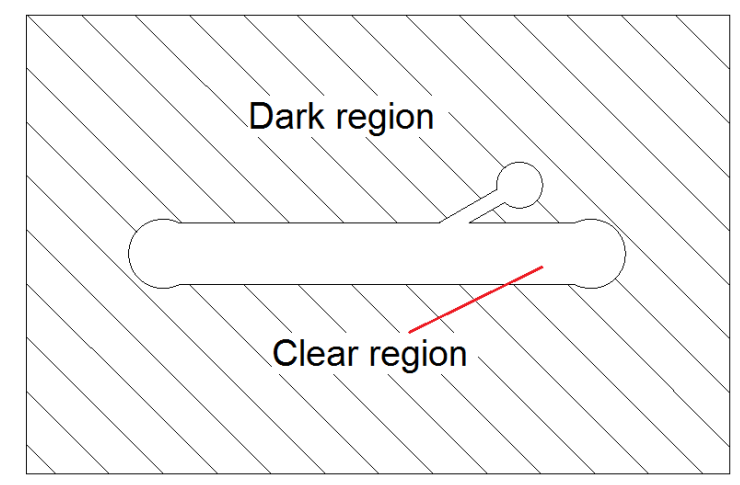

Figure 3-3. The photomask was designed using AutoCAD and printed with desired patterns. The photoresists underlying the clear region was expected to be exposed and polymerized, which would cause the resists to remain on substrates.

Standard photolithography were used to transfer the patterns onto master molds. Si wafers were firstly cleaned with acetone and methanol, followed by a de-ionized (DI) water rinse. The wafers were then dehydrated on top of a hot plate at $150{ }^{\circ} \mathrm{C}$ for 1 hour prior to spin-coating the photoresist. The SU-8 2050 resist were then spin-coated n onto Si wafers at $1000 \mathrm{rpm}$ for 30 seconds to form a film with the thickness of around $150 \mu \mathrm{m}$. Soft bake was performed at $65{ }^{\circ} \mathrm{C}$ for 5 mins and $95^{\circ} \mathrm{C}$ for another 30 mins to make the resists photosensitive, respectively. The baked photoresist film was exposed under UV radiation with total energy of $350 \mathrm{~mJ} / \mathrm{cm}^{2}$ using a flood exposure system (OAI model 150). Post exposure bake (conditions) was performed directly after the exposure to reduce mechanical stress formed during soft bake and exposure processes. SU-8 developer was applied to remove the unexposed parts of the photoresists and the raised features with the thickness of $150 \mu \mathrm{m}$ were thus left on the Si wafers. 
Finally, the Si master molds were fabricated after the wafers were rinsed with DI water, dried with nitrogen and treated with hard bake at $150{ }^{\circ} \mathrm{C}$ for 1 hour.

Soft lithography technique was used to create PDMS microfluidic channels. PDMS prepolymer was prepared at 10:1 (base: curing agent) mixing ratio and cast onto the Si molds. The PDMS layers together with the master molds were baked at $60^{\circ} \mathrm{C}$ for 3 hours to cure the PDMS, and then, the PDMS layers were peeled off the molds. Stamping bonding was used to form a leakage free bonding between the membrane and PDMS channels. PDMS pre-polymer was spun on a cleaned glass slide at $4000 \mathrm{rpm}$ for 60 seconds. Two PDMS layers were stamped onto the glass slide, respectively, to have a very thin liquid PDMS layer adhere to the bonding sides. Additionally, extra liquid PDMS was carefully applied to the edges of the trimmed membrane. The membrane was then sandwiched between the top and bottom PDMS microfluidic channel layer. The whole device was put inside the oven to completely cure the PDMS. Holes were punched to allow the access of cells and growth medium and the placement of electrodes. The fabricated microfluidic impedance biosensor was shown in Figure 3-4.

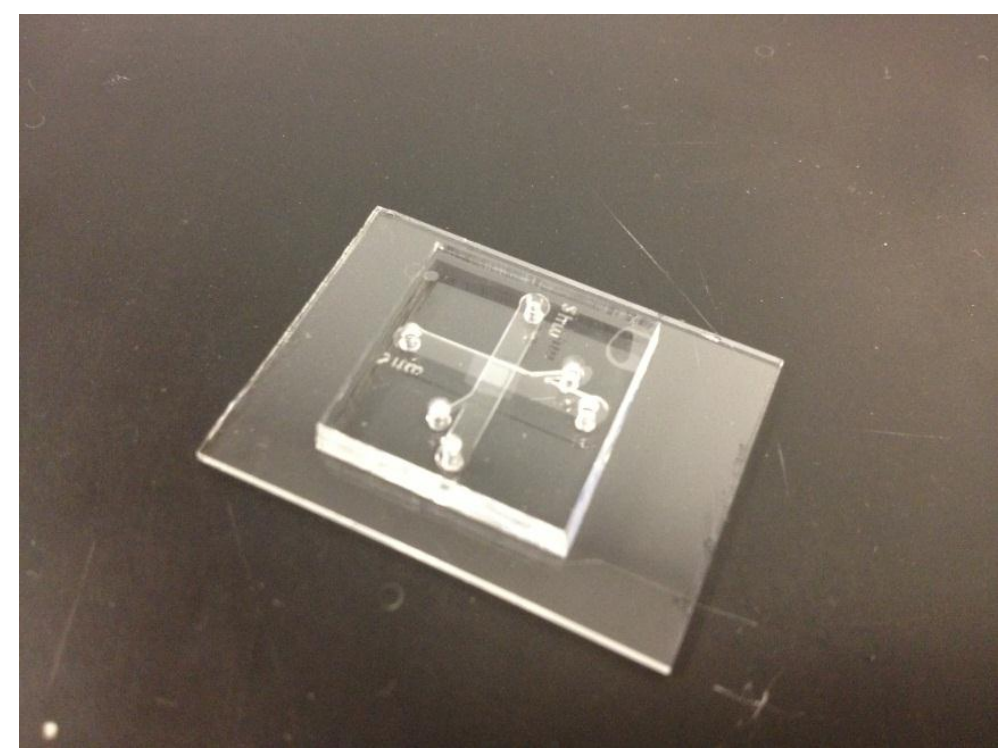

Figure 3-4. The fabricated microfluidic impedance-metric biosensor 


\subsection{SEM characterization}

The degree of accuracy is an important criterion for characterizing if the biosensor is feasible for EIS measurement. With high electrical resistance, the PDMS material can ideally confine electrical current inside the microfluidic channel. However, leakage of the current would be resulted from gap between the top and the bottom PDMS channels and thus affect the accuracy. PDMS stamping bonding, as discussed in the fabrication section, was used to seal the membrane inside the device. Scanning electron microscopy (SEM) was used to examine the membrane bonding between two PDMS layers. As shown in Figure 3-4, a complete sealing of the membrane with the PDMS layers was confirmed. In addition, the cells were only observed on the top channel layer during cell loading and culturing, and it further confirmed a complete sealing.

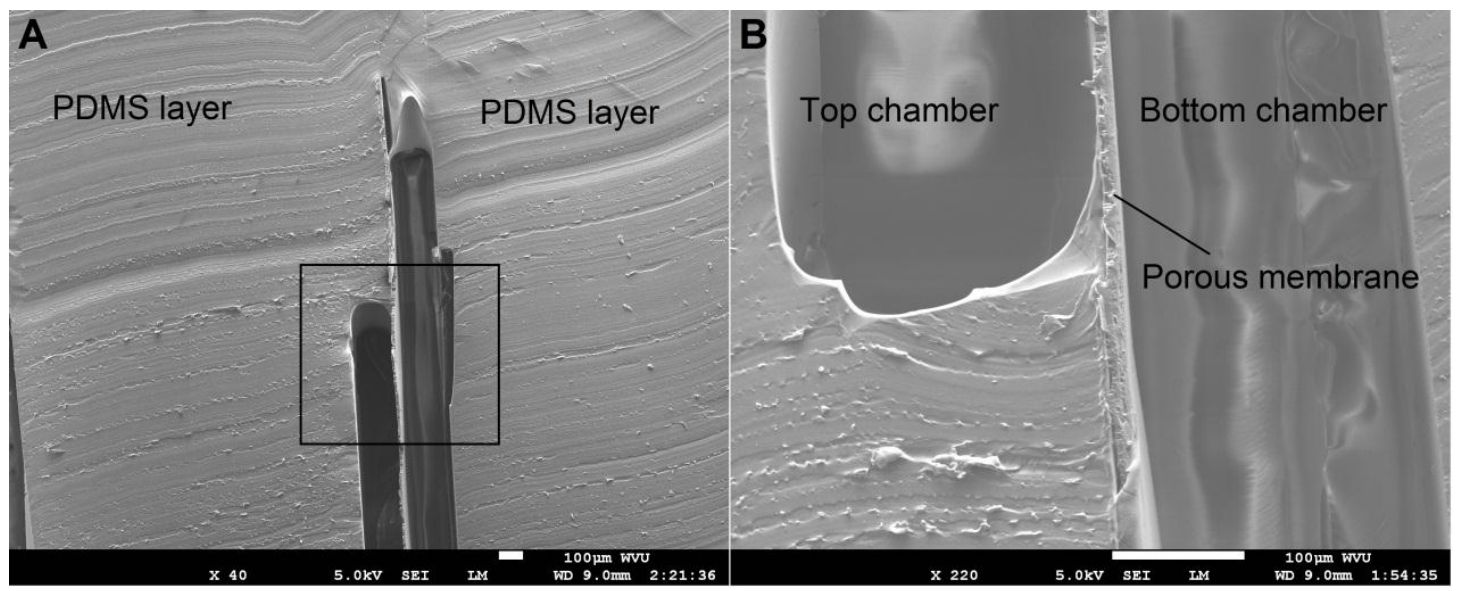

Figure 3-5. A) SEM picture shows the membrane bonding between two PDMS channels; B) Enlarged SEM picture shows the bonding between membrane and the PDMS.

\subsection{Device preparation for cell loading}

The direct use of PDMS in cell culture is limited by the hydrophobic property, which makes introducing culture medium and other aqueous testing solutions into the PDMS microfluidic channels difficult. ${ }^{58}$ Many methods have been developed to modify and control its surface 
properties. In this thesis, the fabricated microfluidic biosensor was treated with 5 mins oxygen plasma, which can generate silanol groups and render the hydrophobic PDMS surfaces to be hydrophilic. ${ }^{42}$ Another limit of the PDMS is resulted from the fast hydrophobic recovery. The hydrophobicity would be regained after a few minutes due to the migration of low molar chains from the bulk of the PDMS to the surface. ${ }^{59}$ Here we pre-wetted the microfluidic biosensor with DI water immediately after the oxygen plasma treatment to maintain the hydrophilicity.

In addition, a sterile microenvironment is required to achieve regular cell viability in the microfluidic biosensor. UV sterilization was applied to treat the biosensor due to the excellent optical transparency of PDMS. After 8 hours treatment by the UV light inside the bio-laminar hood, the biosensor was finally prepared for cell experiments. Prior to cell seeding, the water in the channels was completely washed out using pre-warmed cell growth medium. 


\section{CHAPTER 4. CELL CULTURE}

\subsection{Calu-3 cell line as a lung epithelium model}

The culture of primary human lung epithelial cells is normally limited with short life spans and restricted availability, and in vivo models and animal studies are high cost and difficult in manipulation. An in vitro model, which potentially provides extended supplies of cells, would be an efficient and valuable tool for studying the mechanism of lung epithelium. ${ }^{60}$

Calu-3 cells are a human bronchial epithelial cell line isolated from an adenocarcinoma of the lung. ${ }^{61}$ The Calu-3 cell line, which is well-differentiated and characterized, can reflect the properties of human bronchial submucosal glands as a major source of active substances on the

airway surfaces. ${ }^{62,}{ }^{63}$ With the capability to form tight monolayers in culture and to mimic the respiratory epithelium, the Calu-3 cell line was used as in vitro models to mimic and study the barrier functions and permeability of human lung epithelium.

In this thesis work, the Calu-3 cell line was used in the microfluidic impedance-metric biosensors to study MWCNTs effects on epithelial permeability. A confluent Calu-3 cell monolayer was expected to form on the sandwiched permeable support membrane in the biosensor. Cell culture medium was loaded into both chambers on the top and the bottom of the cell monolayer. Alternating current was applied across the monolayer and the change in the impedance spectra induced by the exposure of MWCNTs was measured and analyzed.

\subsection{Cell seeding and culture}

An initial important step to obtaining viable cultures in microfluidic devices is cell seeding. ${ }^{64}$ Here a pipet-based injection method was used to achieve efficient and uniform seeding in the biosensors, the procedure of which is shown in Figure 4-1. Firstly, human bronchial epithelial 
calu-3 cells were obtained from American Type Culture Collection (ATCC, VA, USA). They were thawed and cultured in regular culture dishes with MEM medium (ATCC) with 15\% fetal bovine serum, $1 \%$ Penicillin/Streptomycin and 1\% L-Glutamine. The cells were maintained at a humidified atmosphere of $37^{\circ} \mathrm{C}$ and $5 \% \mathrm{CO}_{2}$, and the medium was changed every two days. After reaching 70 80\% confluence, the cells were washed with $1 \times$ PBS and detached from culture dishes with $0.05 \%$ trypsin/EDTA. The cells were then collected to $15 \mathrm{ml}$ tubes and centrifuged at 1000rpm for 5 mins. By re-suspending the cells located in the bottom of the tubes with appropriate volumes of culture medium, the Calu- 3 cells at concentration of $1 \times 10^{6}$ cells $/ \mathrm{mL}$ were obtained. Finally by using pipet injection, the cell culture medium inside the upper microfluidic channels was completely replaced by the media with suspended cells.

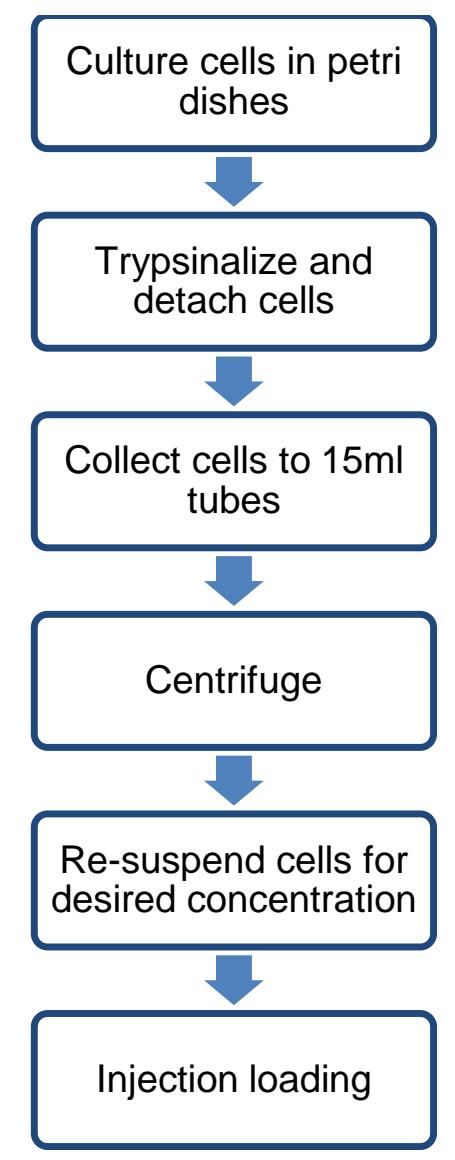

Figure 4-1. The processes of pipet-based injection cell seeding 
Compared to conventional cell culture, the culture inside microfluidic devices possess different physicochemical characteristics as introduced in the Chapter 2. It is important to properly control cellular microenvironment in the microfluidic biosensor for maintaining healthy and regular cell conditions. Temperature, $\mathrm{pH}$ and gas concentrations are key factors to influence cell metabolism and proliferation. After the cell seeding, the microfluidic devices were placed inside an incubator with the temperature of $37{ }^{\circ} \mathrm{C}$, gas concentrations of $5 \%$ and $20 \%$ for $\mathrm{CO}_{2}$ and oxygen, respectively. Benefiting from the properties of PDMS, which is unreactive toward the Calu-3 cell culture medium and insulates heated solutions, the temperature in the microenvironment can be well maintained. In addition, the gas permeability of PDMS allows the oxygen and $\mathrm{CO}_{2}$ exchange between inside and outside of the biosensor. However, because of the gas permeability, evaporation would be a problem and adversely affect the cell growth and should be prevented. A sterile wet tissue is therefore placed aside the biosensor to keep the humidity of the micro system. Air bubble is another major problem in the microscale cell culture. Many factors like the evaporation may result in the appearance of the bubbles in the microfluidic channels. The bubbles would be trapped near the porous membranes when they enter the culture chamber and the culture microenvironment would be disturbed. The accuracy of electrical impedance measurements would also be reduced by air bubbles trapped in the microfluidic channels. In addition to maintain the humidity of the devices, the air trapped inside reservoirs (tubing connection and media access) need to be removed before cell seeding or changing culture medium to avoid introducing any bubbles into the system.

After a few hours culture, the cells were observed to attach onto the membrane. Nutrient depletion and waste accumulation could result in low viability of the cells. The media change at regular time interval is therefore required for the maintenance of cell cultures in the microfluidic 
biosensor. ${ }^{64}$ Due to the higher SAV ratios, the effective culture time interval need be concerned in a different way from the conventional cell culture. By trial and error, it was found that the media change at a daily basis can maintain normal calu-3 cell culture in the devices. The cells were found to form into a monolayer after 10 days culturing in the microfluidic biosensor. The optical image of the cell monolayer is shown in Figure 4-2.

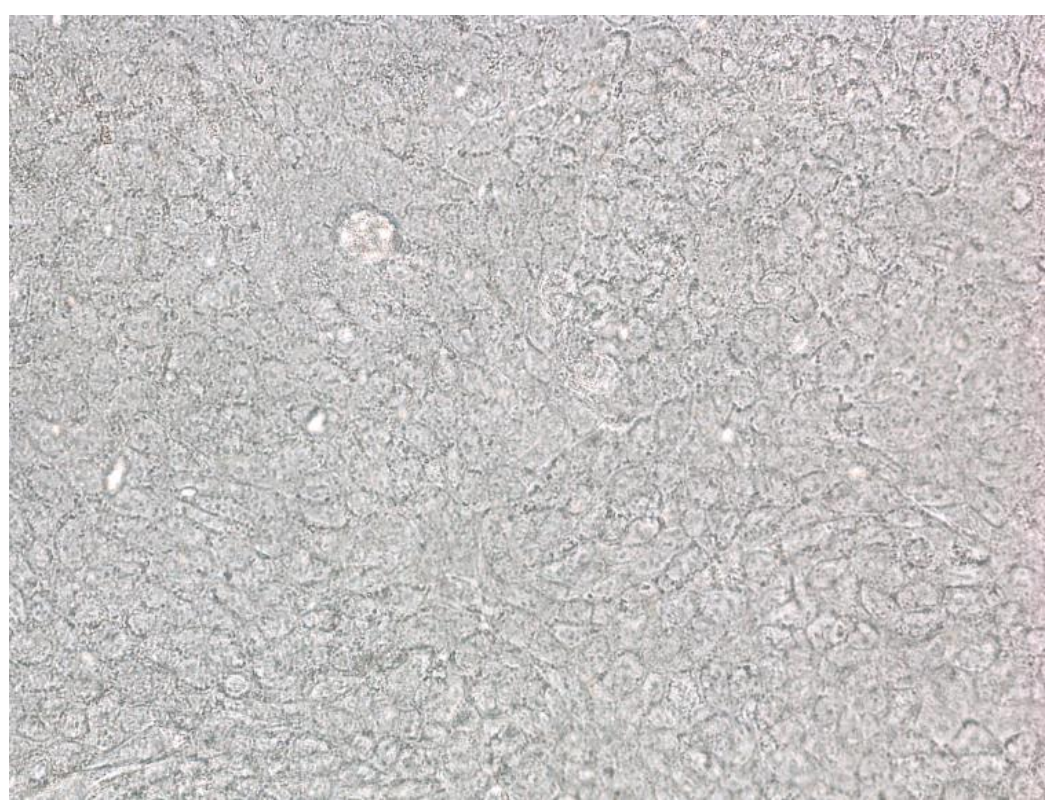

Figure 4-2. Calu-3 cell monolayer was formed after $\sim 10$ days culturing in the microfluidic biosensor

\subsection{Immunofluorescence characterization}

Immunofluorescence, which is a technique to visualize the distribution of specific biomolecules targeted by fluorescent dyes with fluorescent microscopes, has been widely used in biological studies to characterize proteins, glycans and DNA. ${ }^{65}$ The fluorescence staining was performed here to study the cell monolayer on the porous membrane and to test if tight junction proteins were formed in the monolayer. The staining process was accomplished inside the biosensors, and all the staining agents were loaded through the microfluidic channels. Specifically, the cells were firstly fixed with $3.7 \%$ formaldehyde for 30 mins at room temperature, and then permeabilized 
and blocked using a solution containing $0.5 \%$ saponin, $1 \%$ bovine serum, and $1.5 \%$ goat serum for $30 \mathrm{~min}$. Primary antibody (Anti-ZO1 tight junction protein antibody (1: 50; Abcam)) was applied to the cell monolayers for 1 hour at room temperature, then the cells were washed and incubated with secondary antibody (1:100 Alexa Fluor 488-conjugated; Invitrogen) for 1 hour. The actin cytoskeleton was stained with 1:200 Alexa Fluor 546-conjugated phalloidin (Invitrogen). The membrane together with the cell monolayer was cut from the device and placed onto a glass slide and then mounted using the ProLong® GOLD anti-fade reagent (Invitrogen) with Hoechst 30551 to visualize cell nuclei. Immunofluorescence was imaged (Figure 4-3) using an inverted microscope (Nikon Eclipse Ti, Japan), which clearly shows the formation of tight junction proteins ZO-1. The results indicated that the in vitro model of lung epithelial cell monolayers were successfully created in the microfluidic biosensors for further impedance studies.

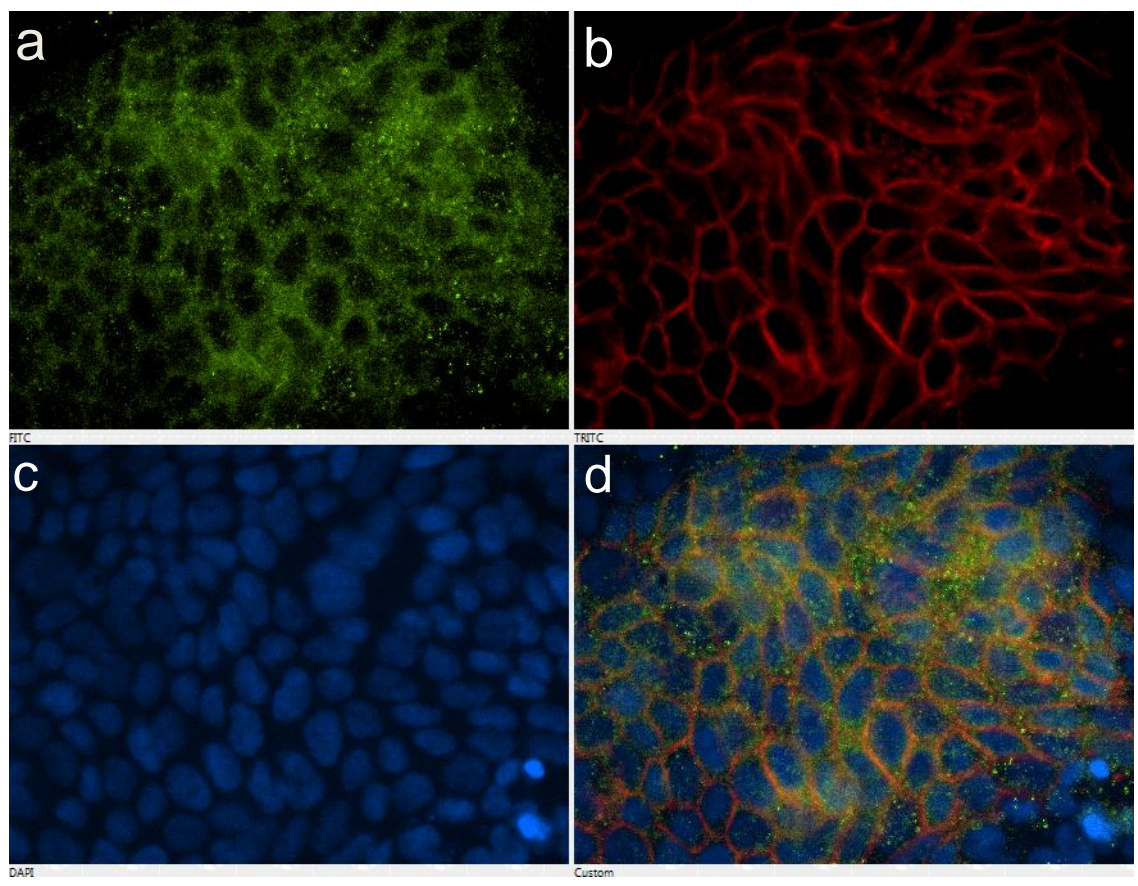

Figure 4-3. Immunohistochemical staining showed Calu-3 cells growing into a tight monolayer in the microfluidic impedance biosensor. a) ZO-1 (green) for tight junction protein staining, b) actin staining (red), and c) nucleus staining (blue); d) combined image indicated monolayer formation. 


\section{CHAPTER 5. ELECTRICAL IMPEDANCE SPECTROSCOPY}

\subsection{EIS measurement}

After the tight lung epithelial cell monolayer was formed inside the microfluidic biosensor, electrical impedance spectroscopy can be applied to monitor the epithelial monolayer electrical properties and test the effects of CNTs on its permeability. Potentiostatic EIS technique, which measures the impedance by applying a sinusoidal voltage to a sample and measuring the corresponding current, was performed using a Gamry EIS system called Reference 3000 (Figure 5-1). The instrument can provide an alternating current at frequencies ranging from $10 \mu \mathrm{Hz}$ to 1 $\mathrm{MHz}$ and collect measured data to a computer for further analysis.

Large electrical current passing through an electrode could change its potential thus to affect measuring accuracy. Therefore a three-electrode system is normally used for the Potentiostatic EIS measurements, in which the stable potential can be obtained between the working and reference electrodes and electrical current is applied through the working and counter electrodes. In our microfluidic biosensor, the two-electrode measuring system was designed to avoid difficult design and fabrication of integrating three electrodes to the biosensor. Potentiostatic condition can still be achieved since the electrical current across the calu-3 cell monolayer was expected to be quite low to avoid cell damage.

There are five cell cables for carrying electrical current on the front panel of the Reference 3000 , each of which has a cell lead with distinct color. The blue and green cell leads were connected to one $\mathrm{Ag} / \mathrm{AgCl}$ electrode, which was dipped into cell culture medium inside the microfluidic biosensor and served as working electrode. The red, orange and white cell leads were connected to the other electrode which served as reference electrode. Electrical current was 
applied by the instrument across the two electrodes and through the micro system to obtain the impedance spectra.

The Potentiostatic EIS measuring process was manipulated by using the software Gamry Instrument Framework which was connected to the Reference 3000. All the parameters for the measurements were set up as shown in Figure 5-2. The alternating current was applied in the frequency range scanning from $0.1 \mathrm{~Hz}$ to $1 \mathrm{MHz}$ with 6 intervals per decade by setting the values of initial frequency as $0.1 \mathrm{~Hz}$, final frequency as $1 \mathrm{MHz}$ and Points/decade as 6. The potential amplitude of the current was set as $10 \mathrm{mV}$ and this value did not induce damages to the cultured cells. It took around 5 min to conduct one frequency spectrum scan and a total of 43 impedance measurements were generated.

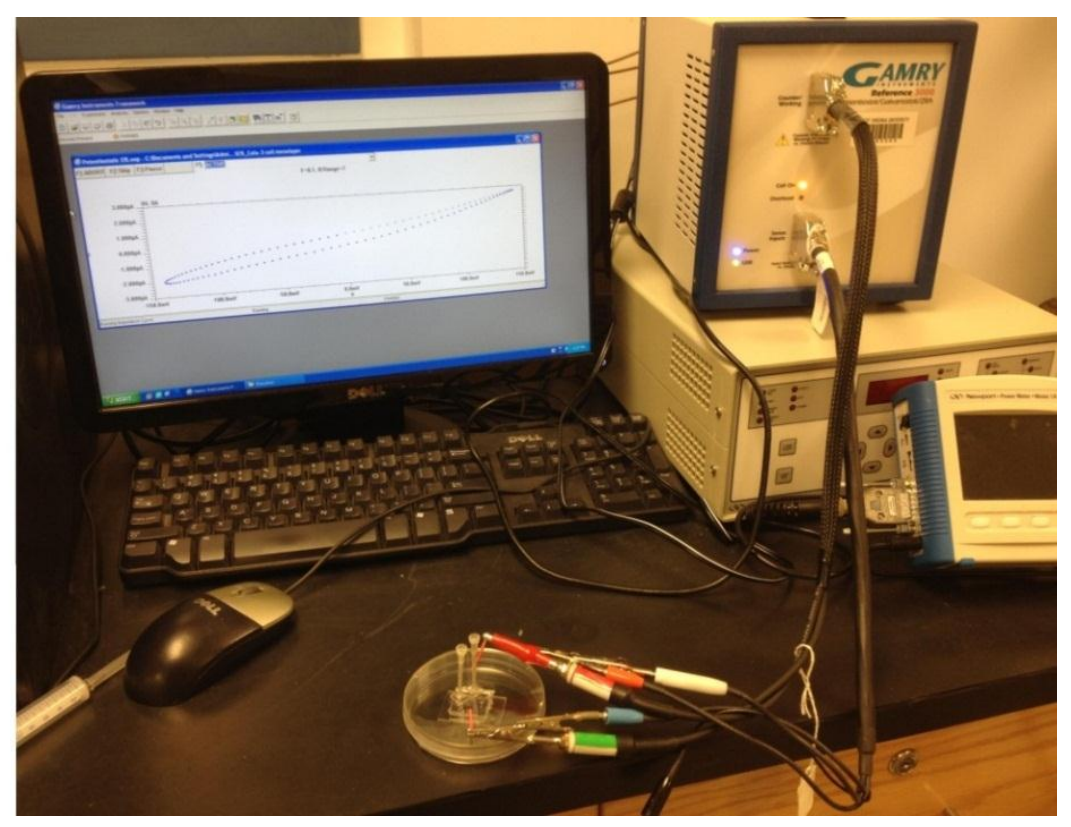

Figure 5-1. Gamry Reference 3000 was used to measure impedance of cell monolayers and collect data to a computer 


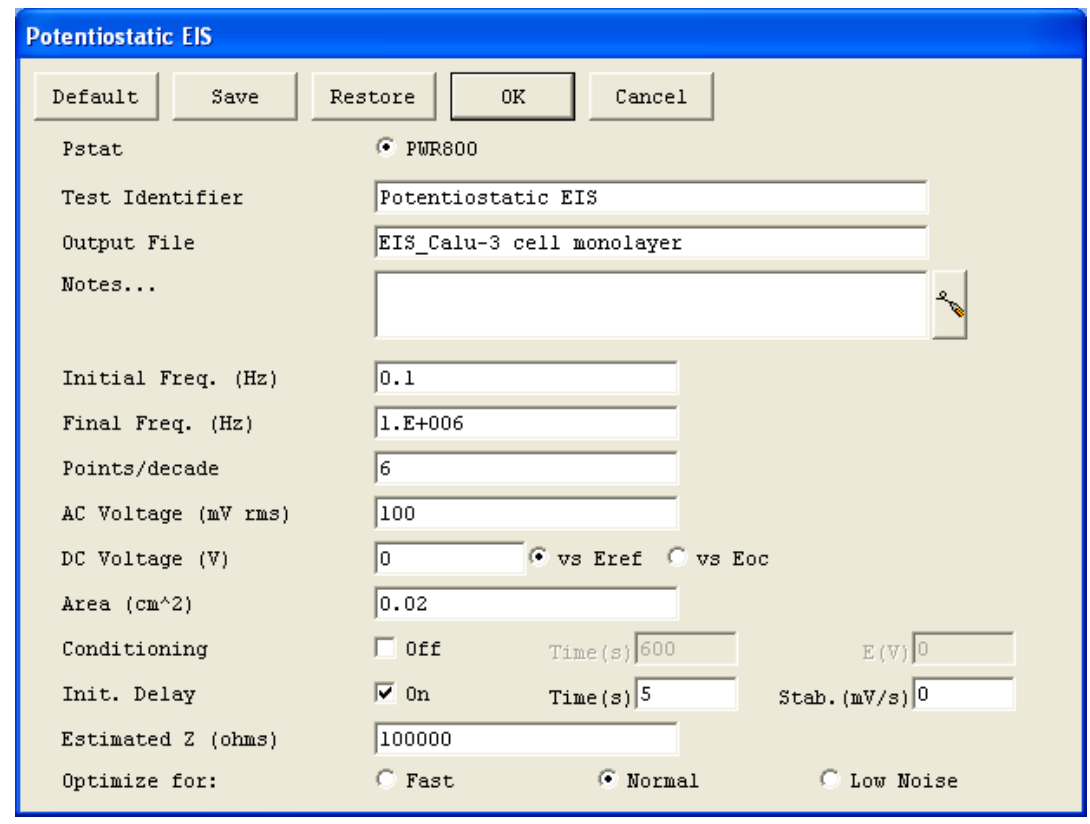

Figure 5-2. Setup window in the Gamry Framework for Potentiostatic EIS.

Both Bode and Nyquist impedance diagrams of the microfluidic biosensor can be obtained from measured impedance data by using the Echem Analyst software, as shown in Figure 5-3. The Bode plot expresses the measured impedance magnitude $|Z|$ versus frequency, drawn with a log-frequency axis, to show the frequency responses of the biosensor. ${ }^{66}$ The magnitude of measured impedance was found to be reduced at high frequencies. In the Nyquist plot, the real part of the impedance is plotted on the $\mathrm{X}$-axis and the imaginary part on the $\mathrm{Y}$-axis, respectively. Each point on the plot represents the impedance of the microfluidic biosensor at one frequency value. 


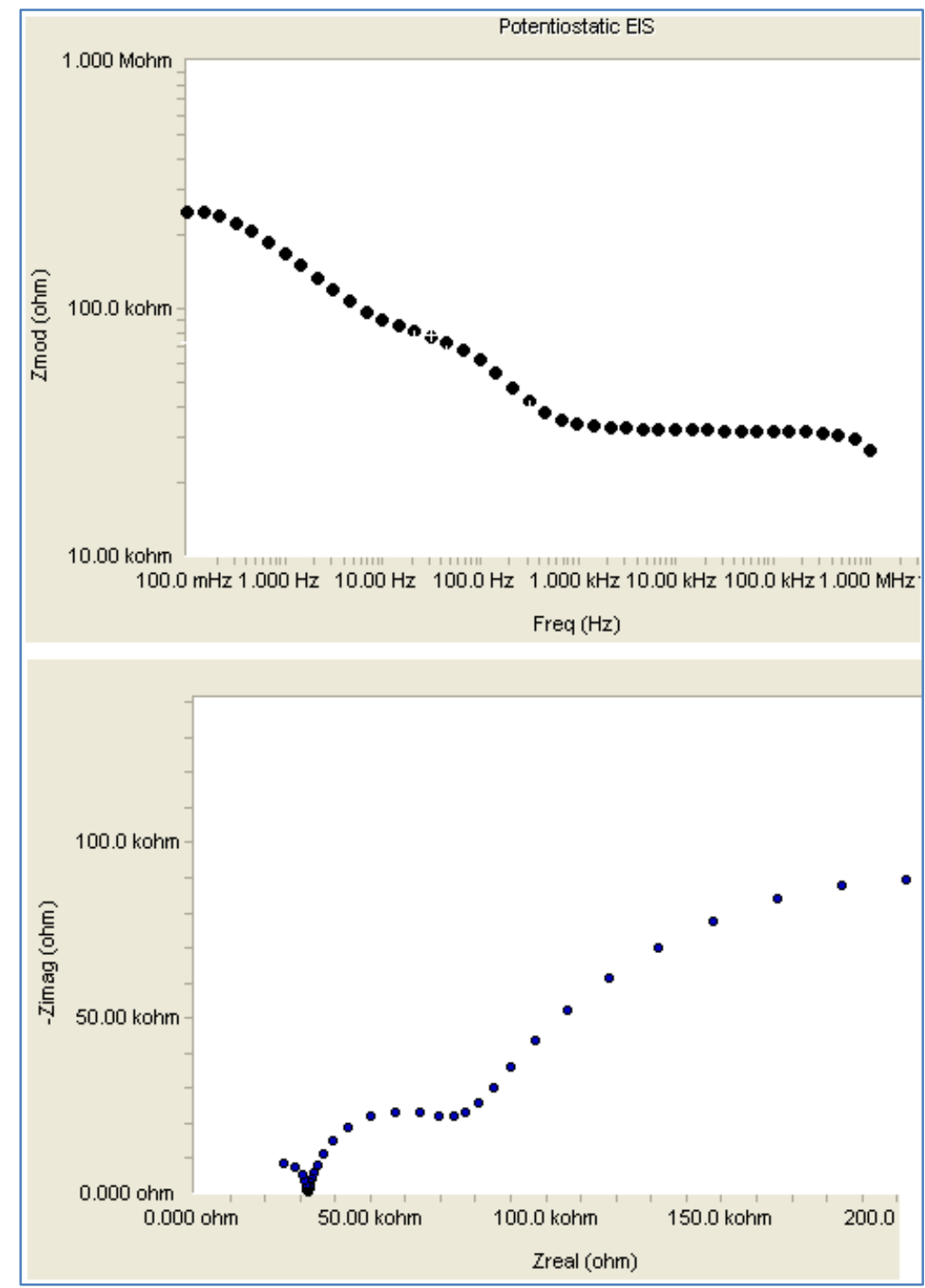

Figure 5-3. Bode (top) and Nyquist (bottom) diagrams were acquired by the Potentiostatic EIS measurement.

The frequencis of recorded points are limited to be identified on a Nyquist plot, and this is a major shortcoming of the plot compared to a Bode diagram. However, the electrical characteristics of a system can well be studied from the Nyquist impedance diagram of the system. For example, the impedance of a circuit which consists of a resistor and a capacitor in parallel (Figure 5-4) can be expressed as $Z=\frac{R}{1+\omega^{2} R^{2} C^{2}}-\frac{j \omega R^{2} C}{1+\omega^{2} R^{2} C^{2}}$, where the $R$ and $C$ represent the resistance and capacitance of the resistor and capacitor, respectively, and $\omega$ is the angular 
frequency. A semicircle with the diameter of R in the Nyquist diagram (Figure 5-4) corresponds to this parallel RC circuit, showing the characteristic of the single "time constant".

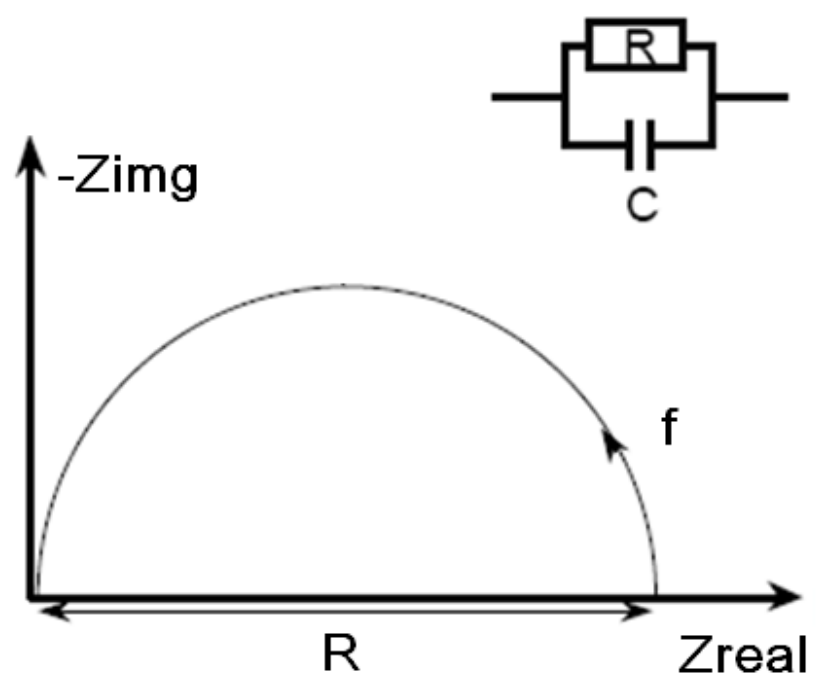

Figure 5-4. Nyquist diagram of a parallel RC circuit is plotted to be a semicircle with the diameter of R.

The feasibility of recording EIS data in microfluidic channels containing cell culture medium instead of specific conductive electrolyte solutions has been reported. ${ }^{56}$ The EMEM medium was used here as the electrolyte to eliminate the need of loading and removing another solution before and after the EIS measurements. Prior to seeding the calu-3 cells, the impedance of the device, including the electrodes, medium, and the polyester membrane, was measured. After the cells were loaded into the upper channel and attached to the porous membrane, the impedance measurements of the whole system were taken daily to monitor the formation of the cell monolayer. The change in impedance spectra was observed after the cells reached completely confluence in the microfluidic biosensor, as shown in Figure 5-5. The curve in the Bode diagram was "pushed" up between $10 \mathrm{~Hz}$ and $1 \mathrm{kHz}$, showing an observable increase of impedance magnitude in this frequency range. A semicircle was found in the Nyquist plot, which indicates that the electrical model of the lung epithelial cell monolayer should include a RC parallel circuit. 
More details about the electrical properties of the microfluidic system will be discussed in the following sections.

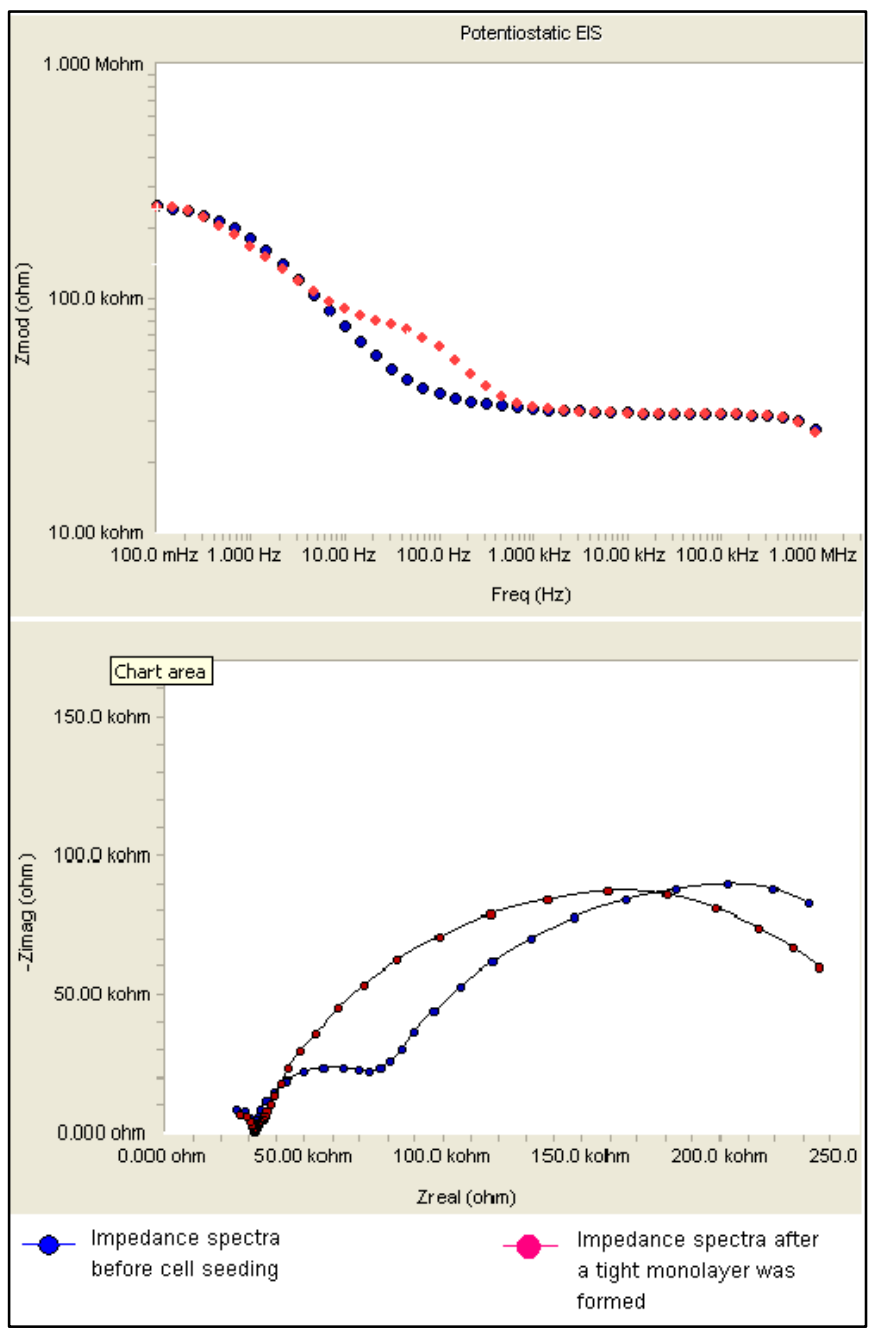

Figure 5-5. The Bode (top) and Nyquist (bottom) plots before cells were seeded and after a complete tight monolayer was formed.

\subsection{Equivalent Electrical Circuit}

\subsubsection{The electrode/culture medium system without cells}

The $\mathrm{Ag} / \mathrm{AgCl}$ electrode, as a reference electrode, is perfectly non-polarizable and allows electrical current to freely pass across the electrode-electrolyte interface. However, when the $\mathrm{Ag} / \mathrm{AgCl}$ was used as the working electrode, an electrical double layer would be formed at the interface the electrode and electrolyte. An equivalent circuit containing a Warburg structure with 
a series resistor was modeled to characterize this double layer, as shown in Figure 5-6. The Warburg model consists of a resistor connected to a constant phase element (CPE) in parallel, and represents the electrical properties of the double layer.

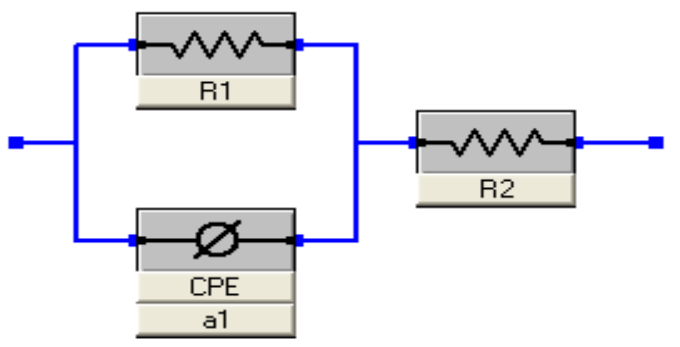

Figure 5-6. Equivalent circuit for the $\mathrm{Ag} / \mathrm{AgCl}$ working electrode

The culture medium, which was used as electrolyte for the impedance measurements, can be considered as a dielectric located between the two conductive electrodes. A parallel RC circuit was therefore used to model its resistivity and dielectric property, as shown in Figure 5-7.

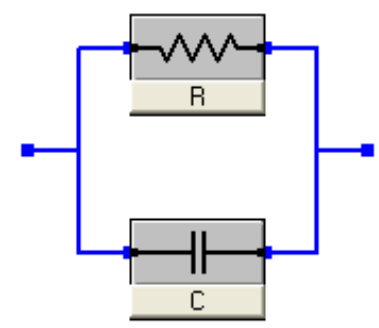

Figure 5-7. Equivalent circuit of the cell culture medium

In summary, the whole electrode/culture medium system without cells was theoretically modeled by the equivalent circuit which contains the two electrical circuits described above, as shown in Figure 5-8. 


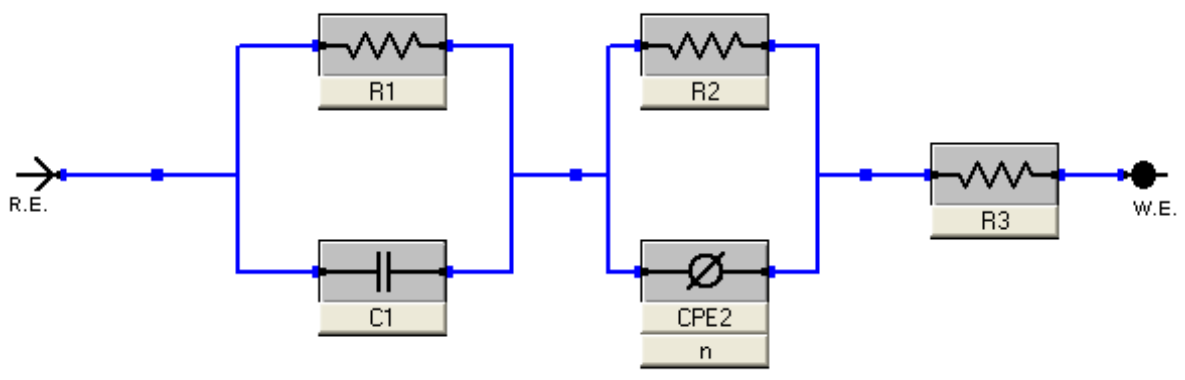

Figure 5-8. An equivalent electrical circuit was generated to model the microfluidic system without cells, in which the $\mathrm{R}_{1}$ and $\mathrm{C}_{1}$ represent the culture medium, and $\mathrm{R}_{2}, \mathrm{CPE}_{2}$ and $\mathrm{R}_{3}$ represent the interface between the working $\mathrm{Ag} / \mathrm{AgCl}$ electrode and the medium.

\subsubsection{The system with cultured Calu-3 cell monolayer}

Electrical current would pass across the Calu-3 cell monolayer in the microfluidic biosensor through two parallel paths including the transcellular (inside cells) and paracellular routes (between cells) during the EIS measurement. The transcellular path can be modeled by the internal resistance of cells in series with the capacitance of both apical and basolateral cell membranes. The paracellular path, that is, through tight junction proteins in the monolayer, can be modeled by a resistor which indicates the TEER value which determines the permeability of epithelial monolayer. The internal resistance of cells can well be neglected in the first order approximation. The equivalent electrical circuit for characterizing the cell monolayer was thus shown in Figure 5-9.

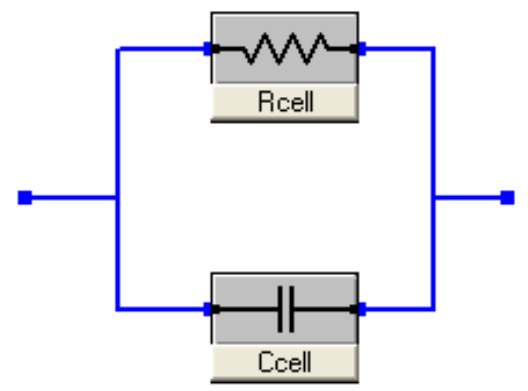

Figure 5-9. Equivalent electrical circuit of Calu-3 epithelial cell monolayer 
Combining the equivalent circuit of Calu-3 cell monolayer with that of the system without cells leads to the electrical circuit model which characterizes the whole microfluidic system with cultured cell monolayer for the impedance measurements, as shown in Figure 5-10. Summarily, the resistor $R_{1}$ in parallel with the capacitor $C_{1}$ represent the electrical properties of culture medium located between two electrodes; the resistor $\mathrm{R}_{3}$ in series with the parallel connection of $\mathrm{R}_{2}$ and $\mathrm{CPE}_{2}$ represent the model of the electrode-electrolyte interface; and the $\mathrm{R}_{\text {cell }}$ and $\mathrm{C}_{\text {cell }}$ represent the resistance and capacitance of the tight monolayer, respectively.

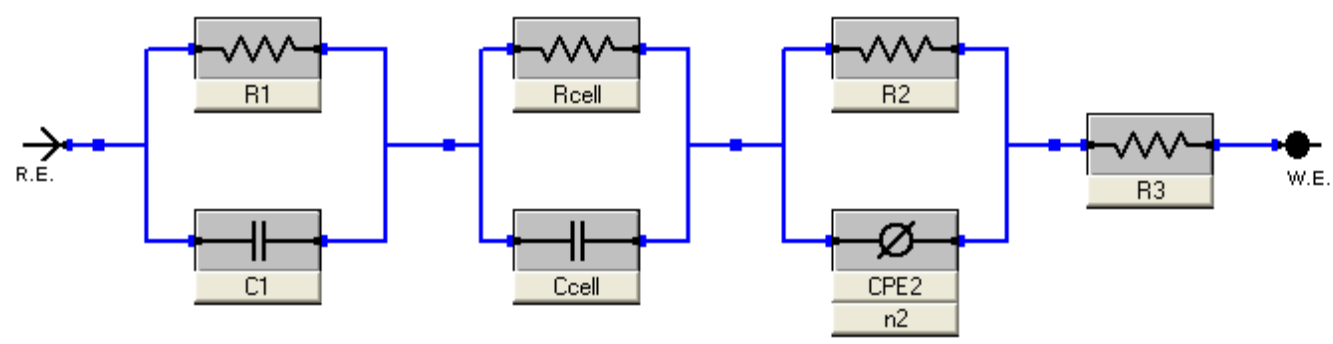

Figure 5-10. The equivalent circuit model of the microfluidic system for EIS measurements.

\subsection{Analysis of the Impedance Spectra}

Impedance data were firstly measured before seeding cells in the microfluidic system and impedance spectrum was obtained in the Echem Analyst software, as shown in Figure 5-11. Two semicircles were observed in the Nyquist diagram, one of which was small and incomplete and the other was much larger and depressed. The small semicircle represented the parallel connection of the $\mathrm{R}_{1}$ and $\mathrm{C}_{1}$ in the equivalent circuit, and the large one was attributed to all the other elements in the circuit. All the parameters in the equivalent circuit (Figure 5-8) can be obtained by fitting measured impedance spectra to the circuit model, as shown in Figure 5-11, and Simplex Method was used in the Echem Analyst to minimize the fitting errors. 

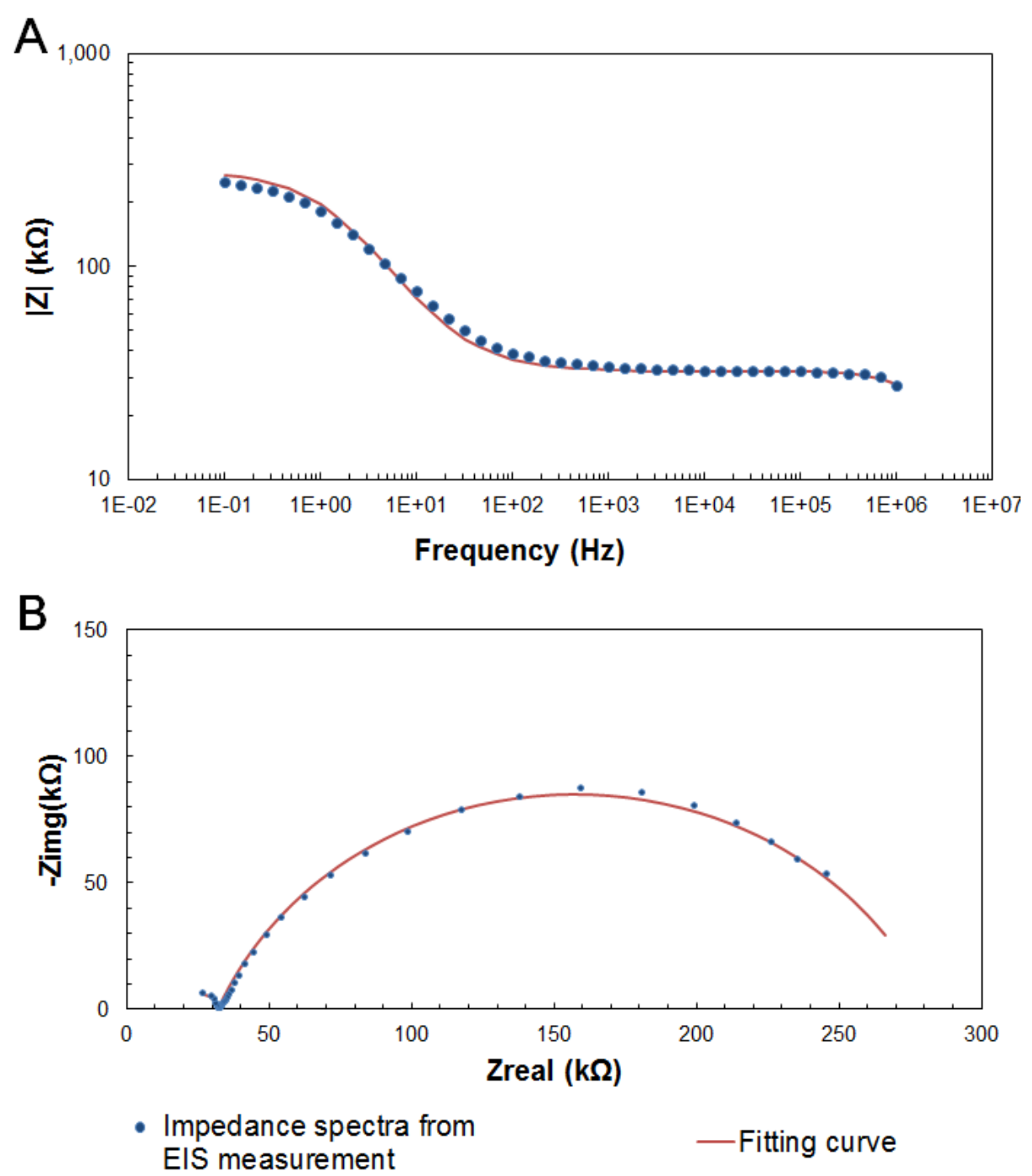

Figure 5-11. Impedance spectra for the microfluidic system without cells. A) Bode diagram. B) Nyquist diagram.

The fitting results (Table 5-1) showed that the internal resistance of the culture medium $\left(\mathrm{R}_{1}\right)$ was around $11 \mathrm{k} \Omega$ and the capacitance was around $15 \mathrm{pF}$ in this measurement. The empirical constant (n) of the CPE was found to be 0.75 , which was less than 1 and accordant with the depressed semicircle. 
Table 5-1. The fitting results of one impedance spectrum measured before cell loading.

\begin{tabular}{|l|l|l|l|}
\hline Parameter & Value & Error & Units \\
\hline $\mathrm{R}_{1}$ & 11.5 & 0 & $\mathrm{k} \Omega$ \\
\hline $\mathrm{C}_{1}$ & 14.3 & 1.025 & $\mathrm{pF}$ \\
\hline $\mathrm{R}_{2}$ & 256.4 & 0 & $\mathrm{k} \Omega$ \\
\hline $\mathrm{CPE}_{2}$ & $8.55 \mathrm{E}-07$ & $1.43 \mathrm{E}-08$ & $\mathrm{~S}^{*} \mathrm{~s}^{\wedge} \mathrm{a}$ \\
\hline $\mathrm{n}_{2}$ & 0.75 & 0 & \\
\hline $\mathrm{R}_{3}$ & 21.37 & 0.21 & $\mathrm{k} \Omega$ \\
\hline
\end{tabular}

After the cells were seeded into the microfluidic biosensor, the EIS measurements were performed daily to monitor the change in electrical properties of the biosensor. A third semicircle was observed in the Nyquist plot (Figure 5-12) when the cells reached complete confluence, and its diameter was continuously increasing for around one week after the formation of the cell monolayer and then remained stable. The three semicircles in the plot confirmed the equivalent circuit model containing three parallel RC circuits. Specifically the third one described the electrical behavior of the epithelial monolayer and the growing of the semicircle corresponded to the increase of TEER values.

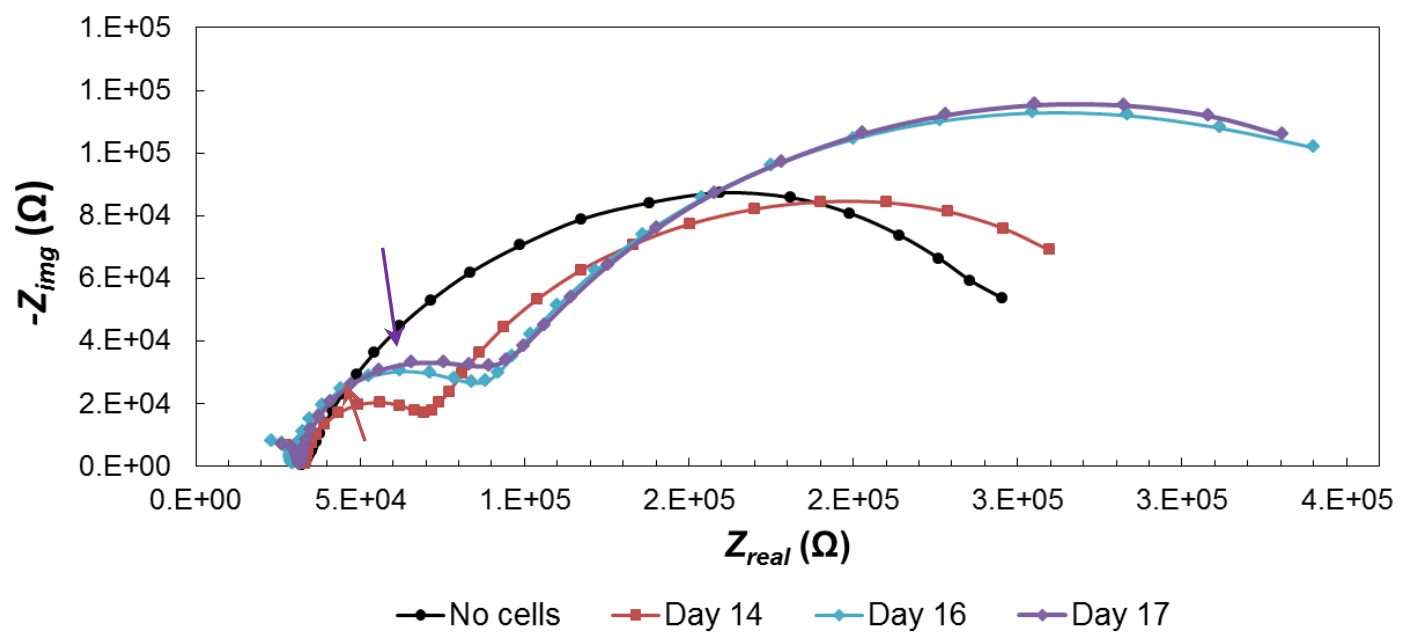

Figure 5-12. Nyquist plots showed the appearance and growing of a third semicircle (arrow). 
Critical frequency, a significant characteristic of RC circuit, is expressed as $f=1 / 2 \pi R C$ and can be determined from the peak imaginary impedance of the Bode diagram. Figure 5-13 shows the critical frequencies for the EIS measurements before and after the formation of the cell monolayer. Prior to the seeding of the Calu-3 cells, two critical frequencies were found in the microsystem, one of which was around $1 \mathrm{~Hz}$ and the other was $32 \mathrm{kHz}$, representing the electrical properties of the culture medium and the electrodes. An additional critical frequency was found to be $\sim 100 \mathrm{~Hz}$ when the epithelial monolayer was formed in the biosensor, which further confirmed the circuit model of the cell monolayer.

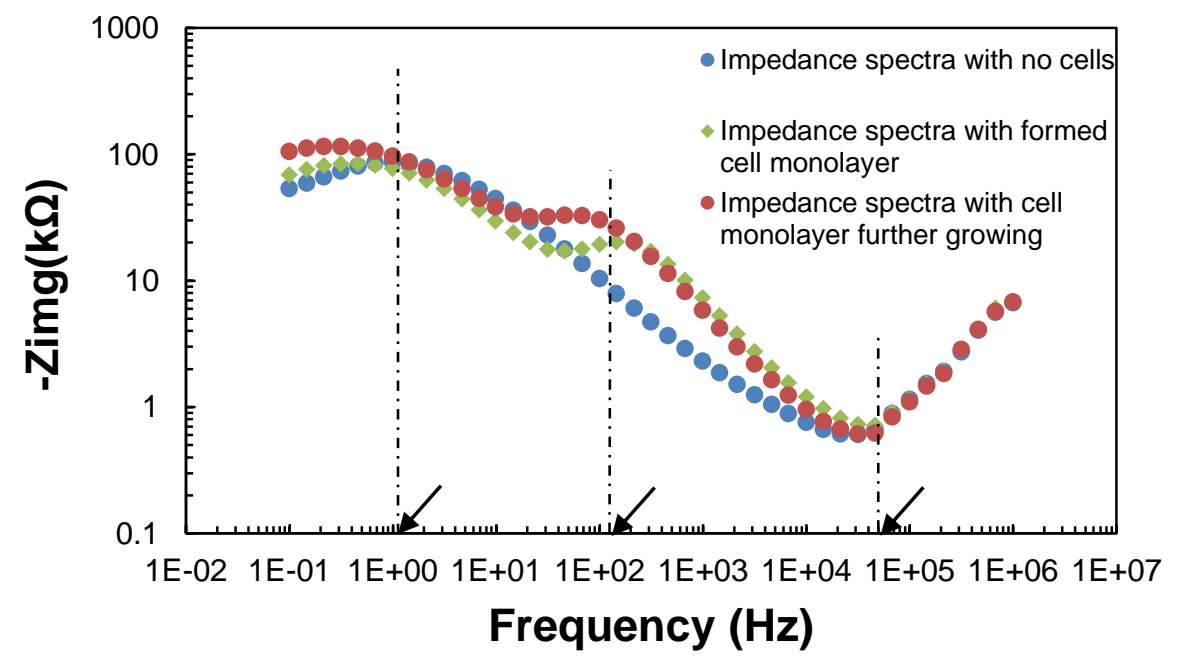

Figure 5-13. Bode diagram showed the frequency response of imaginary impedance during the formation of epithelial cell monolayer. Arrows indicate the critical frequencies of the microfluidic biosensor.

The resistance and capacitance of lung epithelial cell monolayer can be obtained by fitting impedance spectra of the microfluidic biosensor with cell monolayer to the equivalent circuit model. The impedance spectrum from one measurement and the fitting curve were obtained as shown in Figure 5-14. The fitting results in Table 5-2 showed that the $\mathrm{R}_{\text {cell }}$ was $\sim 45 \mathrm{k} \Omega$ and the 
$\mathrm{C}_{\text {cell }}$ was $\sim 45 \mathrm{nF}$. Normalized TEER value can be calculated by multiplying the $\mathrm{R}_{\text {cell }}$ by the area of the cell monolayer, i.e. the area of culture chamber in the microfluidic biosensors:

$$
\begin{aligned}
\text { Normalized TEER } & =R_{\text {cell }} \times \text { area of cell monolayer } \\
& =45 \mathrm{k} \Omega \times 0.04 \mathrm{~cm}^{2} \\
& =1800 \Omega \cdot \mathrm{cm}^{2}
\end{aligned}
$$
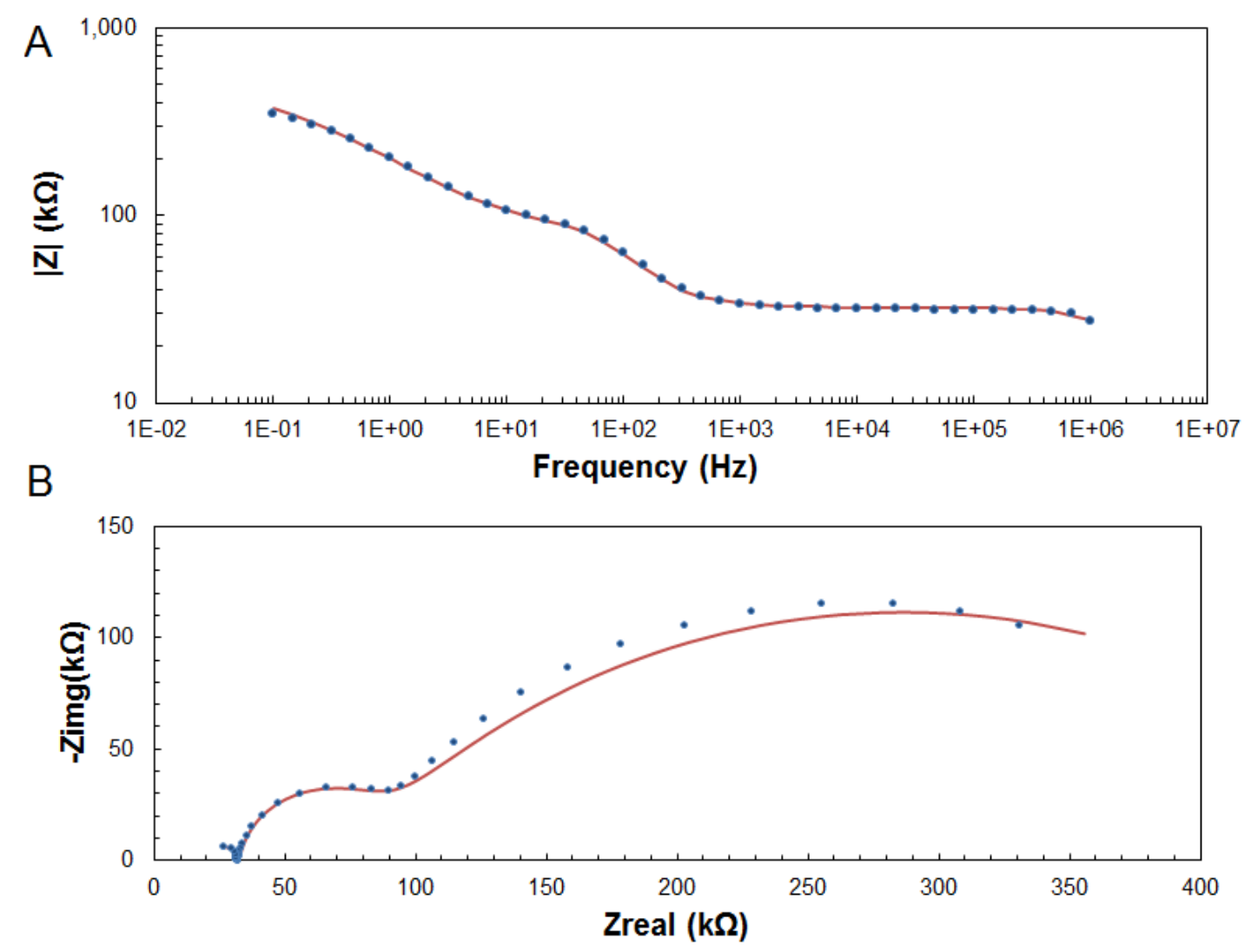

- Impedance spectra from EIS measurement

Figure 5-14. Impedance Fitting was performed to obtain the values of parameters in the equivalent circuit model which described the behavior of the microfluidic system with a tight epithelial cell monolayer being formed. A) Fitting result in Bode plot. B) Fitting result in Nyquist plot. 
Table 5-2. The fitting results of one impedance spectrum which was measured after tight cell monolayer was formed in the biosensor.

\begin{tabular}{|l|l|l|c|}
\hline Parameter & Value & Error & Units \\
\hline $\mathrm{R}_{1}$ & 13 & 0 & $\mathrm{k} \Omega$ \\
\hline $\mathrm{C}_{1}$ & 10.08 & 1.025 & $\mathrm{pF}$ \\
\hline $\mathrm{R}_{2}$ & 419.8 & 21 & $\mathrm{k} \Omega$ \\
\hline $\mathrm{CPE}_{2}$ & $1.86 \mathrm{E}-06$ & $8.35 \mathrm{E}-08$ & $\mathrm{~S}^{*} \mathrm{~s}^{\wedge} \mathrm{a}$ \\
\hline $\mathrm{n}_{2}$ & 0.621 & 0.012 & \\
\hline $\mathrm{R}_{3}$ & 19 & 0 & $\mathrm{k} \Omega$ \\
\hline $\mathrm{R}_{\text {cell }}$ & 45 & 0 & $\mathrm{k} \Omega$ \\
\hline $\mathrm{C}_{\text {cell }}$ & 45.23 & 0 & $\mathrm{nF}$ \\
\hline
\end{tabular}

After the formation of Calu-3 cell monolayers, the TEER values were derived and the results were shown in Figure 5-15. For each day, the average and standard error of the measured values were indicated. The statistical analysis was computed from four separate impedance measurements in the microfluidic biosensors.

Our results indicated that the TEER values kept increasing with days of cell culture until a relative constant value was observed as shown in Figure 5-15, which was corresponding to the appearance and growing of the semicircle in the Nyquist plot and matched with the Calu-3 TEER results obtained from conventional Transwell system. ${ }^{67}$ Low TEER values $\left(\sim 160 \Omega \cdot \mathrm{cm}^{2}\right)$ were measured when the cell monolayer was formed. Cell monolayers exhibited high TEER values $\left(\sim 1500 \Omega \cdot \mathrm{cm}^{2}\right)$ after more days of culture (usually one week) in the microfluidic biosensor. The 
results indicated that the microfluidic impedance biosensor is feasible for detection of the impedance changes and monitoring of the permeability of the tight epithelial cell monolayer.

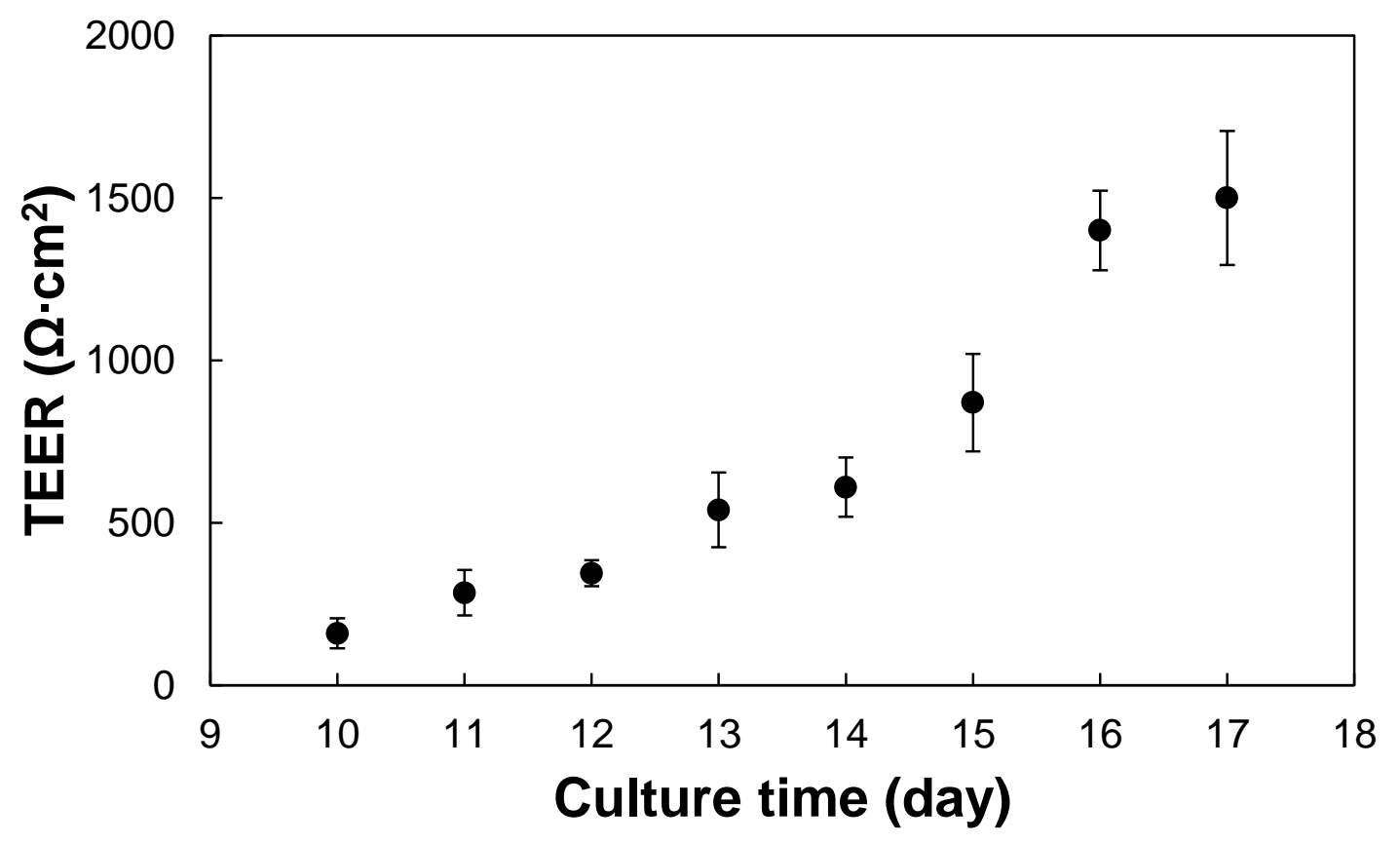

Figure 5-15. TEER values of Calu-3 cell monolayer growing in the biosensors were obtained by analyzing the impedance measurement results. Low TEER values $\left(\sim 160 \Omega \cdot \mathrm{cm}^{2}\right)$ were measured when the cell monolayer was formed. High TEER values $\left(\sim 1500 \Omega \cdot \mathrm{cm}^{2}\right)$ were achieved after more days of culture (usually one week) in the microfluidic biosensor (Mean \pm S.E.M, $N=4$ ). 


\section{CHAPTER 6. MWCNTS EFFECTS ON EPITHELIAL PERMEABILITY}

\subsection{MWCNTs preparation and loading}

MWCNTs have been explored as innovative carriers for drug delivery due to the excellent physical and chemical properties. ${ }^{15}$ Because as-prepared raw MWCNTs ( $r$-MWCNTs) are usually accompanied by carbonaceous or metallic impurities which may disrupt the functions of MWCNTs, a large variety of methods have been used to create purified MWCNTs ( $p$-MWCNTs) for further applications. ${ }^{68}$ In addition, functionalization of MWCNTs has also been developed by using some functional groups including amines and carboxylates to improve the solubility of the MWCNTs and to create MWCNT conjugates endowed with some pharmacological properties. The functionalized MWCNTs (f-MWCNTs) have the capability of carrying therapeutic moieties, which can be used for targeting drugs to specific sites in human body. ${ }^{15}$

We have been successfully established the lung epithelium model by culturing Calu-3 cells into a monolayer using the microfluidic biosensor as discussed in Chapter 4. Because of the importance of studying MWCNTs' pulmonary toxicities, here we presented our studies for testing different types of MWCNTs' effects on the permeability of epithelial monolayer using the microfluidic impedance-metric biosensors. The tested MWCNTs included $r$-MWCNTs, $p$ MWCNTs and carboxyl $f$-MWCNTs. By measuring the changes in the TEER values of the Calu3 cell monolayer, the approach provides a label-free method to indicate the permeability changes. Each type of the MWCNTs were initially dispensed and stored in phosphate buffered saline (PBS) solution at concentration of $1 \mathrm{mg} / \mathrm{mL}$ as shown in Figure 6-1, and were further diluted in cell culture media to different concentrations of $100 \mu \mathrm{g} / \mathrm{mL}$ and $150 \mu \mathrm{g} / \mathrm{mL}$ before the experiment. 


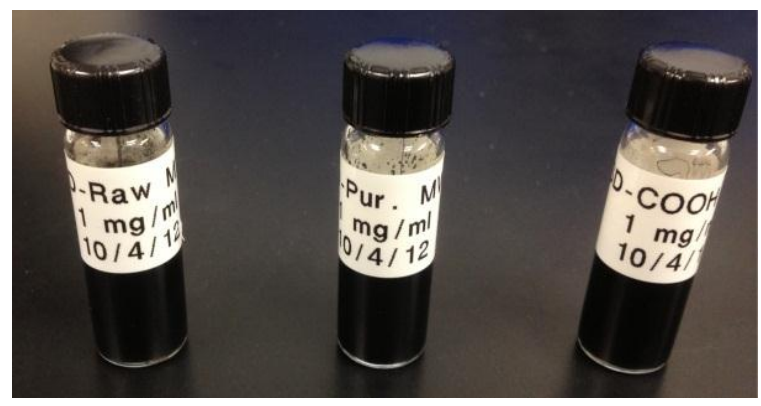

Figure 6-1. Three types of MWCNTs were initially dispensed and stored in PBS

After the tight Calu-3 cell monolayers were formed in the microfluidic biosensors, the diluted samples were sonicated until they were fully dispersed (typically around one hour). The dispersed MWCNTs were added into the upper channel of the biosensors and the EIS measurements were performed every 12 hours up to 3 days of treatment. The testing concentrations of the MWCNTs inside the cell culture chamber with area of $4 \mathrm{~mm}^{2}$ and depth of $150 \mu \mathrm{m}$ were $1.5 \mu \mathrm{g} / \mathrm{cm}^{2}$ and $2.25 \mu \mathrm{g} / \mathrm{cm}^{2}$, corresponding to as-prepared $100 \mu \mathrm{g} / \mathrm{mL}$ and 150 $\mu \mathrm{g} / \mathrm{mL}$ respectively. The MWCNTs were replaced with culture medium before each measurement to avoid the effect of MWCNTs on impedance spectra and new dispersed MWCNTs were loaded to the cell monolayers to maintain continuous exposure. The impedance data were collected into the computer and impedance spectra were analyzed by using Echem Analyst to derive the TEER values of the exposed Calu-3 cell monolayers as discussed in Chapter 5.

\subsection{Results and Discussion}

Our experimental results as shown in the Chapter 5 indicated that it took about 10 days for the Calu-3 cells forming into a confluence monolayer when they were seeding inside of the microfluidic biosensor. The TEER values of the monolayer were then progressively increased up to one week and reach values as high as $1500 \Omega \cdot \mathrm{cm}^{2}$. The MWCNTs were then added to the 
apical chamber of the tight Calu-3 monolayer and their effects on the monolayer were reflected by the changes of TEER values.

As shown in Figure 6-2, during the 72 hours exposure to the $r$-MWCNTs at the concentration of $1.5 \mu \mathrm{g} / \mathrm{cm}^{2}$, no obvious change in the TEER values was found compared to the TEER values before loading the CNTs. However, a significant decrease in the resistances was detected after 12 hours treatment of the same type of MWCNTs at a higher concentration of $2.25 \mu \mathrm{g} / \mathrm{cm}^{2}$. The TEER value was continuously reduced to $8 \%$ of the initial value within three days. The results indicated that the $r$-MWCNTs at a higher concentration $\left(2.25 \mu \mathrm{g} / \mathrm{cm}^{2}\right)$ can largely affect the permeability of the lung epithelial cell monolayer.

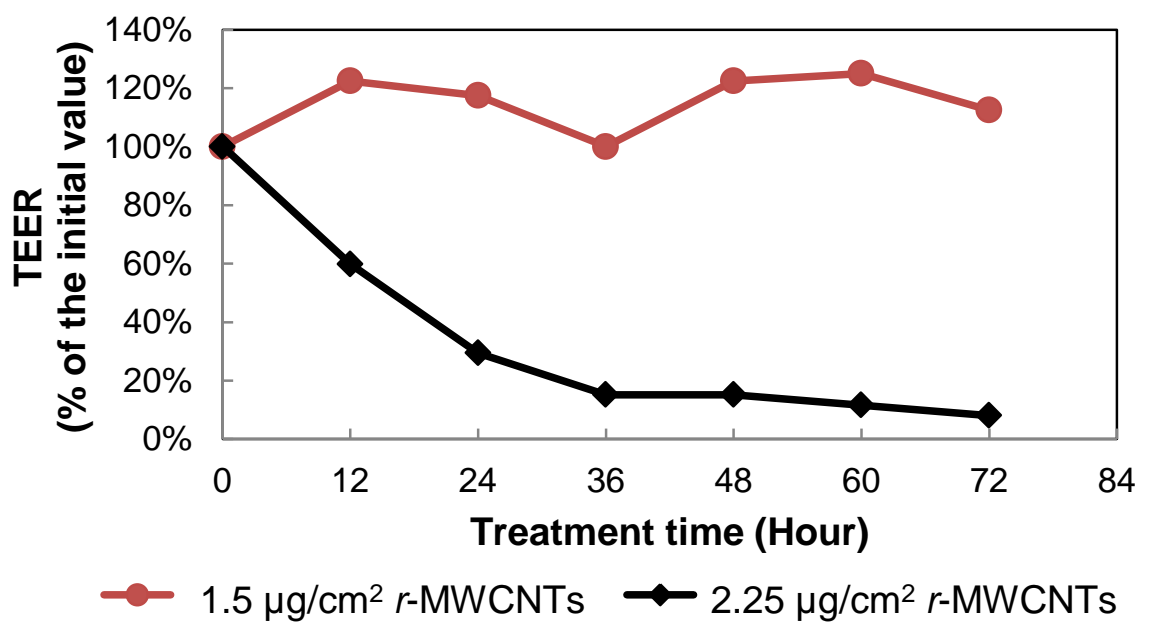

Figure 6-2. Dose-dependent effects of $r$-MWCNTs on the TEER of tight Calu-3 cell monolayers.

The effect of $p$-MWCNTs on the TEER of tight monolayers was also monitored for 3 days. No significant change in the TEER was caused by the 72 hours treatment of $p$-MWCNTs at the concentration of $1.5 \mu \mathrm{g} / \mathrm{cm}^{2}$, while the values significantly decreased when the dose increased to $2.25 \mu \mathrm{g} / \mathrm{cm}^{2}$, as shown in Figure 6-3. 
The effects of $r$-MWCNTs and $p$-MWCNTs on the TEER of the Calu-3 cell monolayers indicated that the concentrations of MWCNTs played an important role in CNT-induced epithelial permeability. Although the contamination of impurities contained in $r$-MWCNTs is a concern for $r$-MWCNTs' toxicities, the results did not show much difference between $r$ MWCNTs and $p$-MWCNTs at the concentration of $1.5 \mu \mathrm{g} / \mathrm{cm}^{2}$. Both CNTs can significantly change the TEER values at the concentration of $2.25 \mu \mathrm{g} / \mathrm{cm}^{2}$.

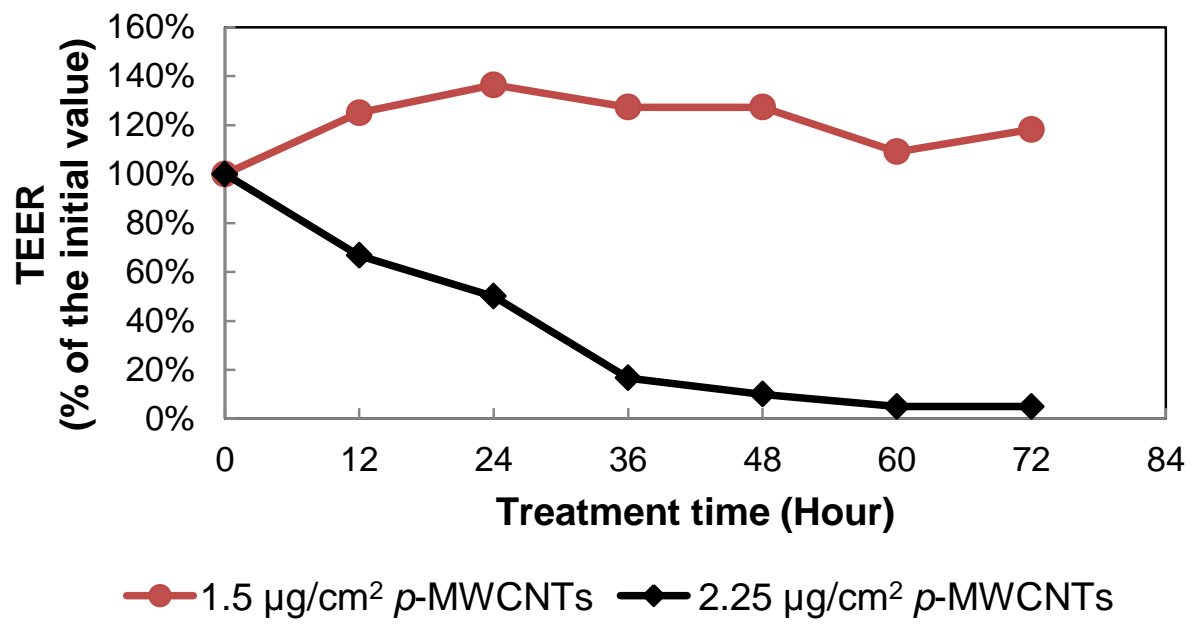

Figure 6-3. Dose-dependent effects of $p$-MWCNTs on the TEER of tight Calu-3 cell monolayers.

Different results were obtained when the tight monolayers in the microfluidic biosensors were exposed to carboxyl-terminated $f$-MWCNTs. As shown in Figure 6-4, compared with other two CNTs' treatments, the TEER of the epithelial monolayers was not affected by the $f$ MWCNTs when the concentration was increased to $2.25 \mu \mathrm{g} / \mathrm{cm}^{2}$. The results indicated that the $f$ MWCNTs have less toxicity effects to the epithelial cell monolayer than non-functionalized CNTs.

Summarily, the addition of each type of MWCNTs at the lower concentration $\left(1.5 \mu \mathrm{g} / \mathrm{cm}^{2}\right)$ produced no significant changes in the TEER of Calu-3 cell monolayers, whereas different 
effects of the treatment of the MWCNTs at the higher concentration $\left(2.25 \mu \mathrm{g} / \mathrm{cm}^{2}\right)$ were tested by the EIS measurements, as shown in Figure 6-5. This result showed that the functionalization of MWCNTs can significantly reduce the adverse effect on the barrier function of lung epithelium.

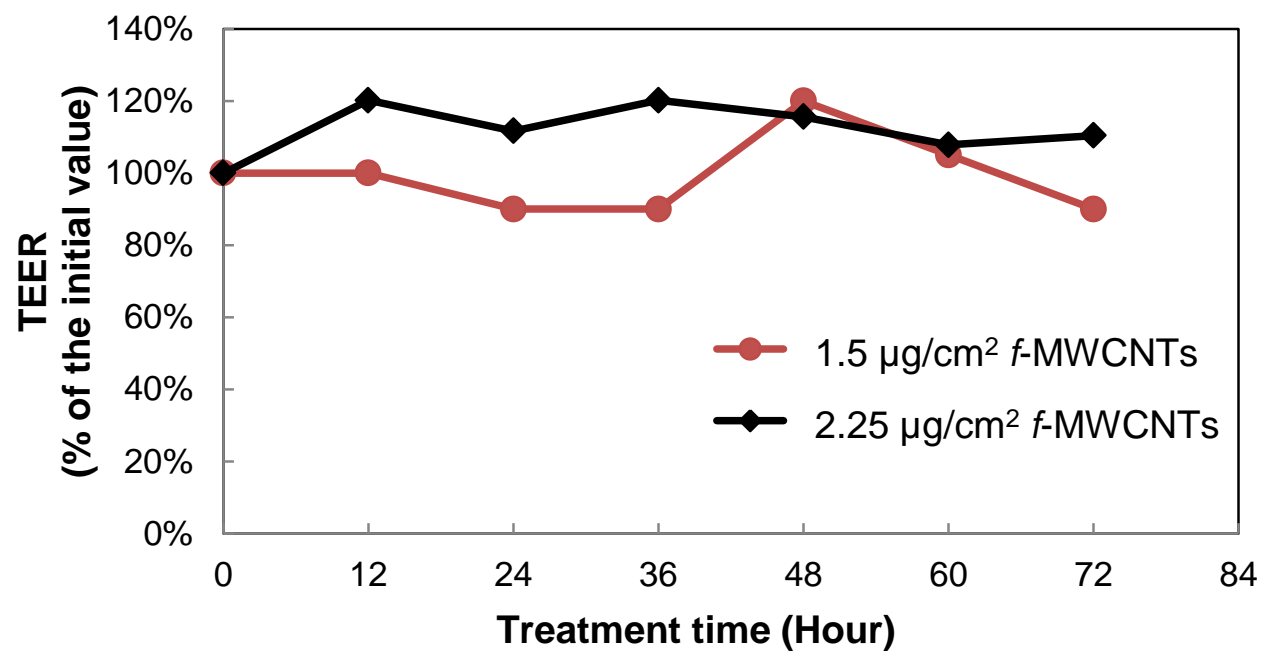

Figure 6-4. The effects of carboxyl $f$-MWCNTs on the TEER of tight Calu-3 cell monolayers in the microfluidic impedance-metric biosensors.

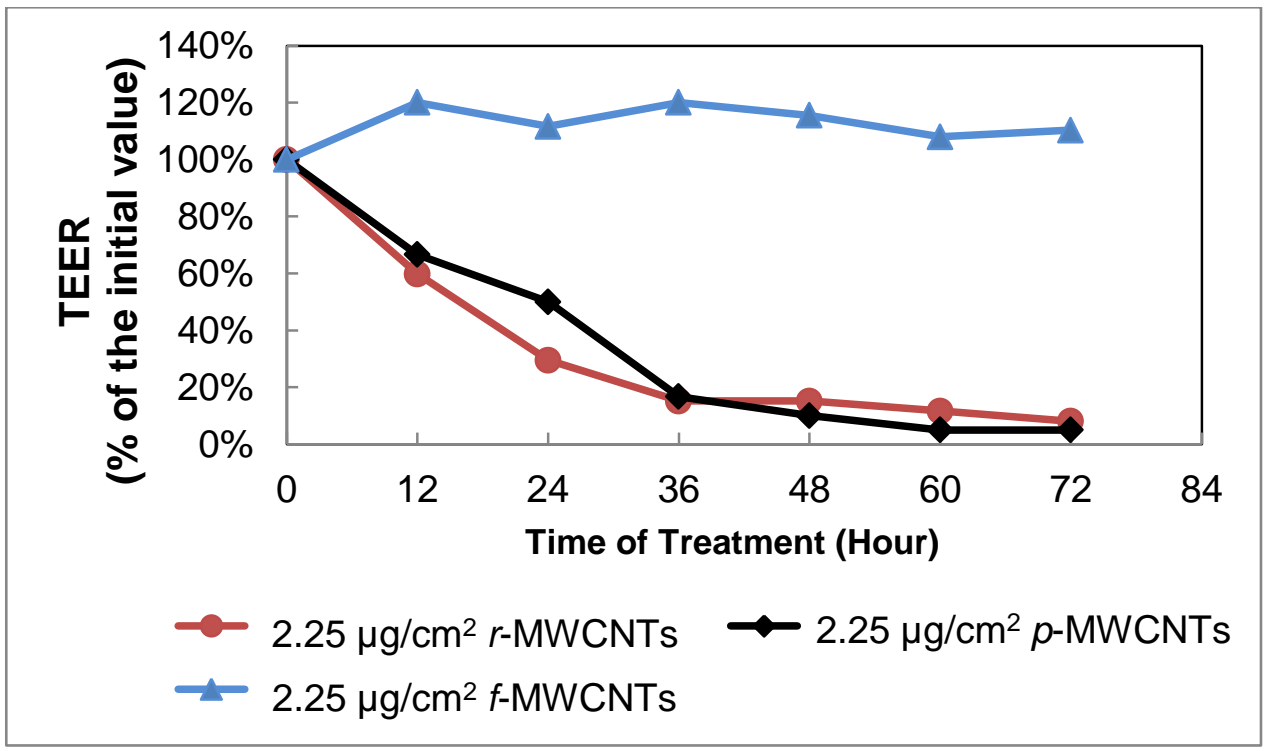

Figure 6-5. The change in the TEER of tight Calu-3 monolayers exposed to different types of MWCNTs at the concentration of $2.25 \mu \mathrm{g} / \mathrm{cm}^{2}$. 
Although the cytotoxicity of MWCNTs has been shown in many in vitro ${ }^{69,70}$ and in vivo models $^{71,72}$, the mechanisms and physical properties of the toxic effects remain uncertain. The barrier functions of lung epithelium are mainly achieved by tight junction proteins, which are formed between adjacent cells and act as selective permeability barriers. We fixed and stained the Calu-3 cells in the biosensor after they were treated with the raw and purified MWCNTs. However, there was no observable change in the expression of the tight junctions in the fluorescent images. In addition of the reduced TEER values, the decrease of the capacitance of cell monolayer was observed during the treatment of non-functionalized MWCNTs at the concentration of $2.25 \mu \mathrm{g} / \mathrm{cm}^{2}$ as shown in Figure 6-6.

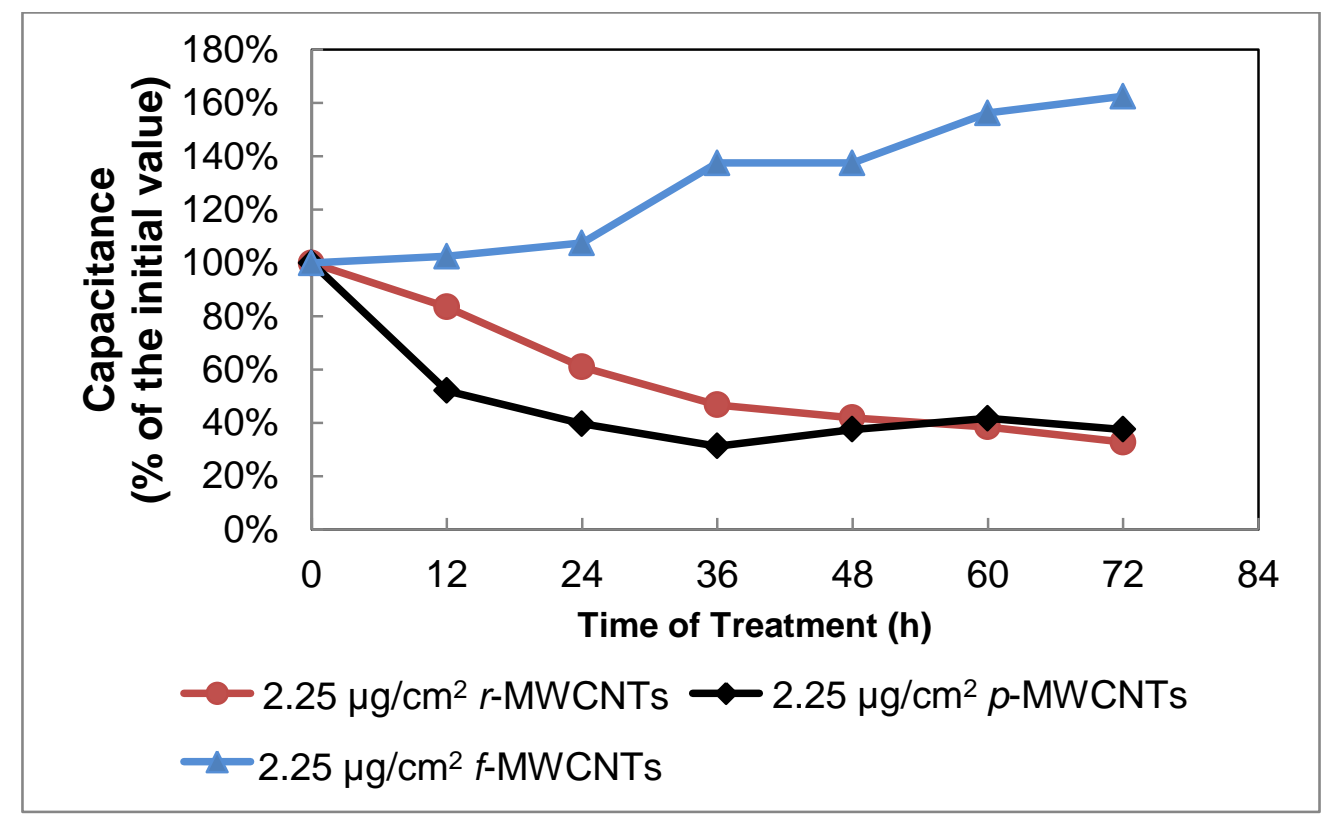

Figure 6-6. The effect of MWCNTs on the capacitance of lung epithelial cell monolayer was studied and significant decrease during the treatment of non-functionalized MWCNTs was observed.

This result indicated that the permeability induced by the treatment might be resulted from the disruption of cell membranes instead of tight junction proteins. Although many questions remain in the toxicity of this class of nanoparticles and more studies of the physiology and 
pathophysiology are needed, our developed microfluidic biosensor is helpful to provide a potable, low-cost and low-reagent-required platform to reflect the toxicity by detecting their effects on the electrical properties of the epithelium. 


\section{CHAPTER 7. CONCLUSIONS AND FUTURE WORK}

As an important barrier in human body, lung epithelium are exposed to a number of external agents, including inhaling environmental pollutants and by-products of drug delivery. The changes of the permeability of the lung epithelium can work as an indicator to determine the biological effects of these substances. CNTs have been widely produced and utilized because of their excellent physiochemical properties, which on the other hand increase the health concerns of their potential toxicities. A microfluidic impedance biosensor has been developed as a platform to characterize the lung epithelial cell monolayer and study CNTs effects on epithelial permeability by electrical impedance spectroscopy. The TEER values resolved from the impedance spectrum can be used to indicate the formation of epithelial tight monolayer, which was further confirmed by the immunohistochemical staining. The effects of different MWCNTs (raw, purified and carboxyl functionalized MWCNTs) on epithelial permeabilities were tested using the developed biosensors, and our results demonstrated the biosensor's feasibility and capabilities as a novel approach to study nanotoxicities. The developed biosensor is potable, low cost, low reagent required and capable for real-time monitoring. Our results showed that no obvious impedance change was found upon the treatment of $f$-MWCNTs, indicating that dramatic reduction of adverse effect can be achieved by the functionalization of MWCNTs with the $-\mathrm{COOH}$ group. Our future work will be focused on providing more evident data to represent the biocompatibility of $f$-MWCNTs by further increasing the concentration of treatment. More repeated impedance measuring experiments will be conducted to reinforce the reliability of the result of our nanotoxicity study. 


\section{REFERENCES}

1. M Ochs, J R Nyengaard, A Jung, L Knudsen, M Voigt, T Wahlers, J Richter, and H J G Gundersen, The Number of Alveoli in the Human Lung, Am J Respir Crit Care Med, 2004, 169,120 .

2 . http://upload.wikimedia.org/wikipedia/commons/d/db/Illu_bronchi_lungs.jpg, accessed on February 11, 2013.

3. M Strengert and U G Knaus, Analysis of Epithelial Barrier Integrity in Polarized Lung Epithelial Cells, Methods in Molecular Biology, 2011, 763, 195.

4. D E Schraufnagel, Breathing in America: Disease, Progress, and Hope, 2010, American Thoracic Society.

5. http://www.vetmed.vt.edu/education/curriculum/vm8054/labs/Lab25/lab25.htm, accessed on February 11, 2013.

6. http://en.wikipedia.org/wiki/Drug_delivery, accessed on February 12, 2013.

7. K A Foster, M L Avery, M Yazdanian, and K L Audus, Characterization of the Calu-3 cell line as a tool to screen pulmonary drug delivery, International Journal of Pharmaceutics, 2000, 208, 1 .

8. BSI PAS 71: Vocabulary. Nanoparticles, 2005, accessed on November 132008.

9. NIH: environmental, health, and safety research strategy, accessed in October, 2011.

10. S Iijima and T Ichihashi, Single-shell carbon nanotubes of 1-nm diameter, Nature, 1993, 363, 603.

11. D S Bethune, C H Klang, M S de Vries, G Gorman, R Savoy, J Vazquez, and R Beyers, Cobalt-catalysed growth of carbon nanotubes with single-atomic-layer walls, Nature, 1993, 363,605 .

12. S Iijima, Helical microtubules of graphitic carbon, Nature, 1991, 354, 56.

13. A Bianco, K Kostarelos, and M Prato, Applications of carbon nanotubes in drug delivery, Current Opinion in Chemical Biology, 2005, 9, 674.

14. Y Sato, A Yokoyama, K Shibata, Y Akimoto, S Ogino, Y Nodasaka, T Kohgo, K Tamura, T Akasaka, M Uo, K Motomiya, B Jeyadevan, M Ishiguro, R Hatakeyama, F Watarib, and K Tohji, Influence of length on cytotoxicity of multi-walled carbon nanotubes against human acute monocytic leukemia cell line THP-1 in vitro and subcutaneous tissue of rats in vivo, Mol. BioSyst., 2005, 1, 176. 
15. M Prato, K Kostarelos, and A Bianco, Functionalized Carbon Nanotubes in Drug Design and Discovery, Acc. Chem. Res., 2008, 41 (1), 60.

16. D Pantarotto, R Singh, D McCarthy, M Erhardt, J P Briand, M Prato, K Kostarelos, and A Bianco, Functionalized Carbon Nanotubes for Plasmid DNA Gene Delivery, Angew Chem Int Ed Engl. 2004, 43(39), 5242-6.

17. B Fugetsu , S Satoh , T Shiba, T Mizutani, Y B Lin , N Terui, Y Nodasaka, K Sasa, K Shimizu, T Akasaka, M Shindoh, K Shibata, A Yokoyama, M Mori, K Tanaka, Y Sato, K Tohji, S Tanaka, N Nishi, and F Watari, Caged Multiwalled Carbon Nanotubes as the Adsorbents for Affinity-Based Elimination of Ionic Dyes, Environ. Sci. Technol., 2004, 38, 6890.

18. J P Kaiser, P Wick, P Manser, P Spohn, and A Bruinink, Single walled carbon nanotubes (SWCNT) affect cell physiology and cell architecture, J Mater Sci: Mater Med, 2008, 19, 1523.

19. L Wang, Y Rojanasakul, V Castranova, A Qiu, Y Lu, J F Scabilloni, N Wu, and R R Mercer, Direct fibrogenic effects of dispersed single-walled carbon nanotubes on human lung fibroblasts, Journal of Toxicology and Environmental Health, 2010, 73(5), 410.

20. D W Porter, A F Hubbs, R R Mercer, N Wu, M G Wolfarth, K S, S Leonard, L Battelli, D Schwegler-Berry, S Friend, M Andrew, B T Chen, S Tsuruoka, M Endo, and V Castranova, Mouse Pulmonary Dose- and Time Course-Responses Induced by Exposure to Multi-Walled Carbon Nanotubes, Toxicology, 2010, 269, 136.

21. C Salvador-Morales, P Townsend, E Flahaut, C Vénien-Bryan, A Vlandas, M L H Green, and Robert B. Sim, Binding of pulmonary surfactant proteins to carbon nanotubes; potential for damage to lung immune defense mechanisms, Carbon, 2007, 45, 607.

22. B M Rotoli, O Bussolati1, A Barilli, P P Zanello, M G Bianchi, A Magrini, A Pietroiusti, A Bergamaschi, and E Bergamaschi, Airway barrier dysfunction induced by exposure to carbon nanotubes in vitro: which role for fiber length? Human \& Experimental Toxicology, 2009, 28, 361 .

23. M G Farquhar and G E Palade, Junctional complexes in various epithelia, The Journal of Cell Biology, 1963, 17.

24. http://en.wikipedia.org/wiki/Tight_junction\#cite_note-0, accessed on March 15, 2013.

25. D Brown and J L Stow, Protein Trafficking and Polarity in Kidney Epithelium: From Cell Biology to Physiology, Physiological Reviews, 1996, 76, 245. 
26. http://cellbiology.med.unsw.edu.au/units/science/lecture0808.htm, accessed on March 15, 2013.

27. N R Mathias, K J Kim, T W Robison, and V H L Lee, Development and Characterization of Rabbit Tracheal Epithelial Cell Monolayer Models for Drug Transport Studies, Pharmaceutical Research, 1995, 12, 10.

28. H M Roche, A M Terres, I B Black,M J Gibney, and D Kelleher, Fatty acids and epithelial permeability: effect of conjugated linoleic acid in Caco-2 cells, Gut, 2001,48, 797.

29. M Cereijido, E S Robbins, W J Dolan, C A Rotunno, and D D Sabatini, Polarized monolayers formed by epithelial cells on a permeable and translucent support. $J$ Cell Biol, $1978,77,853$.

30. A M Ez-Palomo, I Meza, G Beaty, and M Cereijido, Experimental modulation of occluding junctions in a cultured transporting epithelium, J Cell Biol, 1980, 87, 736.

31. http://www.pharmaceutical-int.com/article/trans-epithelial-electric-resistance-teermeasurements.html, accessed on March 1, 2013.

32. C Schulze, C Smales, L L Rubin, and J M Staddon, Lysophosphatidic Acid Increases Tight Junction Permeability in Cultured Brain Endothelial Cells, J. Neurochem. 1997,68, 991.

33. C Iliescu, D P Poenar, and S T Selvan, Frequency dependence on the accuracy of electrical impedance spectroscopy measurements in microfluidic devices, J. Micromech. Microeng, 2010, 20 No. 2, 022001.

34.G M Whitesides, The origins and the future of microfluidics, Nature, 2006,442, 368.

35. A Manz, D J Harrison, E Verpoorte, and H M Widmer, Planar chips technology for miniaturization and integration of separation techniques into monitoring systems - capillary electrophoresis on a chip, J. Chromatog., 1992, 593, 253.

36. N L Jeon, H Baskaran, S K W Dertinger, G M Whitesides, Livingston Van De Water, and Mehmet Toner, Neutrophil chemotaxis in linear and complex gradients of interleukin-8 formed in a microfabricated device, nature biotechnology, 2002, 20, 826.

37. S Pennathur, C D Meinhart, and H T Soh, How to exploit the features of microfluidics technology, Lab Chip, 2008, 8, 20.

38. A Chen, T Byvank, W J Chang, A Bharde, G Vieira, B Miller, J J Chalmers, R Bashird, and R Sooryakumar, On-Chip Magnetic Separation and Encapsulation of Cells in Droplets, Lab Chip, 2013,13, 1172. 
39. T Thorsen, S J Maerkl, and S R Quake, Microfluidic Large-Scale Integration, Science, 298, 580.

40. Y Xia and G M Whitesides, Soft Lithography, Annu. Rev. Mater. Sci., 1998, 28, 153.

41. P Sethu and C H Mastrangelo, Cast epoxy-based microfluidic systems and their application in biotechnology, Sensors and Actuators B, 2004, 98, 337.

42. J C McDonald, D C Duffy, J R Anderson, D T Chiu, H Wu, O J A Schueller, G M Whitesides, Fabrication of Microfluidic Systems in Poly(dimethylsiloxane), Electrophoresis, $2000,21,27$.

43. J C McDonald and G M Whitesides, Poly(dimethylsiloxane) as a material for fabricating microfluidic devices, Acc. Chem. Res. 2002, 35(7), 491.

44. C L Hansen, E Skordalakes, J M Berger, and S R Quake, A robust and scalable microfluidic metering method that allows protein crystal growth by free interface diffusion. Proc. Natl Acad. Sci. USA, 2002, 99, 16531.

45 C S Effenhauser, G J M Bruin, A Paulus, and M Ehrat, Integrated Capillary Electrophoresis on Flexible Silicone Microdevices: Analysis of DNA Restriction Fragments and Detection of Single DNA Molecules on Microchips, Anal. Chem., 1997, 69, 3451.

46. D B Weibel and G M Whitesides, Applications of microfluidics in chemical biology, Current Opinion in Chemical Biology, 2006, 10, 584.

47. W M Saltzman and W L Olbricht, Building drug delivery into tissue engineering, Nature Reviews Drug Discovery, 2002, 1, 177.

48. J El-Ali, P K Sorger, and K F Jensen, Cells on chips, Nature, 2006, 442, 403.

49 A A S Bhagat, H Bow, H W Hou, S J Tan, J Han, and C T Lim, Microfluidics for cell separation, Med Biol Eng Comput, 2010, 48, 999.

50. M M Wang, E Tu, D E Raymond, J M Yang, H Zhang, N Hagen, B Dees, E M Mercer, A H Forster, I Kariv, P J Marchand, and William F Butler, Microfluidic sorting of mammalian cells by optical force switching, Nature Biotechnology, 2005, 23, 83.

51 D Huh, B D Matthews, A Mammoto, M Montoya-Zavala, H Y Hsin, and D E Ingber, Reconstituting Organ-Level Lung Functions on a Chip, Science, 2010, 328.

52. H E Ayliffe, A B Frazier, and R D Rabbitt, Electric Impedance Spectroscopy Using Microchannels with Integrated Metal Electrodes, Ieee Journal Of Microelectromechanical Systems, 1999, 8, 50. 
53. F Asphahani, K Wang, M Thein, O Veiseh, S Yung, J Xu, and M Zhang, Single-cell bioelectrical impedance platform for monitoring cellular response to drug treatment, Phys. Biol. 2011, 8 .

54. J Guan, Y Miao, and Q Zhang, Impedimetric Biosensors, Journal of Bioscience and Bioengineering, 2004, 97, 219.

55. M Erben, S Decker, H Franke, and H J Galla, Electrical resistance measurements on cerebral capillary endothelial cells - a new technique to study small surface, J. B\&hem. Biophys. Methods, 1995, 30, 227.

56. N J Douville, Y C Tung, R Li, J D Wang, M E H El-Sayed, and S Takayama, Fabrication of Two-Layered Channel System with Embedded Electrodes to Measure Resistance Across Epithelial and Endothelial Barriers, Anal. Chem. 2010, 82, 2505.

57 F Moussy and D J Harrison, Prevention of the rapid degradation of subcutaneously implanted $\mathrm{Ag} / \mathrm{AgCl}$ reference electrodes using polymer coatings, Anal Chem., 1994, 66(5), 674.

58. V Barbier, M Tatoulian, H Li, F A Khonsari, A Ajdari, and P Tabeling, Stable Modification of PDMS Surface Properties by Plasma Polymerization: Application to the Formation of Double Emulsions in Microfluidic Systems, Langmuir, 2006, 22, 5230.

59. H Hillborg, J F Ankner, U W Gedde, G D Smith, H K Yasuda, and K Wilstro“m, Crosslinked polydimethylsiloxane exposed to oxygen plasma studied by neutron reflectometry and other surface specific techniques, Polymer, 2000, 41, 6851.

60. B Q Shen, W E Finkbeiner, J J Wine, R J Mrsny, and J H Widdicombe, Calu-3: a human airway epithelial cell line that shows cAMP-dependent Cl- secretion. Am. J. Physiol. 1994, 266, L493.

61. J Fogh, Human Tumor Cells In Vitro, Plenum Press, New York, 1975, 115.

62. Y Zhu, A Chidekel, and T H Shaffer, Cultured Human Airway Epithelial Cells (Calu-3): A Model of Human Respiratory Function, Structure, and Inflammatory Responses, Critical Care Research and Practice, 2010, Volume 2010.

63. A C da Paula, A S Ramalho, C M Farinha1, J Cheung, R Maurisse, D C Gruenert, J Ousingsawat, K Kunzelmann, and M D Amaral, Characterization of novel airway submucosal gland cellmodels for cystic fibrosis studies, Cellular Physiology and Biochemistry, 2005, 15, 251 .

64. E W K Young and D J Beebe, Fundamentals of microfluidic cell culture in controlled microenvironments, Chem. Soc. Rev., 2010, 39, 1036.

65. http://en.wikipedia.org/wiki/Immunofluorescence, accessed on March 25, 2013. 
66. http://en.wikipedia.org/wiki/Bode_plot, accessed on March 25, 2013.

67. S Loman, J Radl, H M Jansen, T A Out, and R Lutter, Vectorial transcytosis of dimeric IgA by the Calu-3 human lung epithelial cell line: upregulation by IFN-gamma, Am J Physiol Lung Cell Mol Physiol, 1997, 272, L951.

68. P X Hou, C Liu, and H M Cheng, Purification of carbon nanotubes, Carbon, 2008, 46, 2003.

69. R F Hamilton, M Buford, C Xiang, Wu N, and A Holian, NLRP3 inflammasome activation in murine alveolar macrophages and related lung pathology is associated with MWCNT nickel contamination, Inhal Toxicol, 2012, 24, 995.

70. R F Hamilton, C Xiang, M Li, I Ka, F Yang, D Ma, D W Porter, N Wu, and A Holian, Purification and sidewall functionalization of multiwalled carbon nanotubes and resulting bioactivity in two macrophage models, Inhal Toxicol, 2013, 25, 199.

71. K Donaldson, R Aitken, L Tran, V Stone, R Doffin, G Forrest, and A Alexander, Carbon nanotubes: a review of their properties in relation to pulmonary toxicology and workplace safety, Toxicol Sci, 2006, 92, 5.

72. D W Porter, A F Hubbs, R R Mercer, N Wu, M G Wolfarth, K Sriram, S Leonard, L Battelli, D Schwegler-Berry, S Friend, M Andrew, B T Chen, S Tsuruoka, M Endo, and V Castranova, Mouse pulmonary doseand time course-responses induced by exposure to multi-walled carbon nanotubes, Toxicology, 2010, 269,136. 